Adriana Moro Maieski do Rosário

\title{
Avaliação de instrumentos que investigam abuso de álcool e outras drogas em adolescentes: revisão de literatura
}

Dissertação apresentada à Faculdade de Medicina da Universidade de São Paulo, para obtenção do título de Mestre em Ciências

Programa de Medicina Preventiva

Orientador: Prof. Dr. Heráclito Barbosa de Carvalho

\section{São Paulo}


Adriana Moro Maieski do Rosário

\title{
Avaliação de instrumentos que investigam abuso de álcool e outras drogas em adolescentes: revisão de literatura
}

Dissertação apresentada à Faculdade de Medicina da Universidade de São Paulo, para obtenção do título de Mestre em Ciências

Programa de Medicina Preventiva

Orientador: Prof. Dr. Heráclito Barbosa de Carvalho

\author{
São Paulo
}


Dados Internacionais de Catalogação na Publicação (CIP)

Preparada pela Biblioteca da

Faculdade de Medicina da Universidade de São Paulo

\section{Creprodução autorizada pelo autor}

Rosário, Adriana Moro Maieski do

Avaliação de instrumentos que investigam abuso de álcool e outras drogas em adolescentes : revisão de literatura / Adriana Moro Maieski do Rosário. -- São Paulo, 2011.

Dissertação (mestrado)--Faculdade de Medicina da Universidade de São Paulo. Programa de Medicina Preventiva.

Orientador: Heráclito Barbosa de Carvalho.

Descritores: 1.TEEN ASI 2.DUSI 3.CBCL 4.Instrumentos 5.Abuso de substâncias 6.Álcool e outras drogas 7.Adolescente 8.Avaliação 9.Triagem

USP/FM/DBD-401/11 
Dedico ao criador e eterno Deus, ao meu marido e grande companheiro Joaquim, à minha querida mãe Maria Aparecida e aos meus irmãos e grandes amigos, Valéria e André. 


\section{Agradecimentos}

A Deus, pela força e coragem em persistir, apesar das dificuldades.

Ao Prof. Dr. Heráclito Barbosa de Carvalho, pela oportunidade, orientações e paciência.

Aos professores e funcionários do Departamento de Medicina Preventiva, pelos ensinamentos na área de epidemiologia, em especial ao Prof. Dr. Paulo Rossi Menezes e à Profa. Dra. Maria Fernanda Peres, que participaram da banca de qualificação e contribuíram com sugestões para a melhoria da estrutura do trabalho.

À secretária Lilian, que sempre me informou e esclareceu sobre as questões administrativas da pós-graduação.

À Profa. Dra. Denise De Micheli Avalone, do Departamento de Psicobiologia da Universidade Federal de São Paulo, por ter participado da banca de qualificação e ter contribuído com importantes sugestões para a melhoria do trabalho, principalmente referente aos estudos sobre os instrumentos DUSI-R e Teen ASI.

À Profa. Dra. Laisa Marcorela Sartes, do Departamento de Psicologia da Universidade Federal de Juiz de Fora, que, no início do trabalho, contribuiu com sugestões relevantes, principalmente referentes aos estudos sobre o instrumento Teen ASI.

A Joaquim Cardoso, que auxiliou na revisão final deste trabalho, que apoiou e incentivou para que eu perseverasse em meio às muitas dificuldades.

Ao André Moro Maieski, que apoiou e incentivou para que eu permanecesse firme até o fim deste trabalho.

Meus agradecimentos. 
O maior inimigo [do acadêmico em tempos de guerra] é a ansiedade - aquela tendência de pensar na guerra e senti-la quando, na verdade, o que pretendíamos fazer mesmo era pensar no nosso trabalho. A melhor defesa é reconfecer que nisso, como em outros aspectos, na verdade, a guerra não trouxe nenhum novo inimigo, apenas piorou o antigo. Sempre temos inúmeros inimigos no trabalho. Vivemos nos apaixonando e competindo, procurando um emprego ou com medo de perdê-lo, ficando doente e nos recuperando, acompanhando escândalos públicos. Se nos deixarmos levar, estaremos sempre esperando o término de alguma distração ou outra para, então, nos concentrar no nosso trabalho. As únicas pessoas que alcançam êxito são as que querem tanto o conhecimento que insistem em buscá-lo mesmo em condições pouco favoráveis. $\mathcal{N}$ unca temos condições favoráveis. É claro que há momentos em que a pressão da ansiedade é tão grande que só o autocontrole de um super-homem seria capaz de resisti-la. Esses momentos acabam chegando tanto na guerra quanto na paz. Precisamos fazer o melhor que conseguimos. 


\section{Sumário}

Lista de Siglas

Lista de Tabelas

Resumo

Summary

\section{INTRODUÇÃO}

1.1 Adolescência - uma fase de transformação ................................................... 15

1.2 Principais fatores de risco e proteção no abuso de álcool e outras drogas........... 16

1.3 Adolescência e o fenômeno social do abuso de álcool e outras drogas ............... 19

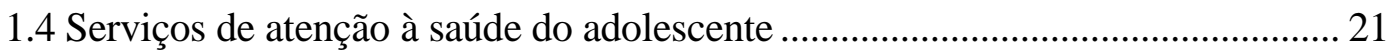

1.5 A necessidade de avaliação do uso de substâncias em adolescentes .................. 22

1.6 Alguns instrumentos gerais para a avaliação do uso de substâncias................... 25

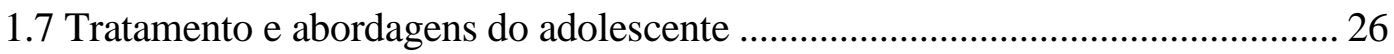

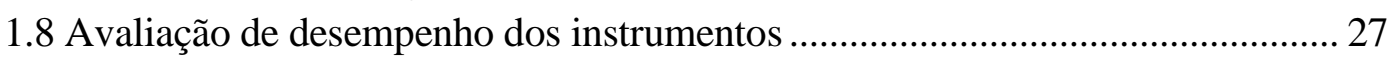

1.9 Recomendações do NIDA para questionários e escalas...................................... 34

1.10 Principais instrumentos para adolescentes - traduzidos e validados para o

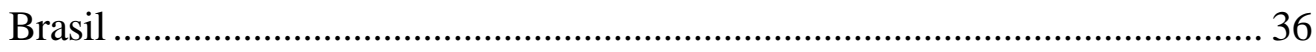

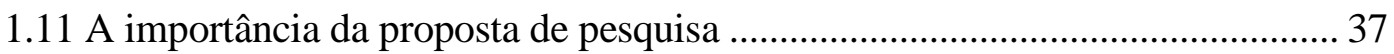

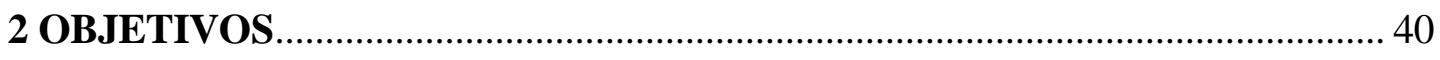

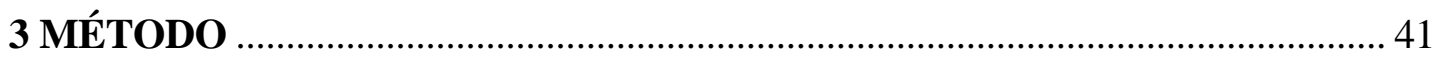

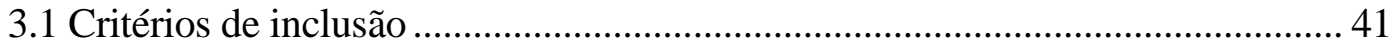

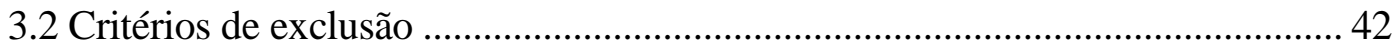

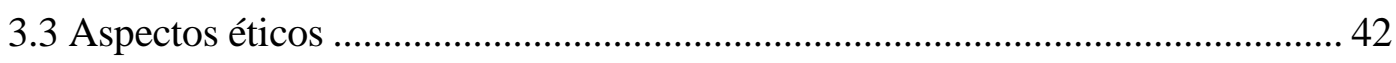

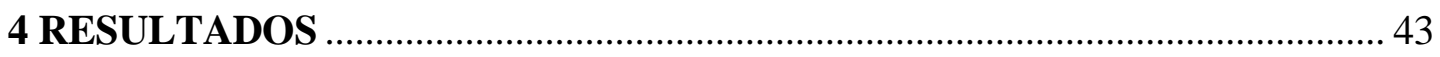

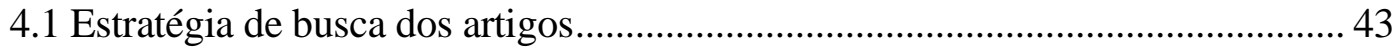

4.2 Aplicação do método e tabela geral dos artigos pesquisados.............................. 44

4.2.1 Tabela geral dos artigos pesquisados com aplicação do instrumento

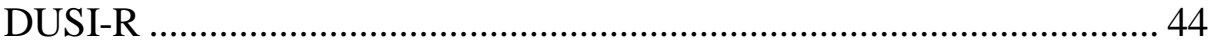

4.2.2 Artigos com aplicação do instrumento Teen ASI ................................... 47

4.2.3 Tabela com artigos com aplicação do instrumento CBCL ...................... 48

4.3 Descrição e análise dos instrumentos e artigos pesquisados ............................... 50

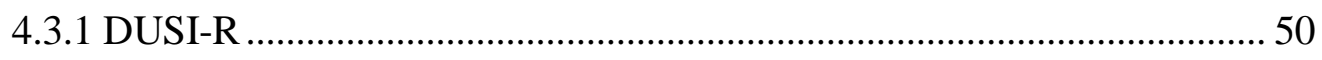

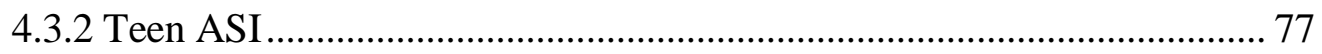

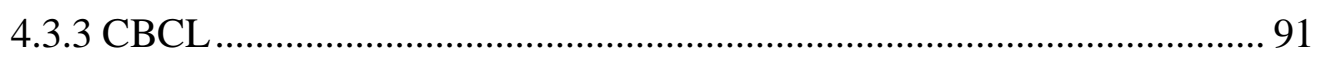

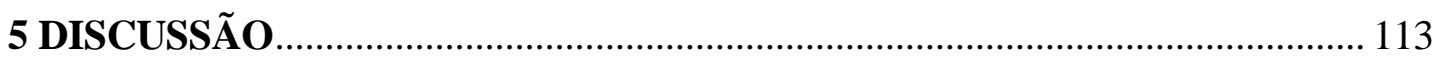

5.1 DUSI-R - vantagens e limitações encontradas nos estudos................................ 116

5.2 Teen ASI - vantagens e limitações encontradas nos estudos............................ 123 
5.3 CBCL - vantagens e limitações encontradas nos estudos 128

5.4 Considerações finais. 130

6 CONCLUSÃO E RECOMENDAÇÕES …..................................................... 132

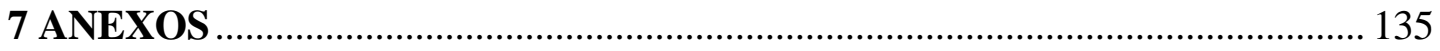

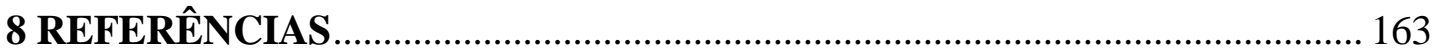

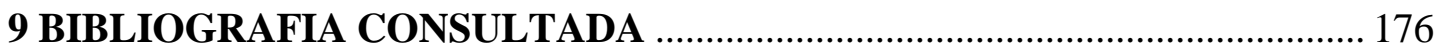




\section{Lista de Siglas}

\begin{tabular}{|c|c|}
\hline AAIS & Adolescent Alcohol Involvement Scale \\
\hline ADHD & Attention-Deficit/Hyperactivity Disorder \\
\hline ADI & Adolescent Drinking Index \\
\hline ADS & Alcohol Dependence Scale \\
\hline ASEBA & Achenbach System of Empirically Based Assessment \\
\hline ASI & Addiction Severity Index \\
\hline ASSIST & Alcohol, Smoking and Substance Involvement Screening Test \\
\hline AUDIT & Alcohol Use Disorders Identification Test \\
\hline CAGE & Cut-down-Annoyed-Guilty-Eye-opener \\
\hline CAPPesq & Comissão de Ética para Análise de Projetos de Pesquisa \\
\hline CAPS & Centro de Atenção Psicossocial \\
\hline CAPS AD & Centro de Atenção Psicossocial Álcool e outras Drogas \\
\hline CBCL & Child Behavior Checklist \\
\hline CDDR & Customary Drinking and Drug Use Record \\
\hline CEDRO & Centro de Informação e Educação para Prevenção do Abuso às Drogas \\
\hline CGI & Clinical Global Impression \\
\hline CIDI & Composite International Diagnostic Interview \\
\hline CRS & Conners Rating Scale \\
\hline CSAT & Center for Substance Abuse Treatment \\
\hline CSI-S & Cliente Substance Index-Short \\
\hline DAP & Drug and Alcohol Problem \\
\hline DAST & Drug Abuse Screening Test \\
\hline
\end{tabular}




\begin{tabular}{|c|c|}
\hline DF-E & Desenho de Família com Estórias \\
\hline DICA & Diagnostic Interview for Children and Adolescent \\
\hline DIMESAD & Disciplina Medicina e Sociologia do Abuso de Drogas \\
\hline DISC & Diagnostic Interview Schedule for Children \\
\hline DOTS-R & Dimensions of Temperament Survey Revised \\
\hline DSM-III-R & $\begin{array}{l}\text { Diagnostic and Statistical Manual of Mental Disorders - Third Edition } \\
\text { - Revised }\end{array}$ \\
\hline DSM-IV & $\begin{array}{l}\text { Diagnostic and Statistical Manual of Mental Disorders - Fourth } \\
\text { Edition }\end{array}$ \\
\hline DSM-IV-TR & Diagnostic and Statistical Manual - Fourth Edition - Text Revision \\
\hline DUSI & Drug Use Screening Inventory \\
\hline DUSI-R & Drug Use Screening Inventory Revised \\
\hline ECA & Estatuto da Criança e do Adolescente \\
\hline EM & Escala de Mentira \\
\hline ESA & Escala de Severidade de Alcoolismo \\
\hline FAM & Family Assessment Measure \\
\hline FAPESP & Fundação de Amparo à Pesquisa do Estado de São Paulo \\
\hline FES & Family Environment Scale \\
\hline F-SMAST & Adapted Short Michigan Alcoholism Screening Test for Fathers \\
\hline GAIN & Global Appraisal of Individual Needs \\
\hline GSRS & Group Sessions Rating Scale \\
\hline HAM-D & Hamilton Rating Scale for Depression \\
\hline K-SADS & Kiddie-Schedule for Affective Disorders and Schizophrenia \\
\hline Lilacs & Literatura Latino-Americana e do Caribe em Ciências da Saúde \\
\hline MAST & Michigan Alcoholism Screening Instrument for Teenagers \\
\hline
\end{tabular}




\begin{tabular}{|c|c|}
\hline MedLine & Medical Literature Analysis and Retrieval System Online \\
\hline M-SMAST & Adapted Short Michigan Alcoholism Screening Test for Mothers \\
\hline NIAAA & National Institute on Alcohol Abuse and Alcoholism \\
\hline NIDA & National Institute on Drug Abuse \\
\hline OMS & Organização Mundial da Saúde \\
\hline ONG & Organização Não Governamental \\
\hline PESQ & Personal Experience Screening Questionnaire \\
\hline PET & Positron Emission Tomography \\
\hline POSIT & Problem Oriented Screening Instrument for Teenagers \\
\hline RAPI & Rutgers Alcohol Problem Index \\
\hline ROC & Receiver Operating Characteristic \\
\hline SADD & Short Alcohol Dependence Data \\
\hline SASSI & Substance Abuse Subtle Screening Inventory \\
\hline SciELO & Scientific Electronic Library Online \\
\hline SCL-90 & Symptom Checklist-90 \\
\hline SCQ & Situational Confidence Questionnaire \\
\hline SDQ & Strenghts and Difficulties Questionnaire \\
\hline SENAD & Secretaria Nacional de Políticas sobre Drogas \\
\hline SRQ-20 & Self-Reporting Questionnaire \\
\hline T-ACE & $\begin{array}{l}\text { Abreviação das palavras T - tolerance; A - Annoyed; C - cut down; E- } \\
\text { eye - opener }\end{array}$ \\
\hline T-TSR & Teen Treatment Services Review \\
\hline TCC & Terapia Cognitiva Comportamental \\
\hline TDAH & Transtorno do Déficit de Atenção com Hiperatividade \\
\hline Teen ASI & Teen Addiction Severity Index \\
\hline
\end{tabular}


TRF

UDED Unidade de Dependência de Drogas

Unifesp Universidade Federal de São Paulo

WURS Wender Utah Rating Scale

YSR

Youth Self Report 


\section{Lista de Tabelas}

Tabela 1 - Artigos pesquisados com aplicação do instrumento DUSI-R. .................. 44

Tabela 2 - Artigos pesquisados com aplicação do instrumento Teen ASI. ................ 47

Tabela 3 - Artigos pesquisados com aplicação do instrumento CBCL. ..................... 49

Tabela 4 - As 10 áreas de avaliação do DUSI-R..................................................... 51

Tabela 5 - Tempo de aplicação do DUSI-R - Versão completa e reduzida. ............... 53

Tabela 6 - Comparativo entre as propriedades psicométricas do DUSI-R................56

Tabela 7 - Comparativo entre as propriedades psicométricas das versões reduzidas. 59

Tabela 8 - Número de estudos por ano e respectivos países. .................................... 60

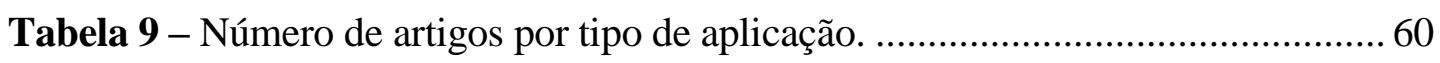

Tabela 10 - Aplicação do DUSI-R por contexto de aplicação. .................................. 74

Tabela 11 - Áreas de avaliação do Teen ASI e o que avaliam. ................................... 78

Tabela 12 - Tempo de aplicação do Teen ASI_........................................................... 79

Tabela 13 - Comparativo entre as propriedades psicométricas do Teen ASI............. 82

Tabela 14 - Número de estudos por ano e respectivos países - Teen ASI. ................. 82

Tabela 15 - Artigos de validação do Teen ASI........................................................ 83

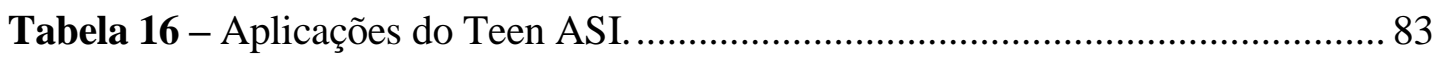

Tabela 17 - Aplicações em conjunto do Teen ASI e outros instrumentos.................... 86

Tabela 18 - Resumo dos instrumentos pesquisados e avaliados - versões brasileiras. 
Rosário AMM. Avaliação de instrumentos que investigam abuso de álcool e outras drogas em adolescentes: revisão de literatura [dissertação]. São Paulo: Faculdade de Medicina, Universidade de São Paulo; 2011.

INTRODUÇÃO: O abuso no consumo de drogas constitui um problema social e de saúde pública na maioria dos países, pelas consequências negativas que esse consumo provoca sobre o desenvolvimento emocional e físico das pessoas. O início do uso de substâncias tem-se apresentado na população de adolescentes cada vez mais cedo e, como consequência, uma avaliação para identificar comportamentos de risco é imprescindível para triagem e encaminhamentos adequados. Assim, o objetivo deste estudo foi revisar estudos e descrever três importantes instrumentos validados para o Brasil e utilizados para avaliação do abuso de álcool e outras drogas em adolescentes. MÉTODO: Estudo de revisão de literatura, realizado no período de janeiro de 1998 a agosto de 2010, em publicações nas bases de dados: Adolec, MedLine, Lilacs, PubMed e SciELO. Na seleção dos estudos, foram avaliados: artigos com aplicação dos instrumentos DUSI-R, Teen ASI e CBCL; o detalhamento do instrumento utilizado para diagnóstico; utilização de algum indicador de desempenho do instrumento; qualidade do estudo que permita avaliação do desempenho do instrumento, assim como a sua coerência com a literatura.

RESULTADOS: Foram encontrados 767 artigos e, de acordo com os critérios de inclusão, foram avaliados 54, após as exclusões daqueles que não atenderam aos critérios. Os artigos com aplicação do instrumento DUSI-R foram 30, sendo 25 referentes a intervenções, prevalência e outros. Os estudos sobre validação do instrumento foram 5, com taxas de sensibilidade variando de 80 a $85 \%$ e especificidade variando de 70 a $90 \%$. Outra medida foi a consistência interna com Alfa de Cronbach de 0,91 a 0,9451, apresentada em dois estudos. Já os artigos com aplicação do Teen ASI foram 12, sendo 8 estudos sobre intervenção, prevalência e outros. Para a validação do instrumento, foram encontrados 4 estudos, com taxa de confiabilidade em 2 estudos com r variando entre 0,69 e 0,90, um estudo com consistência interna com Alfa de Cronbach de 0,54 a 0,88 e outro estudo que avaliou a área sobre a curva de $\mathrm{ROC}=0,88$. Finalmente, os artigos com aplicação do CBCL foram 12, dos quais 8 foram sobre prevalência e fatores de risco. As medidas de desempenho do instrumento foram apresentadas em 4 estudos, sendo que dois mediram a taxa de sensibilidade do instrumento, variando de 80,4 a $87 \%$. Ainda, um estudo apresentou consistência interna com Alfa de Cronbach entre 0,85 e 0,94 e outro estudou as propriedades psicométricas conforme dados da versão alemã do CBCL.

CONCLUSÃO: Os resultados dos estudos apontam que os instrumentos pesquisados avaliam o abuso de álcool e outras drogas em adolescentes, possuindo boas propriedades psicométricas, porém de formas diferentes. O Teen ASI e o DUSI-R identificam e avaliam o uso de substâncias e outras áreas da vida. Por sua vez, o CBCL é voltado para avaliar a saúde mental do adolescente, não sendo específico para avaliar o abuso de álcool e outras drogas. Portanto, na escolha de instrumentos de avaliação, é importante considerar: organização do tempo, investimento na formação de profissionais e consolidação dos resultados que contribua efetivamente na melhora do tratamento.

Descritores: Teen ASI; DUSI-R; CBCL; Instrumentos; Abuso de substâncias; Álcool e outras drogas; Adolescentes; Avaliação; Triagem. 
Rosário AMM. Assessment of instruments that evaluate substance abuse in adolescents: a literature review [dissertation]. São Paulo: Faculdade de Medicina, Universidade de São Paulo; 2011.

INTRODUCTION: The substance abuse is a major social problem in public health in most countries, due to the negative consequences of this behavior on the physical and emotional development of the people involved. The initiation phase of the substance abuse is beginning at earlier ages, and, as a consequence of that, an assessment to identify risk behaviors is very important for an acurate triage and subsequent steps. The objective of this study was to review studies and to describe 3 important instruments validated for Brazil and applied for the assessment of substance abuse in adolescents.

METHOD: A literature review study, in the period from January of 1998 to August of 2010, in the databases of: Adolec, MedLine, Lilacs, PubMed and SciELO. In the selection of the studies the following criteria were evaluated: articles with application of the instruments DUSI-R, Teen ASI, and CBCL; the detailing of the instrument utilized for diagnostics; utilization of a performance indicator; quality of the study that enables the performance assessment of the instrument, and it's coherence with the literature.

RESULTS: 767 articles were found according to the inclusion criteria, and 54 of them were analysed, after the exclusions of the ones that did not meet the detailed criteria. 30 articles for the DUSI-R instrument were found, 25 of them related to interventions, prevalence and others. 5 studies were related to the validation of the instrument, with sensitivity rates varying from 80 to $85 \%$ and specificity variying from 70 to $90 \%$. Another measure was the internal consistency with Cronbach's Alpha varying from 0.91 to 0.9451 , presented in two studies. For the Teen ASI, 12 articles were found, and 8 of them were related to intervention, prevalence and others. For the validation of the instrument, 4 studies were found, with the reliability in 2 studies varying from $r=0.69$ to 0.90 , one study with internal consistency with Cronbach's Alpha varying from 0.54 to 0.88 and another study with the area under the ROC curve $=0.88$. For the CBCL, 12 studies were found, and 8 of them were related to the prevalence and risk factors. The performance measures were presented in 4 studies, where 2 instruments measured the sensitivity rate varying from 80.4 to $87 \%$. One study report the Cronbach's Alpha between 0.85 and 0.94 , and another study studied the psicometric properties for the German version.

CONCLUSION: The results of the studies suggest that the instruments included on the research evaluate the substance abuse in adolescents, with good psychometric properties, although in different ways. The Teen ASI and DUSI-R evaluate the substance abuse and other areas of life. The CBCL is useful to evaluate the mental health, and it's not specific to conduct an assessment for substance abuse. So, when choosing assessment instruments, it's important to consider: time management, investment in the education of the professionals; and consolidation of the results that contribute effectively to the improvement of the treatment.

Keywords: Teen ASI; DUSI-R; CBCL; Instruments; Substance abuse; Alcohol and other drugs; Adolescents; Assessment; Screening. 


\title{
1 INTRODUÇÃO
}

\subsection{Adolescência - uma fase de transformação}

Há inúmeras definições sobre a adolescência. Essa fase da vida é marcada por constantes transformações físicas, emocionais, sociais e, acima de tudo, grandes questionamentos, curiosidades e um constante aprendizado de vida. É uma fase que compreende uma faixa etária, em média, dos 12 aos 18 anos, de acordo com o Estatuto da Criança e do Adolescente (ECA) (Brasil, 1990).

\begin{abstract}
Adolescência é uma fase de metamorfose. Época de grandes transformações, de descobertas, de rupturas e de aprendizados. É por isso mesmo, uma fase da vida que envolve riscos, medos, amadurecimento e instabilidades. As mudanças orgânicas e hormonais, típicas dessa faixa etária, podem deixar os jovens agitados, agressivos, cheios de energia e de disposição num certo momento. Mas, no momento seguinte, eles podem ser acometidos de sonolência, de tédio, e de uma profunda insatisfação com seu próprio corpo, com a escola, com a família, com o mundo e com a própria vida. (Pinsky; Bessa, 2004, p. 11).
\end{abstract}

A adolescência compreende o indivíduo na segunda década de vida, entre 10 e 19 anos. "Porém mesmo os autores que adotam essa definição reconhecem que esses limites são imprecisos e, principalmente, podem variar nas diferentes culturas e de um indivíduo para outro.” (Scivoletto, 2004, p. 23).

O desenvolvimento do adolescente normal inclui a busca de sua identidade, valores e crenças, a necessidade de pertencer a um grupo, a procura de uma razão de viver, entre outros aspectos. Segundo a Organização Mundial da Saúde (OMS, 2003, p. 10), 
faz parte do desenvolvimento normal do adolescente assumir novos papéis e responsabilidades, o que pode significar alguns riscos, renegociar relações na família, na comunidade e na turma de amigos, experimentar alguns 'símbolos da vida adulta', além de levantar questões sobre a família, normas sociais e costumes.

\subsection{Principais fatores de risco e proteção no abuso de álcool e outras drogas}

A identificação dos fatores de risco e de proteção é necessária para o planejamento de programas que visem à prevenção do abuso de álcool e outras drogas e à melhoria das condições de vida dos adolescentes. Hawkins et al., em um artigo publicado em 1992, no Psychological Bulletin, resumiram os possíveis fatores de risco revelados por essas pesquisas - e, do mesmo modo, os fatores de proteção - conforme segue:

Principais fatores de risco:

- Pessoais - primeira infância:

- Histórico familiar de consumo de drogas ou doenças mentais;

- Carência de vínculo com a mãe;

- Carência de monitoramento familiar;

- Graves conflitos familiares;

- Predisposição fisiológica (genética ou bioquímica);

- Rejeição dos colegas;

- Pessoais - segunda infância/adolescência:

- Manifestações precoces de comportamento antissocial e agressivo;

- Insucesso na escola;

- Fraca ligação com a escola; 
- Atitudes positivas em relação ao uso de drogas;

- Alienação ou rebeldia;

- Associação com colegas usuários de drogas;

- Uso precoce de drogas;

- Ambientais:

- Disponibilidade de drogas;

- Privação econômica e social;

- Escasso vínculo com a vizinhança/comunidade desorganizada;

- Difíceis transições (de vida);

- Normas comunitárias favoráveis ao consumo de drogas.

Principais fatores de proteção:

- Pessoais - primeira infância:

- Relação calorosa com a mãe;

- Estabilidade psicológica da mãe;

- Bom gerenciamento familiar;

- Bom temperamento/estabilidade emocional;

- Evitar situações de perigo;

- Bons modelos parentais;

- Pessoais - segunda infância/adolescência:

- Realizações acadêmicas;

- Boas relações com os colegas;

- Envolvimento em atividades comunitárias e sociais; 
- Estrutura familiar recompensadora;

- Monitoramento parental;

- Envolvimento parental de qualidade com as atividades da criança;

- Regras parentais claras relacionadas ao uso de cigarro, álcool ou outras drogas;

- Fortes vínculos escolares;

- Fortes vínculos com colegas;

- Ambientais:

- Limitação nas possibilidades de acesso ao álcool, cigarro e drogas.

Alguns fatores de proteção, como o desenvolvimento da cidadania, da autoestima, do autoconceito e o suporte familiar e social, protegem os jovens de comportamentos negativos, como abuso de álcool e outras drogas. Pesquisas quantitativas nos Estados Unidos mostram que "jovens com mais valores estão menos propensos a terem padrões de comportamento de alto risco, como problemas do uso do álcool, uso de drogas ilícitas, e violência.” (Search Institute, 2003, p. 33).

O relatório sobre jovens em situação de risco, no Brasil, aponta para um crescente comportamento de risco dos jovens, ocasionando o aumento da exclusão social e prejuízos quanto à sua condição de saúde. De acordo com o Banco Mundial (2007),

jovens em situação de risco são pessoas que, pela presença de determinados fatores em suas vidas, podem ser levadas a assumir comportamentos ou experimentar eventos danosos para si mesmos e para a sociedade. Entre os comportamentos de risco estão: evasão escolar, ociosidade, uso de drogas, violência, iniciação sexual precoce e práticas sexuais arriscadas. O relatório considera como jovens pessoas entre 15 e 24 anos. 
No Brasil, os estudos têm reforçado, principalmente, a importância dos fatores sociodemográficos; além desses, Carvalho et al. (1995), numa amostra nacional de estudantes, identificaram a violência doméstica e a qualidade do relacionamento familiar como importantes fatores relacionados ao uso de drogas, enquanto Baus et al. (2002) encontraram associação do uso de drogas com a separação dos pais e a não residência com eles.

Ainda, segundo De Micheli e Formigoni (2002), a baixa condição socioeconômica é um importante fator de risco ao uso de drogas; somando a isso, Carr e Vandiver (2001) relatam ser a pobreza um grande estressor e fator de risco para que jovens se tornem delinquentes.

\subsection{Adolescência e o fenômeno social do abuso de álcool e outras drogas}

O abuso no consumo de drogas constitui um problema social e de saúde pública na maioria dos países, pelas múltiplas consequências negativas que esse consumo provoca sobre o desenvolvimento emocional e físico das pessoas. Relatórios das Nações Unidas mostram que, nos últimos anos, houve incremento no uso de drogas em todo o mundo, sendo que cerca de 155 a 250 milhões de pessoas (de 3,5 a 5,7\% da população mundial de 15 a 64 anos de idade) consumiram substâncias ilícitas (UNODC, 2010).

No caso da juventude, esta mostra traços de uniformidade, na pressão e na necessidade de criação de novos postos de trabalho, de demonstrar uma grande vulnerabilidade à formação de hábitos e padrões de comportamento de risco, levando às diversas formas de morbidade, tais como: AIDS, acidentes de trânsito, violência 
física etc. Um dos principais fenômenos sociais e maiores problemas de saúde pública é o uso e abuso de substâncias psicoativas (álcool e outras drogas), presente no cotidiano de muitos adolescentes brasileiros. De acordo com o $V$ Levantamento nacional sobre o uso de drogas psicotrópicas entre estudantes do ensino fundamental e médio da rede pública de ensino, nas 27 capitais brasileiras, jovens entre 10 e 18 anos relataram ao menos um consumo na vida de álcool, tabaco ou solventes, com as respectivas taxas de 65,2, 24,9 e 15,5\% (Galduróz et al., 2004).

Segundo Carlini et al. (2002), no I Levantamento domiciliar sobre o uso de drogas psicotrópicas no Brasil, cerca de $2 \%$ dos estudantes já usaram cocaína pelo menos uma vez na vida e $0,2 \%$ já usaram o crack. Já no estudo sobre a transição entre vias de administração da cocaína, foi detectado que, embora $87 \%$ dos jovens brasileiros tenham iniciado cheirando, a transição para vias mais prejudiciais, como fumar crack ou injetar, deu-se com maior frequência entre aqueles que iniciaram o uso mais precocemente (Dunn; Laranjeira, 1999).

De acordo com Noto (2010), no levantamento sobre o consumo entre estudantes de escolas privadas paulistanas, que teve a participação de 5.226 alunos do $8^{\circ}$ e $9^{\circ}$ ano do ensino fundamental e dos três anos do ensino médio, em 37 escolas,

de todas as drogas o álcool se mostrou, de longe, a mais usada: $40 \%$ dos estudantes haviam bebido no mês anterior à pesquisa, enquanto $10 \%$ haviam consumido tabaco, a segunda droga mais prevalente. $\mathrm{O}$ álcool é também a droga que começa a ser consumida mais cedo, com média de idade de 12,5 anos. O primeiro consumo de álcool ocorreu em casa para a maior parte dos entrevistados: $46 \%$.

Um dos dados que mais chamaram a atenção no levantamento é que, no ensino médio, 33\% dos alunos consumiram álcool no padrão conhecido como binge drinking - ou "beber pesado episódico" - no mês anterior à pesquisa (Noto, 2010). 
Outros fatores de risco para o comportamento binge, segundo a pesquisa, foram o sexo (o risco aumenta em $70 \%$ entre os meninos), idade (50\% para cada ano a mais de vida), pais separados (30\% a mais risco), não confiar em Deus (40\%) e não conversar com os pais (60\%). Além disso, a condição socioeconômica também influencia: o risco é duas vezes maior entre os alunos das escolas com mensalidade acima de R\$1,2 mil (Noto, 2010).

O consumo "pelo menos uma vez na vida" - que, segundo os pesquisadores, não caracteriza o adolescente como usuário da droga - foi de 80\% para o álcool, 24,6\% para o tabaco, 13,6\% para inalantes, 10,7\% para maconha, 5,3\% para calmantes e 2,2\% para cocaína (Noto, 2010).

Portanto, o abuso de drogas tem origem multifacetada, com influências biológicas, psicológicas e sociais. Entre os aspectos sociais, destacam-se: a falta de oportunidade no mercado de trabalho, a necessidade de pertencer a um grupo social e a exclusão social, que, muitas vezes, aumenta o questionamento dos valores pessoais e culturais próprio dessa fase da vida. Diante disso, segundo Abraão (1999, p. 48),

na adolescência, quando a busca da identidade está associada à escassez de recursos psicológicos, quanto mais cedo ocorrer a experimentação de drogas, maior será o risco de evolução para um quadro abusivo ou até dependente. Nessa etapa, os danos decorrentes do abuso tornam-se evidentes (problemas psíquicos do adolescente, conflitos familiares, escolares e sociais) e cuidados especiais se fazem necessários.

\subsection{Serviços de atenção à saúde do adolescente}

Os principais serviços de saúde de atendimento ao adolescente são: unidades básicas de saúde, programas de saúde da família, hospitais públicos e privados, 
ambulatórios pediátricos nas universidades, Centro de Atenção Psicossocial (CAPS) infantil, CAPS Álcool e outras Drogas (AD), unidades de pesquisa e tratamento do abuso de substâncias, clínicas particulares e Organizações Não Governamentais (ONGs).

Nesse sentido, Raposo (2009) enfatiza as principais dificuldades enfrentadas por serviços de saúde ao adolescente e a necessidade de capacitação dos profissionais para a melhoria na qualidade do serviço prestado:

As dificuldades enfrentadas atualmente pelos serviços de saúde, especialmente os da rede de atenção básica, se colocam na contramão da efetivação da atenção integral à saúde de adolescentes, destacando-se nesse âmbito a ausência de profissionais capacitados para $\mathrm{o}$ atendimento ao adolescente. As iniciativas na área de promoção da saúde de adolescentes e jovens são limitadas e, às vezes, inviabilizadas por conta da carência de recursos materiais e infra-estrutura das unidades de saúde. Além disso, acrescenta-se a ausência de uma rede de serviços de referência e contra-referência para dar suporte às referidas unidades. As ações são fragmentadas e assistemáticas, pois muitas vezes limitam-se ao calendário de datas comemorativas e campanhas de saúde pontuais.

\subsection{A necessidade de avaliação do uso de substâncias em adolescentes}

O processo de avaliação é um elemento importante no tratamento, que deve ser complementado com a incorporação de um ou mais instrumentos para elaborar um bom diagnóstico (Winters; Kaminer, 2008).

Quando os profissionais de saúde deparam-se com um adolescente do qual se suspeita ou se tem conhecimento a respeito do abuso de substâncias, é importante integrar o processo de avaliação com as decisões de tratamento (Winters; Kaminer, 2008). A fase inicial envolve a identificação eficiente do uso de substâncias e problemas relacionados, as comorbidades psiquiátricas e os desajustes psicossociais 
(Tarter, 1990). Esse objetivo pode ser atingido através do uso de instrumentos de triagem, como um primeiro passo breve para a avaliação do uso de substâncias antes de passar para o segundo passo, se necessário, de uma avaliação completa da gravidade do problema, uma vez que se tenha tornado claro que o adolescente pode atender aos critérios de abuso de substâncias (Winters; Kaminer, 2008).

O resultado dessa avaliação é um resumo diagnóstico que identifica a necessidade de tratamento do adolescente (Winters; Kaminer, 2008). Finalmente, um plano de tratamento integrado é desenvolvido para atingir as áreas multidimensionais da disfunção, as quais incluem comorbidades psiquiátricas, bem como os problemas potenciais na escola, família, amigos e na área legal (Kaminer; Bukstein, 2008).

Até o final do século passado, a pesquisa sobre o tratamento do abuso de substâncias com adolescentes esteve historicamente defasada em relação aos estudos com os adultos e muitos estudos têm sido caracterizados por metodologias de pesquisas empíricas inadequadas (Catalano et al., 1990-1991). Considerando que o início do uso de substâncias tem se apresentado na população de adolescentes cada vez mais cedo (Reich et al., 1988) e que a prevalência tem aumentado (Johnston et al., 1996), a eficácia no tratamento de adolescentes tem aumentado na importância. Além disso, outras áreas que estão presentes nas melhores práticas no tratamento orientado a adultos, como alinhamento entre o paciente e o tratamento, manuais de terapia e avaliações dos processos de tratamento, têm sido negligenciadas nas pesquisas com os adolescentes (Kaminer, 1994).

A avaliação é especialmente importante na elaboração da estratégia terapêutica, como, por exemplo, se o tratamento se dará em regime de internação ou ambulatorialmente (Farrell et al., 1992). Ainda, outras áreas que devem ser avaliadas 
sistematicamente são: o desempenho escolar, a vida sexual e o envolvimento em atividades ilegais. Em algumas situações, o screening (teste) toxicológico é indicado na abordagem de adolescentes, especialmente na presença de: a) sintomas psiquiátricos agudos; b) alteração na capacidade cognitiva; c) mudança abrupta de comportamento; e d) ocorrência de acidentes inexplicados e repetitivos (Kaminer, 1994; Semlitz; Gold, 1986).

A avaliação da família e do contexto social do adolescente é obrigatória, uma vez que estes são fatores importantes no início e na manutenção do uso de substâncias psicoativas. Deve-se, portanto, investigar se há outros casos de drogadição na família, assim como antecedentes familiares de criminalidade relacionada ao uso/abuso de drogas e abusos sexuais (Scivoletto, 2001).

A avaliação inicial é uma importante fase do tratamento para identificação dos problemas e o encaminhamento que deve ser utilizado por profissionais de diversas áreas, incluindo educadores e profissionais de saúde. No ambiente da área de saúde, o profissional deve ser muito bem treinado no manejo com jovens e na aplicação de protocolos sistematizados. Deve fazer parte de uma equipe multidisciplinar, em que cada profissional tem sua função bem estabelecida. A avaliação do jovem muda de curso devido ao desenvolvimento psicossocial e biológico, é importante lembrar que:

- A entrevista realizada por qualquer profissional, integrante de equipe escolar ou serviço de saúde, deve ser aberta, sem preconceitos e voltada para o estabelecimento de vínculo, uma aliança, pois esse momento é muito especial e deve ser garantido para a continuidade do processo de investigação sobre o consumo de substâncias psicoativas;

- O diagnóstico deve ser a meta, com a participação proativa do jovem e dos familiares na sua construção, buscando inicialmente diferenciar o uso experimental, abuso, dependência, e todos os fatores que contribuem para o transtorno;

- A escolha do formato da avaliação depende do ambiente e possibilitará um melhor pareamento com a intervenção subseqüente. (Marques, 2004, p. 159).

Ainda de acordo com Marques (2004, p. 153), 
o início do uso de substâncias psicoativas tem começado cada vez mais cedo e como conseqüência uma avaliação para identificar comportamentos de risco são imprescindíveis para uma triagem e encaminhamentos adequados. Para adolescentes de risco, isto é, aqueles que apresentam os fatores de risco, mesmo uma triagem negativa deve ser seguida de uma reavaliação e de um acompanhamento de no mínimo seis meses.

Outra justificativa para a aplicação de instrumentos é a sua utilização na atenção primária, contribuindo para identificar os casos mais graves e possibilitando melhor direcionamento dos recursos disponíveis (Duarte; Bordin, 2000).

\subsection{Alguns instrumentos gerais para a avaliação do uso de substâncias}

Instrumentos padronizados têm sido cada vez mais utilizados como auxiliares na avaliação de diferentes aspectos da saúde mental de crianças e adolescentes. $\mathrm{Na}$ prática clínica, tais instrumentos permitem a documentação do atendimento clínico e, muitas vezes, podem ser importantes auxiliares no diagnóstico e na avaliação da eficácia do tratamento realizado (Streiner, 1998).

De acordo com Formigoni e Castel (1999, p. 268),

os principais instrumentos para triagem são destinados à identificação de indivíduos que provavelmente apresentem problemas relacionados ao uso/abuso de álcool e outras drogas. Nesses instrumentos, dá-se ênfase àqueles com maior sensibilidade, enquanto nos instrumentos de diagnóstico uma grande especificidade é fundamental. Eles devem ser de aplicação rápida, não requerendo muito treinamento dos aplicadores. Há uma grande variabilidade de tamanho, abrangência e sofisticação nesses instrumentos: desde aqueles com apenas quatro questões, como o CAGE, até escalas computadorizadas com 350 itens, levando a variações no tempo de aplicação de 1 minuto a meia hora. São exemplos de instrumentos de triagem: AUDIT $^{1}$, CAGE, DUSI,

\footnotetext{
${ }^{1}$ AUDIT - Alcohol Use Disorders Identification Test.
} 
MAST $^{2}$, POSIT, T-ACE ${ }^{3}$. Alguns deles foram traduzidos e validados para o português.

Há também os instrumentos para avaliação do comprometimento de outras áreas; incluem-se nesse grupo escalas destinadas a avaliar, especificamente, áreas como: estado empregatício, financeiro, moradia, problemas legais, bem-estar psicológico, capacidade cognitiva, relacionamento familiar e social, história familiar de dependência de substâncias psicoativas etc. Instrumentos usados para esse fim incluem: Addiction Severity Index (ASI), Short Alcohol Dependence Data (SADD), Alcohol Dependence Scale (ADS), Drug Abuse Screening Test (DAST), Adapted Short Michigan Alcoholism Screening Test for Mothers (M-SMAST), Adapted Short Michigan Alcoholism Screening Test for Fathers (F-SMAST), Family Environment Scale (FES), Family Assessment Measure (FAM) e Symptom Checklist-90 (SCL-90) (Formigoni; Castel, 1999).

\subsection{Tratamento e abordagens do adolescente}

O tratamento do adolescente deve ser voltado a várias áreas de sua vida, envolvendo, além do uso de substâncias, a situação de saúde geral, familiar, escolar, comportamento sexual de risco, envolvimento com questões legais, bem como sua situação psiquiátrica e ocupacional. "[...] o comportamento do adolescente usuário de substância psicoativa não deve ser considerado isoladamente, necessita ser examinado sob um ponto de vista biopsicossocial [...].” (Noto et al., 2003, p. 28).

\footnotetext{
${ }^{2}$ MAST - Michigan Alcoholism Screening Instrument for Teenagers.

${ }^{3} \mathrm{~T}$-ACE - Abreviação das palavras T - tolerance; A - Annoyed; C - cut down; E - eye - opener.
} 
Conforme Silva e Mattos (2004), uma avaliação compreensiva no início do tratamento deverá abranger todos esses aspectos, além de focar o histórico do envolvimento com a droga e o estágio motivacional, existindo instrumentos que facilitam a avaliação pelo clínico.

No geral, o tratamento para o abuso de álcool e outras drogas é focado na Terapia Cognitiva Comportamental (TCC), entrevista motivacional e farmacoterapia, mas, segundo Silva et al. (2006), é importante lembrar que falta pesquisa de qualidade sobre o tratamento do adolescente que abusa de substância.

Outra abordagem comum nessa área é o modelo Minnessota, ou grupos de apoio, do tipo Alcoólicos Anônimos e Narcóticos Anônimos. Silva et al. (2006) ainda ressaltam que

as necessidades únicas do adolescente exigem que o tratamento seja compreensivo e focado em múltiplos domínios. O tratamento deve objetivar o aumento dos fatores de proteção enquanto diminui os de risco. A medicação para transtornos psiquiátricos co-existentes é fundamental. Os fatores de risco provavelmente interagem com o uso da droga, atuando sinergicamente para produzir resultados desfavoráveis. É difícil encontrar evidências para muitos problemas que aparecem obviamente conseqüências do uso, como prejuízo educacional ou problemas sociais. No entanto, é sabido que a relação com as drogas é muito mais complicada, predispondo o maior risco de dependência, nas pessoas que iniciaram o uso na adolescência.

\subsection{Avaliação de desempenho dos instrumentos}

Para avaliar uma determinada queixa ou anormalidade em pacientes, em diferentes áreas da saúde, é necessário realizar um diagnóstico após aplicar diversos testes diagnósticos, que possuem objetivos e aplicabilidades diferentes para determinada situação e/ou doença, sendo que a validade de um estudo depende da 
capacidade que as variáveis delineadas têm de representar os fenômenos de interesse e da escolha da escala de medida, que influencia o conteúdo informativo (Hulley et al., 2003).

A utilização de instrumentos em pesquisas na área da saúde mental, em especial na dependência química, tornou-se algo imprescindível, de acordo com a metodologia científica, para demonstrar de forma mais precisa as características da população estudada. No entanto, a escolha do instrumento mais adequado para um estudo particular nem sempre é algo simples e direto, pois há um grande número de instrumentos disponíveis e os resultados do estudo podem ser influenciados por essa escolha (Menezes; Nascimento, 1999).

Como qualquer outro tipo de avaliação baseada na percepção de informantes, os questionários de avaliação estão sujeitos a influências culturais. Aliás, as diferenças culturais expressas na linguagem, os costumes na educação das crianças, o sistema educacional, os padrões sociais, a alimentação, o estresse, as estratégias de enfrentamento e as oportunidades podem afetar a prevalência de algum distúrbio, a forma que ele toma e o que é feito quando o distúrbio está presente (Achenbach et al., 1990). Nesse sentido, para melhorar a comunicação entre os profissionais do país e permitir a comparação dos resultados de diferentes culturas, os procedimentos de avaliação devem ser padronizados (Verhulst et al., 1993).

Em relação aos critérios para validação de instrumentos, como há diversas variáveis que podem alterar um diagnóstico psiquiátrico (por exemplo, quem faz a entrevista diagnóstica), entende-se que esse tipo de avaliação não pode ser um critério único para tal (Rettew et al., 2009). 
Segundo Menezes e Nascimento (1999, p. 1), há uma ausência de marcadores biológicos em psiquiatria e a necessidade da utilização de escalas padronizadas e outros instrumentos nessa área:

Até o momento, não se dispõe de marcadores biológicos ou representações objetivamente mensuráveis para a maioria dos transtornos psiquiátricos, como o abuso de substâncias e o diagnóstico clínico ou dos problemas associados a eles pode variar bastante de acordo com a forma com que são avaliados, especialmente quando são realizados por diferentes avaliadores. Por isso, as escalas padronizadas, questionários ou outros instrumentos são, hoje, indispensáveis a qualquer pesquisa na área da psiquiatria. Contudo, essas escalas devem ser continuamente revisadas e testadas conforme a população e a cultura em que estão inseridas.

Portanto, a compreensão de conceitos sobre a acurácia da medida de um teste, padrão-ouro dos instrumentos, confiabilidade e validade dos métodos auxilia na avaliação de desempenho dos instrumentos, para chegar à escolha mais apropriada para determinados estudos.

\section{Principais conceitos e medidas de desempenho dos instrumentos}

\section{- Acurácia da medida de um teste}

Há quatro tipos possíveis de resultados de teste, dois dos quais estão corretos (verdadeiros) e dois, incorretos (falsos). O teste apresenta o resultado correto quando for positivo na presença da doença (verdadeiro positivo) ou negativo na sua ausência (verdadeiro negativo). Por outro lado, será enganoso se for positivo quando a doença estiver ausente (falso positivo) ou negativo quando estiver presente (falso negativo).

A acurácia de um teste é considerada com relação a alguma forma de saber se a doença está realmente presente ou não; ou seja, há uma indicação mais sólida da 
verdade, frequentemente referida como padrão-ouro (ou critério padrão ou padrão de referência) (Fletcher; Fletcher, 2004).

\section{- Confiabilidade}

O termo "confiabilidade" geralmente é utilizado para se referir à reprodutibilidade de uma medida, ou seja, ao grau de concordância entre múltiplas medidas de um mesmo objeto (Armstrong et al., 1994). A confiabilidade não é somente replicar medidas, é necessário fazer as diferenciações entre os pacientes e sobre como coletar as informações; no caso de aplicação de instrumentos de avaliação ou de diagnóstico, para muitos desses instrumentos, o entrevistador precisa possuir conhecimento da área, como, por exemplo, conceitos e tipos de abordagens em casos de dependência química. Ainda, muitos instrumentos exigem um treinamento prévio, para saber conduzir a entrevista de forma objetiva e clara.

No caso da aplicação de instrumentos de diagnóstico ou de avaliação, existem várias fontes de viés que podem afetar a confiabilidade dos dados colhidos (Spitzer et al., 1975; Klerman, 1985), sendo as principais: (1) erros durante a fase de obtenção de informações para diagnóstico ou avaliação (viés de informação): o informante pode fornecer informações incorretas por falta de concentração, por não compreender as perguntas ou por resistência intencional e o entrevistador pode errar na escolha e na formulação de frases ou no registro das respostas; (2) instabilidade do fenômeno clínico que está sendo avaliado (viés de situação): o informante pode responder a uma questão bem formulada de forma verdadeira, mas a resposta pode mudar a cada vez que a questão for feita, de acordo com as mudanças que ocorrem com o entrevistado; (3) utilização de critérios diagnósticos particulares por parte do entrevistador (viés de 
critério): se entrevistadores diferentes têm diferentes conceitos de um sintoma ou diagnóstico, a avaliação destes dependerá do profissional escolhido para realizar a entrevista; (4) a perda da confiabilidade em um estudo também pode ser resultado de inferências inconsistentes, descuidadas ou incompetentes feitas pelos entrevistadores.

\section{Tipos de confiabilidade}

A avaliação da confiabilidade de um instrumento é feita por meio da comparação de diversas aplicações do instrumento ao mesmo sujeito. Dois aspectos da confiabilidade são mais frequentemente avaliados (Menezes; Nascimento, 1999):

1. A confiabilidade entre diferentes avaliadores: os mesmos sujeitos são avaliados por dois ou mais avaliadores, com o objetivo de investigar a concordância de aplicação e/ou de interpretação entre os avaliadores;

2. A confiabilidade teste-reteste: um grupo de sujeitos é avaliado em dois momentos diferentes, visando a estabelecer o grau com que o instrumento pode reproduzir os resultados.

\section{Medidas de confiabilidade}

Um aspecto importante é utilizar medidas de confiabilidade que possam quantificar os coeficientes de forma precisa.

O grau de concordância entre as avaliações é quantificado por meio de coeficientes de confiabilidade, que podem ser calculados de 
várias formas. Medidas como o Kappa (Cohen, 1960), o Kappa ponderado (Cohen, 1968) e o coeficiente de correlação intraclasse (Bartko, 1966), que controlam o efeito do acaso, são medidas de confiabilidade muito mais adequadas. A escolha de um desses coeficientes dependerá da natureza do instrumento que se deseja avaliar (Bartko, 1991). Se o instrumento produz medidas categóricas, como diagnósticos seguindo determinado critério, ou uma medida binária, como ser um provável caso ou não-caso, o coeficiente de confiabilidade utilizado deve ser o Kappa (K). Se o instrumento mede categorias ordenadas, como, por exemplo, o nível de ajustamento social classificado como excelente, bom, regular, ruim ou péssimo, o Kappa ponderado fornece uma estimativa adequada do coeficiente de confiabilidade. Quando o instrumento produz valores numéricos discretos ou contínuos, como escores totais de psicopatologia, utiliza-se o coeficiente de correlação intraclasse como medida de confiabilidade. (Menezes; Nascimento, 1999, p. 25).

\section{Validade}

A validade de um instrumento pode ser definida como a sua capacidade de realmente medir aquilo a que se propõe medir (Kelsey et al., 1996). A avaliação da validade tem três aspectos principais: validade de conteúdo, validade de construto e validade de critério.

A validade de conteúdo tem dois componentes. A validade aparente (face validity) é um julgamento subjetivo sobre se uma medida faz sentido intuitivamente, ou seja, se é razoável. A validade amostral avalia se a medida incorpora todos ou a maioria dos aspectos do fenômeno estudado, por exemplo, uma medida válida de qualidade de vida deveria incluir questões sobre o funcionamento social, físico, emocional e intelectual.

A validade de construto refere-se à capacidade de uma medição de se encaixar dentro da concepção teórica (construto) sobre o fenômeno em estudo. Por exemplo, caso se acredite teoricamente que um determinado traço seja diferente em dois grupos de indivíduos, uma medida com validade de construto deveria mostrar essa diferença.

A validade relativa ao critério é o grau em que a medida correlaciona-se com um critério externo ao fenômeno investigado. Uma variação dela é a validade preditiva, isto é, a capacidade de predizer a ocorrência futura de tal critério. (Hulley et al., 2003, p. $63)$. 
Outro aspecto relevante é a

validade de concorrentes quando o instrumento e o critério são aplicados simultaneamente, a validade de critério de um instrumento é estimada estatisticamente e é expressa por meio da sua sensibilidade (proporção de casos positivos identificados corretamente), especificidade (proporção de casos negativos identificados corretamente), valor preditivo positivo (VPP), que indica a probabilidade de que casos detectados como positivos sejam realmente positivos, valor preditivo negativo (VPN), que se refere à probabilidade de que casos detectados como negativos sejam realmente negativos, e a taxa de classificação incorreta, que é a proporção de indivíduos classificados incorretamente como positivos ou como negativos. (Menezes; Nascimento, 1999, p. 26).

Na construção do conhecimento científico, a confiabilidade e a validade de um instrumento são fatores importantes para avaliações diagnósticas e estudos de prevalência, porém também se faz necessária a análise de outros fatores subjetivos no percurso da doença, como no caso dos usuários de comportamento de risco para o abuso de álcool e outras drogas, em que há multifatores associados. De acordo com Menezes e Nascimento (1999, p. 27), “embora a confiabilidade seja necessária para a validade, uma alta confiabilidade não é suficiente para garantir a validade. O processo científico de validação pode começar com um estudo de confiabilidade e prosseguir muito além da documentação de uma boa confiabilidade."

\section{Análise estatística}

Duas maneiras de calcular a confiabilidade dos instrumentos são através do coeficiente Alfa de Cronbach (Cronbach, 1951) e do coeficiente de confiabilidade split-half (coeficiente Spearman-Brown). Segundo De Micheli e Formigoni (2002), esses coeficientes são os indicadores mais amplamente utilizados para avaliar a 
consistência interna (Cronbach, 1951; Cronbach; Meehl, 1955; Portney; Watkins, 1993). Ainda, de acordo com alguns autores, coeficientes de confiabilidade Alfa de Cronbach e split-half acima de 0,80 podem ser considerados indicadores de confiabilidade de bom a excelente (Carmines; Zelles, 1979; Cronbach, 1951; Cronbach; Meehl, 1955; Portney; Watkins, 1993; Streiner; Norman, 1989).

Por sua vez, a Curva de Receiver Operating Characteristic (ROC) é usada para avaliar a sensibilidade e a especificidade dos instrumentos (Aytaclar et al., 2003), além do poder discriminativo do instrumento com diferentes linhas de corte (De Micheli; Formigoni, 2002). A curva é construída plotando um gráfico bidimensional, sendo que, em um dos eixos, é plotada a sensibilidade (a resposta positiva) e, no outro eixo, a especificada (a resposta negativa). A escala de valores nos eixos varia de 0 a $100 \%$ e a acurácia geral do teste pode ser descrita como a área sobre a curva de ROC, sendo que, quanto maior a área, melhor o resultado do teste (Fletcher et al., 1988).

\subsection{Recomendações do NIDA para questionários e escalas}

O National Institute on Drug Abuse (NIDA), órgão americano mundialmente reconhecido, recomenda uma série de questionários e escalas para adolescentes usuários de substâncias, conforme segue:

- Para triagem:

- Cliente Substance Index-Short (CSI-S);

- Drug and Alcohol Problem (DAP);

- $\quad$ Drug Use Screening Inventory Revised (DUSI-R); 
- Perceived Benefit of Drinking and Drug Use;

- Personal Experience Screening Questionnaire (PESQ);

- Problem Oriented Screening Instrument for Teenagers (POSIT);

- Substance Abuse Subtle Screening Inventory (SASSI);

- Para álcool:

- Adolescent Alcohol Involvement Scale (AAIS);

- Adolescent Drinking Index (ADI);

- Rutgers Alcohol Problem Index (RAPI);

- Entrevistas diagnósticas:

- Diagnostic Interview for Children and Adolescent (DICA);

- Diagnostic Interview Schedule for Children (DISC);

- Kiddie-Schedule for Affective Disorders and Schizophrenia (KSADS);

- Customary Drinking and Drug Use Record (CDDR);

- Global Appraisal of Individual Needs (GAIN) - em processo de validação.

A seleção de um instrumento apropriado pode também contribuir para a realização de um estudo observacional, além de futuros projetos de intervenção para a promoção da reinserção social de jovens, uma vez que há uma relação entre a exclusão social e o consumo de drogas, que inclui baixos níveis de escolaridade, desemprego, saída precoce da escola, estigma social, entre outros. Nesse contexto, a reinserção social pode ser definida como qualquer esforço tendente a integrar os consumidores de drogas na comunidade (OEDR, 2003). 


\subsection{Principais instrumentos para adolescentes - traduzidos e validados para o Brasil}

O Drug Use Screening Inventory (DUSI R), serve para identificar jovens de risco. Para adolescentes dependentes em tratamento, foi desenvolvida a Teen Addiction Severity Index (T-ASI), já traduzida e validada para o Brasil. O T-ASI é uma entrevista adaptada ao adolescente, que investiga várias áreas de sua vida, como o grupo que freqüenta e o desempenho escolar. (Marques, 2004, p. 155).

O Child Behavior Checklist (CBCL) - Inventário de Comportamento da Infância e Adolescência - avalia comportamentos internalizantes e externalizantes, tendo sido validado por Bordin et al (1995). Já o GAIN - entrevista semiestruturada para avaliação do tratamento realizado para tradução e adaptação cultural - está em fase de validação por Claro (2010). Ainda, para o Alcohol, Smoking and Substance Involvement Screening Test (ASSIST) para adolescentes - teste para triagem do envolvimento com fumo, álcool e outras drogas -, foi efetuada a validação concorrente e de confiabilidade da versão brasileira por Carminatti (2010).

Por sua vez, o ADS - questionário padronizado para avaliação do grau de severidade da síndrome da dependência de álcool - foi traduzido para o português por Jorge e Masur (1986) e sua aplicação para adultos e adolescentes foi verificada por Miranda et al. (2004), voltada para pesquisa e diagnóstico. O Composite International Diagnostic Interview (CIDI) - questionário para pesquisa e diagnóstico - foi traduzido para os adolescentes por Miranda et al. (2005). Por fim, a Escala de Severidade de Alcoolismo (ESA) - entrevista semiestruturada para seguimento de dependência de drogas e outra para dependência de álcool em adolescentes - foi elaborada por Scivoletto (1997). 
Diante desse contexto, apresenta-se uma proposta de pesquisa que tem como objeto de estudo uma revisão de literatura sobre os diferentes instrumentos validados para o Brasil, para identificar o comportamento de risco em adolescentes com abuso de álcool e outras drogas.

\subsection{A importância da proposta de pesquisa}

A dependência química segue o modelo biopsicossocial de saúde.

A abordagem exigida para a dependência química é coerente com o modelo psicossocial de saúde em foco na atualidade. Isso porque, tratar a questão do uso abusivo de substâncias psicoativas e a questão da possível dependência que pode emergir em alguns casos, implica discutir não só as questões orgânicas e psicológicas envolvidas, mas também os aspectos sociais, políticos, econômicos, legais e culturais inerentes a esse fenômeno, além das consequências físicas, psíquicas e sociais da mesma. (Occhini; Teixeira, 2006, p. $32)$.

Portanto, o fenômeno da drogadição é complexo e multifatorial. (Cartana et al., 2004; Scivoletto; Morihisa, 2001).

A OMS (2001) destaca, ainda, que a dependência química deve ser tratada, simultaneamente, como uma doença médica crônica e como um problema social. Não basta, portanto, identificar e tratar os sintomas, mas sim identificar as consequências e os motivos que levaram à doença, pensando o indivíduo em sua totalidade, para que se possam oferecer outros referenciais e subsídios que gerem mudanças de comportamento em relação à questão da droga.

A adolescência é uma fase marcada por conflitos e pela busca de identidade. Assim, outro fator de risco seria a própria adolescência, citada como o período de 
maiores chances para o início do consumo de substâncias (Dupont, 1987; Sanchez; Nappo, 2002). "Esta constatação coloca os adolescentes, pelo menos em tese, particularmente suscetíveis ao uso de drogas." (Sanchez et al., 2005).

Em face desse contexto, são necessários estudos que auxiliem a identificar instrumentos que possam ser utilizados para diagnosticar e compreender comportamentos de risco para o abuso de álcool e outras drogas em populações de adolescentes. Nesse sentido, são identificados, no Brasil, pelo menos três instrumentos que medem adequadamente o comportamento de risco e o perfil de gravidade para o abuso de álcool e outras drogas (DUSI-R, Teen Addiction Severity Index - Teen ASI e CBCL). No entanto, não se dispõe de estudos comparativos na aplicação desses instrumentos em que se foquem as principais vantagens e limitações do uso de cada um deles.

De acordo com experiências em serviços de prevenção e tratamento em dependência química, assim como na literatura internacional, para que o processo de mudança de comportamento seja efetivo, são necessárias realizações de pesquisas que possam diagnosticar a realidade, para posteriormente oferecer intervenções eficazes, voltadas tanto ao jovem quanto à sua família, e que também sejam educativas e abrangentes. Segundo Silva et al. (2006), as necessidades únicas do adolescente exigem que o tratamento seja compreensivo e focado em múltiplos domínios, além de ter como objetivo o aumento dos fatores de proteção, enquanto diminuem-se os fatores de riscos.

A implementação dessa proposta de pesquisa tem sua importância pela necessidade, no Brasil, de revisões de literatura que avaliem instrumentos que identifiquem comportamentos de risco em adolescentes, como também a compreensão 
do uso desses instrumentos. Dessa forma, poderia auxiliar, tanto pesquisadores quanto profissionais da saúde, na escolha de uma ferramenta que possa ser útil no diagnóstico e no tratamento do abuso de álcool e outras drogas.

A opinião de vários pesquisadores que validaram instrumentos de pesquisa e tratamento para o Brasil, assim como a experiência de profissionais que atuam no atendimento aos adolescentes usuários de substâncias psicoativas, converge no sentido de eleger os seguintes instrumentos: DUSI-R, Teen ASI e CBCL, que serão foco desta pesquisa. Embora haja outros instrumentos na literatura nacional e internacional, poucos serviços de saúde mental e dependência química no Brasil os utilizam ou eles são específicos de pesquisas e não aplicáveis em ambientes clínicos. 


\section{OBJETIVOS}

\section{Objetivo geral}

- Descrever três importantes instrumentos validados para o Brasil e utilizados para a avaliação do abuso de álcool e outras drogas em adolescentes.

\section{Objetivos específicos}

- Identificar quais as dificuldades e fatores de risco em algumas áreas da vida do adolescente que os instrumentos avaliam, tais como: comportamento, saúde, sexualidade, transtornos psiquiátricos, sociabilidade, sistema familiar, escola, trabalho, relacionamento com amigos, lazer e recreação;

- Identificar o melhor uso de cada instrumento, de acordo com a finalidade: diagnóstico, tratamento ou prevenção;

- Apresentar as medidas de desempenho desses instrumentos nos estudos pesquisados. 


\section{MÉTODO}

- Tipo do estudo: revisão de literatura;

- Período: publicações dos últimos 12 anos (janeiro de 1998 a agosto de 2010);

- Base de dados: foram utilizadas as bases de dados Adolec, Medical Literature Analysis and Retrieval System Online (MedLine), Literatura Latino-Americana e do Caribe em Ciências da Saúde (Lilacs), PubMed e Scientific Electronic Library Online (SciELO);

- Descritores: Teen ASI ou T-ASI, Drug Use Screening Inventory (DUSI), DUSI-R e CBCL;

- Tema: a pesquisa bibliográfica busca os instrumentos validados para o Brasil e utilizados em estudos sobre comportamento de risco para o abuso de álcool e outras drogas em adolescentes.

\subsection{Critérios de inclusão}

a) Estudos que apresentaram aplicação dos instrumentos Teen ASI, DUSI-R e CBCL;

b) Revisão de estudos que tenham utilizado instrumentos que medem fatores de risco associados ao consumo de drogas em adolescentes;

c) Utilização dos descritores Teen ASI ou T-ASI, DUSI, DUSI-R e CBCL. 
Ainda, foram adotados os seguintes critérios de inclusão para a seleção dos estudos:

- Detalhamento do instrumento utilizado para diagnóstico;

- Utilização de algum indicador de desempenho do instrumento;

- Qualidade do estudo, que permita a avaliação do desempenho do instrumento, assim como a sua coerência com a literatura.

\subsection{Critérios de exclusão}

a) Outros instrumentos que medem comportamento de risco em adolescentes e não foram validados para o Brasil ou que se encontram em processo de validação, porém não concluído;

b) Estudos qualitativos sobre consumo de álcool e outras drogas em adolescentes.

\subsection{Aspectos éticos}

A Comissão de Ética para Análise de Projetos de Pesquisa (CAPPesq) da Diretoria Clínica do Hospital das Clínicas e da Faculdade de Medicina da Universidade de São Paulo, em sessão de 07/10/2009, aprovou este Protocolo de Pesquisa $n^{\circ} 0988 / 09$. 


\section{RESULTADOS}

Foram, inicialmente, identificados 767 artigos e, posteriormente, foram selecionados de acordo com os critérios previamente definidos. Ao final, foram avaliados 54 artigos. A Figura 1 apresenta um resumo dos critérios de identificação e seleção dos artigos.

\subsection{Estratégia de busca dos artigos}

Figura 1 - Fluxograma de pesquisa de artigos durante o processo de revisão.

Período: jan. 1998 a ago. 2010.

\begin{tabular}{|l|l|l|l|}
\hline \multicolumn{2}{|l|}{ DESCRITORES } \\
\hline Teen ASI; T-ASI & \multicolumn{2}{l|}{ DUSI; DUSI-R } & CBCL \\
\hline \multicolumn{2}{|l|}{} \\
\begin{tabular}{|l|l|l|l|l|}
\hline Banco de Dados & Teen ASI & DUSI & CBCL & TOTAL \\
\hline SciELO & 0 & 14 & 3 & 17 \\
\hline Adolec & 0 & 32 & 0 & 32 \\
\hline Lilacs & 17 & 10 & 50 & 77 \\
\hline PubMed & 182 & 188 & 271 & 641 \\
\hline TOTAL & 199 & 244 & 324 & 767 \\
\hline
\end{tabular}
\end{tabular}

\section{CRITÉRIOS DE EXCLUSÃO}

- Artigos duplicados ou não originais;

- Faixa etária inferior a 10 anos e superior a 19;

- Artigos não relacionados a comportamento de risco para o abuso de álcool e outras drogas;

- Artigos que não tinham aplicação dos instrumentos.

Artigos descartados: 713.

ARTIGOS INCLUÍDOS NA REVISÃO

\begin{tabular}{|l|l|l|l|l|}
\hline & Teen ASI & DUSI & CBCL & TOTAL \\
\hline TOTAL & 12 & 30 & 12 & 54 \\
\hline
\end{tabular}




\subsection{Aplicação do método e tabela geral dos artigos pesquisados}

\subsubsection{Tabela geral dos artigos pesquisados com aplicação do instrumento DUSI-R}

A Tabela 1 apresenta os artigos selecionados na revisão bibliográfica, segundo autor/fonte, ano de publicação, tipo do estudo, tamanho da amostra e desempenho do instrumento, que utilizaram o instrumento DUSI-R, no período de janeiro de 1998 a agosto de 2010.

Tabela 1 - Artigos pesquisados com aplicação do instrumento DUSI-R.

\begin{tabular}{|c|c|c|c|c|c|c|}
\hline Autor/Fonte & Ano & Título do Artigo & Estudo & $\mathbf{N}$ & \multicolumn{2}{|c|}{$\begin{array}{l}\text { Desempenho do } \\
\text { Instrumento }\end{array}$} \\
\hline $\begin{array}{l}\text { Moss et al./Drug } \\
\text { Alcohol Depen }\end{array}$ & 1998 & $\begin{array}{l}\text { Substance abuse and } \\
\text { associated psychosocial } \\
\text { problems among Ar- } \\
\text { gentina adolescents: sex } \\
\text { heterogeneity and familial } \\
\text { transmission. }\end{array}$ & $\begin{array}{l}\text { Corte Trans- } \\
\text { versal/Tra- } \\
\text { dução }\end{array}$ & 1310 & \multicolumn{2}{|c|}{ Não analisa. } \\
\hline $\begin{array}{l}\text { De Micheli e } \\
\text { Formigoni/Addict } \\
\text { Behav }\end{array}$ & 2000 & $\begin{array}{l}\text { Screening of drug use in a } \\
\text { teenage Brazilian Sample } \\
\text { using the drug use } \\
\text { screening inventory } \\
\text { (DUSI). }\end{array}$ & $\begin{array}{l}\text { Corte Trans- } \\
\text { versal/ } \\
\text { Validação }\end{array}$ & 213 & $\begin{array}{l}\text { Sensib. } \\
80 \%\end{array}$ & $\begin{array}{c}\text { Especif. } \\
90 \%\end{array}$ \\
\hline $\begin{array}{l}\text { Tarter e Kirisci/ } \\
\text { J Child Adolesc } \\
\text { Subst Abuse }\end{array}$ & 2001 & $\begin{array}{l}\text { Validity of drug use } \\
\text { screening inventory for } \\
\text { predicting DSM-III-R. } \\
\text { Substance use disorder. }\end{array}$ & Longitudinal & 354 & $\begin{array}{c}\text { Sensib. } \\
75 \%\end{array}$ & $\begin{array}{c}\text { Especif. } \\
72 \%\end{array}$ \\
\hline $\begin{array}{l}\text { De Micheli et al./ } \\
\text { Alcohol Clin Exp } \\
\text { Res }\end{array}$ & 2002 & $\begin{array}{l}\text { Psychometric properties } \\
\text { of the Brazilian version of } \\
\text { the drugs use screening } \\
\text { inventory. }\end{array}$ & $\begin{array}{l}\text { Corte } \\
\text { Transversal }\end{array}$ & 213 & Sensib. $80 \%$ & $\begin{array}{c}\text { Especif. } \\
90 \%\end{array}$ \\
\hline $\begin{array}{l}\text { Navarro e Pon- } \\
\text { tillo/Actual En- } \\
\text { ferm }\end{array}$ & 2002 & $\begin{array}{l}\text { Autoestima del } \\
\text { adolescente y riesgo de } \\
\text { consume de alcohol. }\end{array}$ & $\begin{array}{l}\text { Corte Trans- } \\
\text { versal }\end{array}$ & 301 & \multicolumn{2}{|c|}{$\begin{array}{c}\mathrm{r}=0,26 \mathrm{c} / \text { nível de } \\
\text { confiança } 95 \%\end{array}$} \\
\hline $\begin{array}{l}\text { Sandi et al./ } \\
\text { Subst Use Misuse }\end{array}$ & 2002 & $\begin{array}{l}\text { Drug use and associated } \\
\text { factors among rural } \\
\text { adolescents in Costa Rica. }\end{array}$ & $\begin{array}{l}\text { Corte Trans- } \\
\text { versal }\end{array}$ & 304 & \multicolumn{2}{|c|}{ Não analisa. } \\
\hline $\begin{array}{l}\text { Tarter et al./Am J } \\
\text { Psychiatry }\end{array}$ & 2002 & $\begin{array}{l}\text { Predicting adolescent } \\
\text { violence: impact of } \\
\text { family history, substance } \\
\text { use, psychiatric history, } \\
\text { and social adjustment. }\end{array}$ & Longitudinal & 99 & $\begin{array}{c}\text { Sensib. } 81 \% \\
\text { Escala }\end{array}$ & $\begin{array}{l}\text { Especif. } \\
76 \% \\
\text { Violência }\end{array}$ \\
\hline
\end{tabular}




\begin{tabular}{|c|c|c|c|c|c|c|}
\hline $\begin{array}{l}\text { Vittetoe et al./ } \\
\text { Rev Panam Salud } \\
\text { Publica }\end{array}$ & 2002 & $\begin{array}{l}\text { Behavioral problems and } \\
\text { tobacco use adolescents } \\
\text { in Central America and } \\
\text { the Dominican Republic. }\end{array}$ & $\begin{array}{l}\text { Corte Trans- } \\
\text { versal/ } \\
\text { Estudo de } \\
\text { Colaboração } \\
\text { Multinacio- } \\
\text { nal (7 } \\
\text { países) }\end{array}$ & $\begin{array}{l}\mathrm{De} \\
451 \mathrm{a} \\
1170\end{array}$ & \multicolumn{2}{|c|}{ Não analisa. } \\
\hline $\begin{array}{l}\text { Aytaclar et al./ } \\
\text { Addict Behav }\end{array}$ & 2003 & $\begin{array}{l}\text { Substance abuse and } \\
\text { associated psychosocial } \\
\text { risk factors among } \\
\text { Turkish male } \\
\text { adolescents. }\end{array}$ & $\begin{array}{l}\text { Corte Trans- } \\
\text { versal/ } \\
\text { Validação } \\
\text { Instrumento }\end{array}$ & 158 & Sensib. $80 \%$ & $\begin{array}{c}\text { Especif. } \\
87 \%\end{array}$ \\
\hline $\begin{array}{l}\text { Dalla-Déa et al./ } \\
\text { Drug Alcohol } \\
\text { Dependen }\end{array}$ & 2003 & $\begin{array}{l}\text { Effects of identification } \\
\text { and usefulness of the lie } \\
\text { scale of drug use } \\
\text { screening inventory } \\
\text { (Dusi-R) in the } \\
\text { assessment of adolescent } \\
\text { drug use. }\end{array}$ & $\begin{array}{l}\text { Corte Trans- } \\
\text { versal }\end{array}$ & 655 & \multicolumn{2}{|c|}{ Não analisa. } \\
\hline $\begin{array}{l}\text { Gosebruch et al./ } \\
\text { Subst Use Misuse }\end{array}$ & 2003 & $\begin{array}{l}\text { Family attention and } \\
\text { tobacco smoking among } \\
\text { adolescents in Central } \\
\text { America, Panama and } \\
\text { Dominican Republica. }\end{array}$ & $\begin{array}{l}\text { Corte Trans- } \\
\text { versal }\end{array}$ & $\begin{array}{c}5549 \\
7 \\
\text { países }\end{array}$ & \multicolumn{2}{|c|}{ Não analisa. } \\
\hline $\begin{array}{l}\text { De Micheli et al./ } \\
\text { Addiction }\end{array}$ & 2004 & $\begin{array}{l}\text { Drug use by Brazilian } \\
\text { students: associations } \\
\text { with family, psychoso- } \\
\text { cial, health, demographic } \\
\text { and behavioral } \\
\text { characteristics. }\end{array}$ & $\begin{array}{l}\text { Corte Trans- } \\
\text { versal }\end{array}$ & 6417 & \multicolumn{2}{|c|}{ Não analisa. } \\
\hline $\begin{array}{l}\text { De Micheli et al./ } \\
\text { Rev Assoc Med } \\
\text { Bras }\end{array}$ & 2004 & $\begin{array}{l}\text { Estudo da efetividade da } \\
\text { intervenção breve para o } \\
\text { uso de álcool e drogas } \\
\text { em adolescentes } \\
\text { atendidos num serviço de } \\
\text { assistência primária à } \\
\text { saúde. }\end{array}$ & $\begin{array}{l}\text { Ensaio Clí- } \\
\text { nico }\end{array}$ & 108 & \multicolumn{2}{|c|}{ Não analisa. } \\
\hline $\begin{array}{l}\text { Figlie et al./Rev } \\
\text { Psiquiatr Clín } \\
\text { (São Paulo) }\end{array}$ & 2004 & $\begin{array}{l}\text { Filhos de dependentes } \\
\text { químicos com fatores de } \\
\text { risco biopsicossociais: } \\
\text { necessitam de um olhar } \\
\text { especial? }\end{array}$ & $\begin{array}{l}\text { Corte Trans- } \\
\text { versal }\end{array}$ & 45 & \multicolumn{2}{|c|}{ Não analisa. } \\
\hline $\begin{array}{l}\text { Fraile Duvicq et } \\
\text { al./Rev Latino Am } \\
\text { Enfermagem }\end{array}$ & 2004 & $\begin{array}{l}\text { Consumo de drogas } \\
\text { lícitas e ilícitas em } \\
\text { escolares \& factores de } \\
\text { protección \& riesgo. }\end{array}$ & $\begin{array}{l}\text { Corte } \\
\text { Transversal }\end{array}$ & 301 & \multicolumn{2}{|c|}{ Não analisa. } \\
\hline $\begin{array}{l}\text { Mathews et al./ } \\
\text { Rev Latino Am } \\
\text { Enfermagem }\end{array}$ & 2004 & $\begin{array}{l}\text { Factores protectores \& de } \\
\text { riesgo asociados al uso } \\
\text { de alcohol em } \\
\text { adolescentes hijos de } \\
\text { padre alcohólico, em el } \\
\text { Peru. }\end{array}$ & $\begin{array}{l}\text { Estudo ex- } \\
\text { ploratório }\end{array}$ & 104 & \multicolumn{2}{|c|}{ Não analisa. } \\
\hline $\begin{array}{l}\text { Rebolledo et al./ } \\
\text { Rev Latino Am } \\
\text { Enfermagem }\end{array}$ & 2004 & $\begin{array}{l}\text { Fatores de riscos } \\
\text { associados ao uso de } \\
\text { drogas entre estudantes } \\
\text { adolescentes. }\end{array}$ & $\begin{array}{l}\text { Corte Trans- } \\
\text { versal }\end{array}$ & 490 & \multicolumn{2}{|c|}{ Não analisa. } \\
\hline
\end{tabular}




\begin{tabular}{|c|c|c|c|c|c|c|}
\hline $\begin{array}{l}\text { Rodríguez e Luis } \\
\text { Villar/Rev Latino } \\
\text { Am Enfermagem }\end{array}$ & 2004 & $\begin{array}{l}\text { Estudio descriptivo del } \\
\text { uso de drogas en } \\
\text { adolescentes de } \\
\text { educación media } \\
\text { superior de la Ciudad de } \\
\text { Monterrey, Nueva León, } \\
\text { Mexico. }\end{array}$ & $\begin{array}{l}\text { Corte Trans- } \\
\text { versal }\end{array}$ & 325 & \multicolumn{2}{|c|}{ Não analisa. } \\
\hline $\begin{array}{l}\text { Siewert et al./ } \\
\text { Addict Behav }\end{array}$ & 2004 & $\begin{array}{l}\text { Factor structure and } \\
\text { concurrent validity of the } \\
\text { drug use inventory in a } \\
\text { community adolescent } \\
\text { sample. }\end{array}$ & $\begin{array}{l}\text { Estudo } \\
\text { Expe- } \\
\text { rimental }\end{array}$ & 1266 & \multicolumn{2}{|c|}{$\begin{array}{l}6 \text { subescalas mostra- } \\
\text { ram consistência } \\
\text { interna adequada. }\end{array}$} \\
\hline $\begin{array}{l}\text { Solhkhah et al./ } \\
\text { J Child Adolesc } \\
\text { Psychopharmacol }\end{array}$ & 2005 & $\begin{array}{l}\text { Bupropion SR for the } \\
\text { treatment of substance- } \\
\text { abusing outpatient } \\
\text { adolescents with } \\
\text { attention-defi- } \\
\text { cit/hyperactivity disorder } \\
\text { and mood disorders. }\end{array}$ & Longitudinal & 14 & \multicolumn{2}{|c|}{ Não analisa. } \\
\hline $\begin{array}{l}\text { Negrete et } \\
\text { al./Adicciones }\end{array}$ & 2006 & $\begin{array}{l}\text { Adaptacion del drug use } \\
\text { inventory para su } \\
\text { aplicación con } \\
\text { adolescentes mexicanos. }\end{array}$ & $\begin{array}{l}\text { Corte Trans- } \\
\text { versal }\end{array}$ & 1983 & \multicolumn{2}{|c|}{$\begin{array}{c}\text { Consistência interna } \\
\text { com Alfa de Cronbach } \\
=0,9451\end{array}$} \\
\hline $\begin{array}{l}\text { Tarter et al./Am J } \\
\text { Psychiatry }\end{array}$ & 2006 & $\begin{array}{l}\text { Predictors of marijuana } \\
\text { use in adolescents before } \\
\text { and after licit drug use: } \\
\text { examination of the } \\
\text { gateway hypothesis. }\end{array}$ & Longitudinal & 224 & \multicolumn{2}{|c|}{ Não analisa. } \\
\hline $\begin{array}{l}\text { Tarter et al./ } \\
\text { Psychol Addict } \\
\text { Behav }\end{array}$ & 2007 & $\begin{array}{l}\text { Modeling the pathways } \\
\text { linking childhood } \\
\text { hyperactivity and sub- } \\
\text { stance use disorder in } \\
\text { young adulthood. }\end{array}$ & Longitudinal & 112 & \multicolumn{2}{|c|}{ Não analisa. } \\
\hline $\begin{array}{l}\text { Negrete e García- } \\
\text { Aurrecoechea/Rev } \\
\text { Panam Salud } \\
\text { Publica }\end{array}$ & 2008 & $\begin{array}{l}\text { Factores psicosociales de } \\
\text { riesgo de consumo de } \\
\text { drogas ilícitas em uma } \\
\text { muestra de estudiantes } \\
\text { mexicanos de educación } \\
\text { media. }\end{array}$ & $\begin{array}{l}\text { Corte trans- } \\
\text { versal }\end{array}$ & 516 & \multicolumn{2}{|c|}{ Não analisa. } \\
\hline $\begin{array}{l}\text { Kirisci et al./Am J } \\
\text { Drug Alcohol } \\
\text { Abuse }\end{array}$ & 2008 & $\begin{array}{l}\text { Screening current and } \\
\text { future diagnosis of } \\
\text { psychiatric disorders } \\
\text { using the revised drug } \\
\text { use screening inventory. }\end{array}$ & Longitudinal & 328 & $\begin{array}{c}\text { Sensib.80- } \\
94 \%\end{array}$ & $\begin{array}{l}\text { Especif. } \\
\text { (acurac.) } \\
72-97 \%\end{array}$ \\
\hline $\begin{array}{l}\text { Jinez et al./Rev } \\
\text { Latino Am Enfer- } \\
\text { magem }\end{array}$ & 2009 & $\begin{array}{l}\text { Uso de drogas e fatores } \\
\text { de risco entre estudantes } \\
\text { de ensino médio. }\end{array}$ & $\begin{array}{l}\text { Corte Trans- } \\
\text { versal }\end{array}$ & 695 & \multicolumn{2}{|c|}{$\begin{array}{l}\text { O DUSI foi adequado } \\
\text { para identificar o uso } \\
\text { de drogas. }\end{array}$} \\
\hline $\begin{array}{l}\text { Kirisci et al./Am J } \\
\text { Addict }\end{array}$ & 2009 & $\begin{array}{l}\text { The violence proneness } \\
\text { scale of the DUSI-R } \\
\text { predicts adverse } \\
\text { outcomes associated with } \\
\text { substance abuse. }\end{array}$ & Longitudinal & 328 & $\begin{array}{c}\text { Sensib.67- } \\
79 \%\end{array}$ & $\begin{array}{l}\text { Especif. } \\
45-64 \%\end{array}$ \\
\hline $\begin{array}{l}\text { Ndetei et al./Subst } \\
\text { Abus }\end{array}$ & 2009 & $\begin{array}{l}\text { Psychosocial and health } \\
\text { aspects of drug use by } \\
\text { students in public sec- } \\
\text { ondary schools in } \\
\text { Nairobi, Kenya. }\end{array}$ & $\begin{array}{l}\text { Corte Trans- } \\
\text { versal }\end{array}$ & 1328 & \multicolumn{2}{|c|}{ Não analisa. } \\
\hline
\end{tabular}




\begin{tabular}{|l|c|l|l|l|l|c|}
\hline $\begin{array}{l}\text { Christie et al./ } \\
\text { Drug Alcohol Rev }\end{array}$ & 2010 & $\begin{array}{l}\text { Do young people } \\
\text { attending addiction } \\
\text { services differ from those } \\
\text { attending youth mental } \\
\text { health services? }\end{array}$ & $\begin{array}{l}\text { Corte Trans- } \\
\text { versal }\end{array}$ & 131 & \multicolumn{2}{|c|}{ Não analisa. } \\
\hline Fidalgo et al./Am & 2010 & $\begin{array}{l}\text { Validation of a short } \\
\text { version of the revised } \\
\text { J Addict } \\
\text { inventory in a Brazilian } \\
\text { sample of adolescents. }\end{array}$ & $\begin{array}{l}\text { Corte Trans- } \\
\text { versal }\end{array}$ & 84 & $\begin{array}{c}\text { Sensib. } \\
85 \%\end{array}$ & $\begin{array}{c}\text { Especif. } \\
70 \%\end{array}$ \\
\hline
\end{tabular}

\subsubsection{Artigos com aplicação do instrumento Teen ASI}

Na Tabela 2, são apresentados os artigos selecionados na revisão bibliográfica, segundo autor/fonte, ano de publicação, tipo do estudo, tamanho da amostra e desempenho do instrumento, que utilizaram o instrumento Teen ASI, no período de janeiro de 1998 a agosto de 2010.

Tabela 2 - Artigos pesquisados com aplicação do instrumento Teen ASI.

\begin{tabular}{|c|c|c|c|c|c|}
\hline Autor/Fonte & Ano & Título do Artigo & Estudo & $\mathbf{N}$ & $\begin{array}{l}\text { Desempenho } \\
\text { do } \\
\text { Instrumento }\end{array}$ \\
\hline $\begin{array}{l}\text { Kaminer et } \\
\text { al./ } \\
\text { J Nerv Ment } \\
\text { Dis }\end{array}$ & 1998 & $\begin{array}{l}\text { Measuring treatment process in } \\
\text { cognitive behavioral and interactional } \\
\text { group therapies for adolescent } \\
\text { substance abusers. }\end{array}$ & Ensaio Clínico & 38 & Não analisa. \\
\hline $\begin{array}{l}\text { Kaminer e } \\
\text { Burleson/Am } \\
\text { J Addict }\end{array}$ & 1999 & $\begin{array}{l}\text { Psychotherapies for adolescent } \\
\text { substance abusers: } 15 \text { month follow up } \\
\text { of a pilot study. }\end{array}$ & $\begin{array}{c}\text { Ensaio Clínico } \\
\text { Randomizado }\end{array}$ & 32 & Não analisa. \\
\hline $\begin{array}{l}\text { Kaminer et } \\
\text { al./ } \\
\text { J Nerv Ment } \\
\text { Dis } \\
\end{array}$ & 2002 & $\begin{array}{l}\text { Cognitive-behavioral coping skills and } \\
\text { psychoeducation therapies for } \\
\text { adolescent substance abuse. }\end{array}$ & $\begin{array}{l}\text { Ensaio Clínico } \\
\text { Randomizado }\end{array}$ & 88 & Não analisa. \\
\hline $\begin{array}{l}\text { Kaminer e } \\
\text { Burleson/ } \\
\text { Subst Abus }\end{array}$ & 2004 & $\begin{array}{l}\text { Correlation between ancillary } \\
\text { community services with adolescent } \\
\text { substance use disorders treatment } \\
\text { outcome. }\end{array}$ & $\begin{array}{c}\text { Ensaio } \\
\text { Clínico/Estudo } \\
\text { Comparativo }\end{array}$ & 88 & Não analisa. \\
\hline $\begin{array}{l}\text { Brodey et al./ } \\
\text { Psychol } \\
\text { Addict Behav }\end{array}$ & 2005 & $\begin{array}{l}\text { Conversion and validation of the teen- } \\
\text { addiction severity index (T-ASI) for } \\
\text { internet and automated-telephone self- } \\
\text { report administration. }\end{array}$ & $\begin{array}{l}\text { Estudo de } \\
\text { conversão } \\
\text { para internet e } \\
\text { telefone }\end{array}$ & 95 & $\begin{array}{c}\text { Versão } \\
\text { internet } \mathrm{r}= \\
0,74 \text { e DP }= \\
0,14 ; \text { Versão } \\
\text { Telefone r }= \\
0,72 \text { e DP }= \\
0,16 .\end{array}$ \\
\hline
\end{tabular}




\begin{tabular}{|c|c|c|c|c|c|}
\hline $\begin{array}{l}\text { Díaz et al./ } \\
\text { Addict Behav }\end{array}$ & 2008 & $\begin{array}{l}\text { Clinical and research utility of Spanish } \\
\text { teen-addiction severity index (T-ASI). }\end{array}$ & $\begin{array}{c}\text { Corte } \\
\text { Transversal }\end{array}$ & 80 & $\begin{array}{l}\text { Rho }=0,90 \mathrm{p} / \\
\text { padrão de uso } \\
\text { de drogas; } \\
\text { Rho }=0,69 \mathrm{p} / \\
\text { problemas } \\
\text { subjetivos c/ } \\
\text { drogas. }\end{array}$ \\
\hline $\begin{array}{l}\text { Brodey et al./ } \\
\text { Subst Abus }\end{array}$ & 2008 & $\begin{array}{l}\text { Psychometric characteristics of the } \\
\text { teen addiction severity index-two (T- } \\
\text { ASI-2). }\end{array}$ & $\begin{array}{c}\text { Corte } \\
\text { Transversal }\end{array}$ & 371 & $\begin{array}{c}\text { Excelente } \\
\text { consistência } \\
\text { interna; Alfa } \\
\text { de Cronbach } \\
\text { de } 0,54 \text { a } 0,88 \text {. }\end{array}$ \\
\hline $\begin{array}{l}\text { Kaminer e } \\
\text { Burleson/ } \\
\text { Subst Abus }\end{array}$ & 2008 & $\begin{array}{l}\text { Does temperament moderate } \\
\text { treatment response in adolescent } \\
\text { substance use disorders? }\end{array}$ & Longitudinal & 88 & Não analisa. \\
\hline $\begin{array}{l}\text { Kaminer/Subst } \\
\text { Abus }\end{array}$ & 2008 & $\begin{array}{l}\text { The teen addiction severity index } \\
\text { around the globe: the tower of Babel } \\
\text { revisited. }\end{array}$ & $\begin{array}{l}\text { Revisão das } \\
\text { Validações }\end{array}$ & $\begin{array}{c}10 \\
\text { ver- } \\
\text { sões }\end{array}$ & Não analisa. \\
\hline $\begin{array}{l}\text { Winters e } \\
\text { Kaminer/ } \\
\text { J Am Acad } \\
\text { Child } \\
\text { Adolesc } \\
\text { Psychiatry }\end{array}$ & 2008 & $\begin{array}{l}\text { Screening and assessing adolescent } \\
\text { substance use disorders in clinical } \\
\text { populations. }\end{array}$ & $\begin{array}{l}\text { Revisão de } \\
\text { Instrumentos }\end{array}$ & $\begin{array}{c}5 \\
\text { inst. }\end{array}$ & Não analisa. \\
\hline $\begin{array}{l}\text { Sartes et al./ } \\
\text { Eur Child } \\
\text { Adolesc } \\
\text { Psychiatry }\end{array}$ & 2009 & $\begin{array}{l}\text { Psychometric and discriminative } \\
\text { properties of the teen addiction } \\
\text { severety index (Brazilian Portuguese } \\
\text { version). }\end{array}$ & $\begin{array}{l}\text { Corte } \\
\text { Transversal/ } \\
\text { Validação do } \\
\text { uso de } \\
\text { substâncias }\end{array}$ & 208 & $\begin{array}{c}\text { Severidade r }= \\
0,73 ; \\
\text { Composto } \\
0,72 ; \text { Área } \\
\text { sobre a curva } \\
\text { de ROC }= \\
0,88 .\end{array}$ \\
\hline $\begin{array}{l}\text { Castro- } \\
\text { Fornieles et } \\
\text { al./Eur Addict } \\
\text { Res }\end{array}$ & 2010 & $\begin{array}{l}\text { Prevalence and factors related to } \\
\text { substance use among adolescent with } \\
\text { eating disorders. }\end{array}$ & $\begin{array}{c}\text { Corte } \\
\text { Transversal }\end{array}$ & 95 & Não analisa. \\
\hline
\end{tabular}

\subsubsection{Tabela com artigos com aplicação do instrumento CBCL}

A Tabela 3 apresenta os artigos selecionados na revisão bibliográfica, segundo autor/fonte, ano de publicação, tipo do estudo, tamanho da amostra e desempenho do instrumento, que utilizaram o instrumento CBCL, no período de janeiro de 1998 a agosto de 2010. 
Tabela 3 - Artigos pesquisados com aplicação do instrumento CBCL.

\begin{tabular}{|c|c|c|c|c|c|}
\hline Autor/Fonte & Ano & Título do Artigo & Estudo & $\mathbf{N}$ & $\begin{array}{c}\text { Desempenho } \\
\text { do } \\
\text { Instrumento }\end{array}$ \\
\hline $\begin{array}{l}\text { Cristensen et al./ } \\
\text { Eur Child } \\
\text { Adolesc } \\
\text { Psychiatry }\end{array}$ & 2000 & $\begin{array}{l}\text { Behavioural and emotional } \\
\text { problems in children of alcoholic } \\
\text { in children of alcoholic mothers } \\
\text { and fathers. }\end{array}$ & $\begin{array}{c}\text { Corte } \\
\text { Transversal }\end{array}$ & 103 & Não analisa. \\
\hline $\begin{array}{l}\text { Wall et al./ } \\
\text { Alcohol Clin } \\
\text { Exp Res }\end{array}$ & 2000 & $\begin{array}{l}\text { Parental history of alcoholism and } \\
\text { problem behaviors in Native- } \\
\text { American children and adolescent. }\end{array}$ & $\begin{array}{c}\text { Corte } \\
\text { Transversal }\end{array}$ & 96 & Não analisa. \\
\hline $\begin{array}{l}\text { Ferdinand et al./ } \\
\text { Addiction }\end{array}$ & 2001 & $\begin{array}{l}\text { Psychopathology in adolescence } \\
\text { predicts substance use in young } \\
\text { adulthood. }\end{array}$ & Longitudinal & 787 & Não analisa. \\
\hline $\begin{array}{l}\text { Ehlers et al./ } \\
\text { Psychiatry Res }\end{array}$ & 2001 & $\begin{array}{l}\text { Visual P3 findings in Mission } \\
\text { Indian youth: relationship to } \\
\text { family history of alcohol } \\
\text { dependence and behavioral } \\
\text { problems. }\end{array}$ & $\begin{array}{c}\text { Corte } \\
\text { Transversal }\end{array}$ & 104 & Não analisa. \\
\hline $\begin{array}{l}\text { Salvo et al./ } \\
\text { Estud Psicol } \\
\text { (Campinas) }\end{array}$ & 2005 & $\begin{array}{l}\text { Práticas educativas como forma de } \\
\text { predição de problemas de } \\
\text { comportamento e competência } \\
\text { social. }\end{array}$ & $\begin{array}{c}\text { Corte } \\
\text { Transversal }\end{array}$ & 30 & Não analisa. \\
\hline $\begin{array}{l}\text { Bordin et al./Rev } \\
\text { Bras Psiquiatr }\end{array}$ & 2006 & $\begin{array}{l}\text { Punição física grave e problemas } \\
\text { de saúde mental em população de } \\
\text { crianças e adolescentes } \\
\text { economicamente desfavorecida. }\end{array}$ & $\begin{array}{c}\text { Corte } \\
\text { Transversal }\end{array}$ & 89 & $\begin{array}{c}\text { Confiabilidade } \\
\text { e Propriedades } \\
\text { psicométricas } \\
\text { adequadas do } \\
\text { original } \\
\text { CBCL 4-18; } \\
\text { Alta sensib. } \\
87 \% \text {. }\end{array}$ \\
\hline $\begin{array}{l}\text { Furtado et al./ } \\
\text { BrazJ Med Biol } \\
\text { Res }\end{array}$ & 2006 & $\begin{array}{l}\text { Gender-related pathways for } \\
\text { behavior problems in the offspring } \\
\text { of alcoholic fathers. }\end{array}$ & Longitudinal & 219 & $\begin{array}{c}\text { Propriedades } \\
\text { psicométricas } \\
\text { conforme } \\
\text { dados da } \\
\text { versão alemã } \\
\text { do CBCL. }\end{array}$ \\
\hline $\begin{array}{l}\text { Paula et al./Rev } \\
\text { Bras Psiquiatr }\end{array}$ & 2007 & $\begin{array}{l}\text { Prevalência de problemas de saúde } \\
\text { mental em crianças e adolescentes } \\
\text { da Região Metropolitana de São } \\
\text { Paulo: necessidade de tratamento e } \\
\text { capacidade de atendimento. }\end{array}$ & $\begin{array}{c}\text { Corte } \\
\text { Transversal }\end{array}$ & 479 & $\begin{array}{l}\text { Sensibilidade } \\
\quad 80,4 \% \text {. }\end{array}$ \\
\hline $\begin{array}{l}\text { Schmid et al./ } \\
\text { Child Adolesc } \\
\text { Psychiatry Ment } \\
\text { Health } \\
\end{array}$ & 2008 & $\begin{array}{l}\text { Child and adolescent psychiatry } \\
\text { and mental health. }\end{array}$ & $\begin{array}{l}\text { Corte } \\
\text { transversal }\end{array}$ & 689 & $\begin{array}{c}\text { Alfa de } \\
\text { Cronbach } \\
\text { entre } 0,85 \text { e } \\
0,94 \\
\end{array}$ \\
\hline $\begin{array}{l}\text { Creemers et al./ } \\
\text { J Stud Alcohol } \\
\text { Drugs }\end{array}$ & 2009 & $\begin{array}{l}\text { Predicting onset of cannabis use in } \\
\text { early adolescence: the interrelation } \\
\text { between high-intensity pleasure } \\
\text { and disruptive behavior. The trails } \\
\text { study. }\end{array}$ & Longitudinal & 1804 & Não analisa. \\
\hline $\begin{array}{l}\text { Ornoy et } \\
\text { al./Child Abuse } \\
\text { Negl }\end{array}$ & 2010 & $\begin{array}{l}\text { Neurodevelopmental and } \\
\text { psychological assessment of } \\
\text { adolescents born to drug-addicted } \\
\text { parents: effects of SES and } \\
\text { adoption. }\end{array}$ & $\begin{array}{c}\text { Corte } \\
\text { Transversal }\end{array}$ & 191 & Não analisa. \\
\hline
\end{tabular}




\begin{tabular}{|l|l|l|l|l|c|}
\hline $\begin{array}{l}\text { Korhonen et al./ } \\
\text { J Am Acad } \\
\begin{array}{l}\text { Child Adolesc } \\
\text { Psychiatry }\end{array}\end{array}$ & 2010 & $\begin{array}{l}\text { Externalizing behavior problems } \\
\text { and cigarette smoking as } \\
\text { predictors of cannabis use: the } \\
\text { TRAILS study. }\end{array}$ & Longitudinal & 1606 & Não analisa. \\
\hline
\end{tabular}

\subsection{Descrição e análise dos instrumentos e artigos pesquisados}

\subsubsection{DUSI-R}

\section{Introdução}

Foi desenvolvido originalmente, nos Estados Unidos, pelo professor doutor e pesquisador da Universidade de Pittsburg, Dr. Ralph Tarter, em resposta a uma necessidade prática e objetiva de um questionário que avaliasse de forma rápida e eficiente os problemas associados ao uso de álcool e/ou drogas pelos adolescentes (Tarter, 1990). No Brasil, ele foi adaptado e validado por pesquisadores da Universidade Federal de São Paulo (Unifesp) (De Micheli; Formigoni, 2000), para ser utilizado na população de adolescentes (Sartes; De Micheli, 2008). Está disponível, atualmente, em 15 línguas.

\section{Descrição e objetivos}

O DUSI-R é um instrumento voltado para usuários de álcool e outras drogas que se tem conhecimento ou suspeita. É utilizado para medições da situação atual, identificando áreas com necessidade de prevenção, e para avaliação da magnitude da mudança depois de uma intervenção/tratamento (Tarter, 1990). Sua identificação é conhecida por DUSI ou DUSI-R. 
O DUSI-R mede a gravidade de problemas em 10 áreas, fornecendo um perfil de intensidade de problemas em relação: 1) uso de substâncias; 2) comportamento; 3) saúde; 4) transtornos psiquiátricos; 5) sociabilidade; 6) sistema familiar; 7) escola; 8) trabalho; 9) relacionamento com amigos; e 10) lazer/recreação. As questões são respondidas com "Sim" ou "Não", sendo que as respostas afirmativas equivalem à presença de problemas.

Além das 10 áreas mencionadas, o DUSI-R possui uma Escala de Mentira (EM), composta por 10 questões (uma ao final de cada área), que foram acrescentadas com a finalidade de checar a existência de possíveis questionários inválidos (Sartes; De Micheli, 2008). A Tabela 4 apresenta uma síntese das 10 áreas de avaliação do DUSI-R, bem como uma breve descrição de cada área.

Tabela 4 - As 10 áreas de avaliação do DUSI-R.

\begin{tabular}{|c|c|}
\hline $\begin{array}{l}\text { Tabela } 1 \text { - Uso de álcool e outras } \\
\text { drogas }\end{array}$ & $\begin{array}{l}\text { Investiga a frequência do uso de } 13 \text { substâncias no último mês, } \\
\text { drogas de preferência e problemas em decorrência do uso. }\end{array}$ \\
\hline Área 1 - Uso de Substâncias & $\begin{array}{l}\text { Investiga o uso de substâncias nos últimos } 12 \text { meses e a } \\
\text { intensidade do envolvimento com substâncias. }\end{array}$ \\
\hline Área 2 - Comportamento & Investiga o isolamento social e problemas de comportamento. \\
\hline Área 3 - Saúde & Investiga acidentes, prejuízos e doenças. \\
\hline Área 4 - Desordens Psiquiátricas & Investiga ansiedade, depressão e comportamento antissocial. \\
\hline Área 5 - Competência Social & Investiga as habilidades e interações sociais. \\
\hline Área 6 - Sistema Familiar & $\begin{array}{l}\text { Investiga conflitos familiares, supervisão dos pais e qualidade } \\
\text { de relacionamento. }\end{array}$ \\
\hline Área 7 - Escola & Investiga o desempenho acadêmico. \\
\hline Área 8 - Trabalho & Investiga a motivação para o trabalho. \\
\hline Área 9 - Relacionamento com Amigos & $\begin{array}{l}\text { Investiga a rede social, o envolvimento em gangues e a } \\
\text { qualidade do relacionamento com amigos. }\end{array}$ \\
\hline Área 10 - Lazer/Recreação & Investiga a qualidade das atividades durante o tempo de lazer. \\
\hline
\end{tabular}

Fonte: Sartes; De Micheli (2008, p. 33). 


\section{Utilidade clínica}

Uma das principais utilizações é para triagem, para identificar os casos com abuso de álcool e outras drogas. Sugere-se a aplicação da tabela de frequência do uso de substâncias no último mês, seguida pelas 15 questões da área de uso de substâncias, que abordam a fissura (craving), a tolerância e a abstinência por álcool e ou outras drogas (De Micheli; Formigoni, 2002).

Ainda, auxilia na avaliação em 10 áreas da vida do indivíduo e contribui para o monitoramento do tratamento e na avaliação pós-intervenção (Tarter, 1990).

- Número de escalas: 10 ;

- Número de questões: 149 ;

- Ambientes de aplicação: ambulatórios médicos não especializados, ambulatórios e clínicas de tratamento do uso de substâncias e escolas;

- Aplicabilidade em pesquisa: quantificação da gravidade em 10 áreas, estudos sobre heterogeneidade dos subtipos, alinhamento da avaliação do paciente com o plano de tratamento, levantamentos epidemiológicos e avaliação das necessidades (Tarter; Kirisci, 2001);

- População-Alvo:

- Faixa etária da versão americana: crianças e adolescentes acima de 10 anos e adultos (Tarter, 1990);

- Faixa etária da versão brasileira: adolescentes de 12 a 19 anos (De Micheli; Formigoni, 2000), conforme o ECA;

- Aplicação: 
- Formato: autopreenchimento com caneta em papel, entrevista, autopreenchimento no computador;

- Administrador por: entrevistador ou pela própria pessoa;

- Treinamento para aplicação: não necessariamente. É importante observar que, para a versão de autopreenchimento, exige-se um nível de leitura para pessoas com grau de instrução com ensino fundamental ( $5^{\mathrm{a}}$ a $8^{\mathrm{a}}$ série);

- Tempo de aplicação: o tempo estimado para aplicação é de 15 a 20 minutos completos. Na pesquisa realizada no México, por Jinez et al. (2009), usando a versão brasileira do DUSI-R adaptada para o espanhol, o tempo de aplicação variou de 30 a 40 minutos, de maneira autoaplicável. Caso seja aplicada somente a tabela de frequência do uso de substâncias no último mês, seguida das 15 questões da área do uso de substâncias, o tempo de preenchimento é de 3 a 5 minutos (De Micheli; Formigoni, 2002).

A seguir, é apresentado, em formato de tabela, o tempo de aplicação da versão completa e reduzida do DUSI-R validada para o Brasil.

Tabela 5 - Tempo de aplicação do DUSI-R - Versão completa e reduzida.

\begin{tabular}{|l|c|c|}
\hline \multicolumn{1}{|c|}{ Questionário } & Número de Questões & Tempo de aplicação médio \\
\hline DUSI-R completo & 149 & $20-40$ minutos \\
\hline $\begin{array}{l}\text { DUSI-R reduzido } \\
\text { (escala de substâncias) }\end{array}$ & 15 & 5 minutos \\
\hline
\end{tabular}

- Investimento: domínio público. 


\section{Análise dos resultados após aplicação do DUSI-R}

Após a aplicação do DUSI-R, quatro índices podem ser calculados:

a) Densidade absoluta de problemas: indica a intensidade de problemas em cada área, isoladamente;

b) Densidade relativa de problemas: indica a contribuição percentual de cada área no total de problemas;

c) Densidade global de problemas: indica a intensidade geral de problemas;

d) EM: reflete a confiabilidade das respostas fornecidas.

\section{Escala de mentira}

Alguns autores avaliaram aspectos de resposta dos instrumentos, quanto a mentir no seu preenchimento e também quanto aos efeitos da identificação do sujeito versus o anonimato dos adolescentes.

Inicialmente, Kirisci et al. (1994) desenvolveram uma EM (lie scale), na versão revisada do DUSI (DUSI-R), composta por 10 questões, sendo uma ao final de cada área, as quais foram acrescentadas com a finalidade de checar a existência de possíveis questionários inválidos. Sendo 10 áreas no total, uma pontuação total de 5 ou mais respostas negativas na EM alerta para possíveis resultados inválidos. $\mathrm{EM}=$ soma das respostas negativas da última questão de cada área (Sartes; De Micheli, 2008).

Uma década mais tarde, Dalla-Déa et al. (2003) avaliaram os efeitos da identificação do sujeito versus o anonimato dos adolescentes, usando o DUSI-R para 
avaliar a utilidade de uma EM para esse instrumento. O estudo foi aplicado em uma amostra de 655 estudantes brasileiros no ensino fundamental e médio de uma escola pública de São Paulo. Os resultados encontrados sugerem que a identificação ou o anonimato na pesquisa não afetam a resposta dos estudantes para a aplicação do DUSI$\mathrm{R}$, confirmando a aplicabilidade do uso da EM. Portanto, os resultados encontrados por esses autores indicam que, a princípio, não há a necessidade da aplicação da EM do referido instrumento.

- Medidas de confiabilidade utilizadas: teste e reteste, confiabilidade e split-half;

- Medidas de validação derivadas/desenvolvidas: conteúdo, construto e critério.

\section{Propriedades psicométricas detalhadas por país}

A próxima tabela apresenta uma síntese dos resultados de validação do DUSI$\mathrm{R}$, com as respectivas propriedades psicométricas. Além dos 3 estudos encontrados no período desta revisão, foram adicionados também os 2 estudos anteriores de validação, para os Estados Unidos (que incluem o desenvolvimento do instrumento) e para a Venezuela, de maneira a apresentar um quadro completo dos resultados obtidos com o instrumento. 
Tabela 6 - Comparativo entre as propriedades psicométricas do DUSI-R.

\begin{tabular}{|c|c|c|l|}
\hline Versão & Fonte & Questões & \multicolumn{1}{|c|}{ Resultados } \\
\hline Estados Unidos & Tarter et al. (1994) & 149 & $\begin{array}{l}\text { Alfa de Cronbach } \\
\text { - Masculino: } 0,87 \\
\text { - Feminino: } 0,88\end{array}$ \\
\hline Venezuela & Amesty (1996) & 149 & $\begin{array}{l}\text { Alfa de Cronbach } \\
\text { - Masculino: } 0,74 \\
\text { - Feminino: } 0,78\end{array}$ \\
\hline Brasil & De Micheli e Formigoni & 149 & $\begin{array}{l}\text { Sensibilidade: } 80 \% \\
\text { Especificidade: } 90 \%\end{array}$ \\
\hline Turquia & Aytaclar et al. (2003) & 116 & $\begin{array}{l}\text { Sensibilidade: } 80 \% \\
\text { Especificidade: } 87 \%\end{array}$ \\
\hline México & Negrete et al. (2006) & 87 & $\begin{array}{l}\text { Cons.Int.: } 0,9451 \\
\text { Confiab.: superior a } 80 \%\end{array}$ \\
\hline
\end{tabular}

\section{Propriedades psicométricas da versão americana}

Análises psicométricas demonstraram que o DUSI-R tem uma alta confiabilidade, bem como validade concorrente e construto satisfatórios. A validação da versão americana apresentou boas propriedades psicométricas (Tarter et al., 1994), reportando um Alfa de Cronbach para uso de substâncias de 0,87 e 0,88, respectivamente, para o sexo masculino e feminino. Já para a área do estado de saúde, o Alfa de Cronbach não foi tão relevante, apresentando os índices de 0,49 para adolescentes do sexo masculino e 0,54 para adolescentes do sexo feminino. Para a área de relacionamento familiar, também foram encontrados altos índices, sendo 0,52 e 0,61, para adolescentes do sexo masculino e feminino, respectivamente.

\section{Propriedades psicométricas da versão brasileira}

De Micheli e Formigoni (2000) realizaram a tradução, adaptação e validação do DUSI-R para o Brasil. Nesse sentido, o CIDI e o DUSI indicaram que esse 
instrumento pode ser útil na triagem do uso de substâncias entre adolescentes brasileiros.

No estudo sobre as propriedades psicométricas da versão brasileira, em relação às respostas afirmativas na área do uso de substâncias, o DUSI-R apresentou $80 \%$ de sensibilidade e $90 \%$ de especificidade, com uma taxa de acerto de $83,6 \%$ para a totalidade da amostra. Já a área sob a curva de ROC foi de 0,93 , o que demonstrou um bom desempenho global na área do uso de substâncias. Ainda, a versão brasileira apresentou uma forte consistência interna e confiabilidade para toda a amostra, sendo o coeficiente Alfa de Cronbach e a confiabilidade em todas as 10 áreas, respectivamente, 0,96 (desvio padrão de 0,02) e 0,88 (desvio padrão de 0,08) (De Micheli; Formigoni, 2002).

$\mathrm{Na}$ versão brasileira para a amostra de dependentes de drogas, foi encontrado um Alfa de Cronbach de 0,98 para a área de uso de substâncias e, na área do estado de saúde, de 0,94. Além disso, a análise da confiabilidade split-half apresentou bons resultados para o estado de saúde $(0,71)$, bem como altos coeficientes foram observados na área de sistema de família $(0,92)$.

\section{Propriedades psicométricas da versão para a Turquia}

Para o contexto da Turquia, Aytaclar et al. (2003) fizeram a tradução e a validação do DUSI-R com adolescentes do sexo masculino. Foram analisados casos clínicos $(\mathrm{N}=90)$, em que foram recrutados pacientes em tratamento para dependência química no serviço ambulatorial e hospitalar no Hospital Estadual de Bakirkoy, em 
Istambul, Turquia. Os casos não clínicos $(\mathrm{N}=68)$ foram recrutados na comunidade, através de convite direto dos pesquisadores e de anúncios.

A linha de corte de gravidade de $35 \%$ na pontuação geral da densidade do problema classificou corretamente $83 \%$ dos indivíduos, com sensibilidade de $80 \%$ e especificidade de $87 \%$. Além disso, a escala de densidade geral de problemas do DUSI-R identificou o uso e o envolvimento com substâncias, nos últimos 30 dias. Finalmente, o histórico familiar e o uso de substâncias foram identificados como fatores que determinam o uso de substâncias por parte dos filhos.

\section{Versões reduzidas do DUSI-R}

Inicialmente, Murrelle et al. (1977) desenvolveram uma versão reduzida do DUSI-R para a Costa Rica, a qual é um instrumento desenhado para quantificar e categorizar os indicadores de consumo de drogas, em relação ao estado físico, emocional, psicossocial, familiar e escolar do adolescente. Para tanto, o questionário é composto de 3 partes: 1) a identificação da escola; 2) um conjunto de 48 perguntas, que fazem referência a comportamentos ou ações problemáticas e são agrupadas em áreas problemáticas ou escalas de conduta, emocional, familiar, escolar, relacionamento com os colegas, recreação, agressividade, depressão e drogas; 3) finalmente, é apresentada uma lista de substâncias lícitas e ilícitas, em que são anotadas a idade do paciente e a frequência de consumo. Algumas vantagens desse instrumento são a sua rápida aplicação e a não necessidade de treinamento prévio.

Também foram desenvolvidas versões reduzidas do instrumento no Chile (Fraile Duvicq et al., 2004), a partir do trabalho inicial desenvolvido na Costa Rica 
(Murrelle et al., 1977), e no Brasil (Fidalgo et al., 2010). Na tabela a seguir, é apresentada uma síntese dos resultados psicométricos das versões reduzidas do DUSIR para o Chile e o Brasil.

Tabela 7 - Comparativo entre as propriedades psicométricas das versões reduzidas.

\begin{tabular}{|c|c|l|c|l|}
\hline Versão & Perguntas & \multicolumn{1}{|c|}{ Fonte } & N & \multicolumn{1}{c|}{ Resultados } \\
\hline Chile & 48 & $\begin{array}{l}\text { Fraile Duvicq et } \\
\text { al. (2004) }\end{array}$ & 301 & Alfa de Cronbach global: 0,91 \\
\hline Brasil & 15 & $\begin{array}{l}\text { Fidalgo et al. } \\
(2010)\end{array}$ & 41 & $\begin{array}{l}\text { Sensibilidade: } 85 \% \\
\text { Especificidade: } 70 \%\end{array}$ \\
\hline
\end{tabular}

Ressalte-se que Fraile Duvicq et al. (2004) validaram o DUSI-R reduzido (48 perguntas) para uma aplicação com estudantes no Chile, por meio de uma amostra piloto aplicada a $10 \%$ do tamanho da amostra $(\mathrm{N}=301)$, em uma população distinta, porém com características semelhantes de idade e escolaridade. Após a validação, os autores fizeram a aplicação do instrumento para identificar as características dos consumidores de substâncias lícitas e ilícitas entre estudantes da $6^{\mathrm{a}}$ série das escolas municipais urbanas de Chiguayante (Chile), relacionando-as a fatores de risco e de proteção.

\section{Desenvolvimento e disseminação}

A Tabela 8 apresenta uma síntese da disseminação do DUSI-R nos últimos 12 anos (1998-2010), em diferentes países, abrangidos no período deste estudo, em meio à população de adolescentes. 
Tabela 8 - Número de estudos por ano e respectivos países.

\begin{tabular}{|c|c|l|}
\hline Ano & Núm. Estudos & \multicolumn{1}{c|}{ País(es) } \\
\hline 1998 & 1 & Argentina \\
\hline 1999 & - & - \\
\hline 2000 & 1 & Brasil \\
\hline 2001 & 1 & Estados Unidos \\
\hline 2002 & 5 & $\begin{array}{l}\text { Brasil, Colômbia, Costa Rica, Estados Unidos, República } \\
\text { Dominicana }\end{array}$ \\
\hline 2003 & 3 & Turquia, Brasil, América Central, Panamá, República Dominicana \\
\hline 2004 & 8 & $\begin{array}{l}\text { Brasil (3 estudos), Argentina, Peru, Venezuela, México, Estados } \\
\text { Unidos }\end{array}$ \\
\hline 2005 & 1 & Estados Unidos \\
\hline 2006 & 2 & México, Estados Unidos \\
\hline 2007 & 1 & Estados Unidos \\
\hline 2008 & 2 & México, Estados Unidos \\
\hline 2009 & 3 & México, Estados Unidos, Quênia \\
\hline 2010 & 2 & Nova Zelândia \\
\hline $\mathbf{1 9 9 8 - 2 0 1 0}$ & $\mathbf{3 0}$ & $\mathbf{1 4}$ Países + América Central \\
\hline
\end{tabular}

\section{Tipos de aplicação e utilização}

A tabela a seguir apresenta uma síntese dos tipos de aplicações do DUSI-R encontrados, bem como o respectivo número de ocorrências associado. Passamos a apresentar, na sequência, os resultados desta análise. Cumpre informar que não foram incluídos na tabela os 4 artigos de validação do instrumento em outros países (Moss et al., 1998; De Micheli; Formigoni, 2000, 2002; Tarter; Kirisci, 2001), no período abrangido por este estudo, posteriores à sua validação original (Tarter, 1990).

Tabela 9 - Número de artigos por tipo de aplicação.

\begin{tabular}{|l|c|c|}
\hline \multicolumn{1}{|c|}{ Aplicação } & Número de Artigos & Percentual (\%) \\
\hline Prevalência e fatores de risco & 15 & 60 \\
\hline $\begin{aligned} \text { Intervenções } \\
\text { - Intervenções terapêuticas (1) }\end{aligned}$ & 4 & 16 \\
- Intervenções farmacológicas (1) $\quad$ Intervenções no serviço (2) & & \\
\hline Previsão quanto ao uso & 1 & 4 \\
\hline Uso em conjunto com outros instrumentos & 5 & 20 \\
\hline TOTAL & 25 & 100 \\
\hline
\end{tabular}


Quanto ao tipo de aplicação, a maioria dos artigos encontrados sobre a utilização do DUSI-R foi de estudos de prevalência e fatores de risco, tendo sido encontrados 16 estudos (62\%) dos seguintes autores: Moss et al. (1998); De Michelli e Formigoni (2000, 2004), Sandi et al. (2002), Vittetoe et al. (2002), Díaz et al. (2002), Navarro e Pontillo (2002), Gosebruck et al. (2003), De Micheli et al. (2004), Fraile Duvicq et al. (2004), Rebolledo et al. (2004), Mathews e Pillon (2004), Tarter et al. (2006), Negrete et al. (2006), Negrete e García-Aurrecoechea (2008) e Jinez et al. (2009).

Foi encontrado um número pequeno de aplicações do DUSI-R - apenas 4 (15\%) - na avaliação de intervenções, sendo: 1 em intervenções terapêuticas (De Micheli et al., 2004), 1 em intervenções farmacológicas (Solhkhah et al., 2005) e 2 intervenções no serviço (Figlie et al., 2004; Christie et al., 2010). Como foram obtidas boas respostas com essas aplicações, esse fato constitui, portanto, uma oportunidade para a sua maior utilização. Já do ponto de vista da previsão quanto ao uso de substâncias, foi encontrado apenas 1 estudo, realizado por Tarter e Kirisci (2001) com o propósito de identificar os jovens que podem desenvolver um transtorno de abuso ou dependência na idade de 16 anos, tendo apresentado problemas de uso nas idades de 12-14 anos, cuja hipótese acabou sendo confirmada.

Além das aplicações do DUSI-R isoladamente, foram também encontrados outros 5 estudos (19\%) que se referiam a aplicações em conjunto com outros instrumentos, tais como: Escala de Tendência à Violência (Violence Proneness Scale) (Tarter et al., 2002); Inventário de Autoestima de Stanley Coopersmith (Navarro; Pontillo, 2002); pesquisas com fatores de comportamento genéticos ou outras pesquisas epidemiológicas, com amostras em ambientes não clínicos (Siewert et al., 
2004); "Entrevista Clínica Estruturada" (Structured Clinical Interview) para o Diagnostic and Statistical Manual of Mental Disorders - Fourth Edition (DSM-IV) (Tarter et al., 2007); e escalas que medem problemas psiquiátricos atuais e futuros (Kirisci et al., 2008).

O estudo de Solhkhah et al. (2005) também foi utilizado em conjunto com outros instrumentos (Attention-Deficit/Hyperactivity Disorder - ADHD - Symptom Checklist e Hamilton Rating Scale for Depression - HAM-D), porém foi apresentado na categoria de "intervenções farmacológicas", por ser importante ressaltar a aplicação do DUSI-R para a avaliação de medicações.

\section{Análise das aplicações quanto à prevalência e fatores de risco}

Moss et al. (1998), na Argentina, aplicaram uma versão do DUSI-R traduzida para o espanhol em uma amostra de adolescentes usuários de substâncias e não usuários, cuja meta era esclarecer os efeitos da influência familiar e do comportamento sexual nos problemas concomitantes de uso de substâncias entre adolescentes. Para tanto, a amostra foi composta de adolescentes em escolas, do sexo masculino (956) e do sexo feminino (303), e adolescentes do sexo masculino em um programa de tratamento de drogas $(\mathrm{N}=51)$, na cidade de Buenos Aires. A conclusão do estudo foi que há uma associação entre problemas psicossociais, heterogeneidade sexual, abuso de substâncias entre os adolescentes e família. Além disso, os resultados foram consistentes com problemas de comportamento.

Conforme descrito anteriormente, Fraile Duvicq et al. (2004) validaram o DUSI-R reduzido para uma aplicação com estudantes no Chile. Após a validação, 
fizeram a aplicação do instrumento para identificar as características dos consumidores de substâncias lícitas e ilícitas entre estudantes da $6^{a}$ série das escolas municipais urbanas de Chiguayante (Chile), relacionando-as a fatores de risco e de proteção. A amostra continha 301 estudantes, com idade entre 11 e 13 anos (93\% da amostra), sendo a distribuição por sexo da amostra homogênea.

Concluiu-se que os comportamentos associados ao fator de risco pessoal foram os mais relevantes e os fatores de proteção mais relevantes encontravam-se na esfera microssocial. Também foi confirmada a existência de uma população escolar consumidora de substâncias lícitas com idade de 11 anos, em 45\% dos casos, e encontrou-se que $60 \%$ dos consumidores de substâncias lícitas iniciam o consumo entre 8 e 11 anos, sendo as substâncias mais comuns o álcool e o tabaco (18,7 e 16,3\%, respectivamente). Além disso, $85 \%$ dos consumidores eram do sexo masculino e, destes, 69\% iniciaram o consumo na faixa etária de 11 a 12 anos, havendo predominância de abusadores de substâncias lícitas.

Em outra pesquisa, realizada por De Micheli e Formigoni (2004) com 6.417 alunos de uma escola pública em Barueri (São Paulo), com a aplicação do DUSI-R mediu-se a taxa de prevalência do uso de drogas nos últimos 30 dias, qual seja: álcool $48 \%$, tabaco 22,5\%, maconha 14\%, inalantes/solventes 5\%, cocaína 3\%, tranquilizantes $0,5 \%$, anfetamínicos $0,9 \%$, anabolizantes $0,1 \%$ e ecstasy $0,9 \%$. Além disso, identificaram-se o desempenho escolar pobre, a presença de comportamento antissocial, problemas familiares e amigos com uso de drogas. Com base nesses resultados, os autores recomendam o planejamento e execução de programas de prevenção, que devem ser mais abrangentes, ao invés de serem focados apenas na informação sobre drogas. 
Rebolledo et al. (2004) aplicaram o DUSI-R na Venezuela, usando a versão validada para esse país, a fim de identificar fatores de risco associados ao uso de substâncias lícitas e ilícitas entre estudantes da educação básica de diversas instituições públicas $(\mathrm{N}=2.829)$, de ambos os sexos, com idade entre 12 e 17 anos. A pontuação da escala de Índice de Severidade Total apresentou valores altos, podendo indicar que os adolescentes venezuelanos apresentam altos riscos para o uso de substâncias lícitas e ilícitas, ao mesmo tempo que apresentam menores índices de uso de drogas, ou seja, a presença de fatores de proteção inter-relacionados com os fatores de risco para modificá-los.

Por sua vez, Mathews e Pillon (2004) aplicaram o DUSI-R no Peru, para analisar e identificar os fatores de risco relacionados ao uso de álcool entre adolescentes na faixa etária de 12 a 18 anos, filhos de pais alcoolistas $(\mathrm{N}=104)$. Foi utilizado o DUSI-R reduzido, com 53 questões, validado para a língua espanhola, avaliando as áreas da família, escola e colegas. Os adolescentes filhos de pais alcoolistas apresentaram uso experimental de álcool e alguns casos de embriaguez, porém não com padrão de uso frequente. Verificou-se que os fatores de risco e de proteção para o uso de álcool entre jovens estão, em maior ou menor grau, associados aos comportamentos familiares, grupos de amigos, parentes e contexto social em que estão inseridos.

Tarter et al. (2006) aplicaram o DUSI-R para investigar se a transição do consumo de substâncias lícitas para o uso da maconha é determinada por fatores particulares de risco, como descrito pela "teoria da porta de entrada". Assim, identificou-se que $22,4 \%$ dos participantes que usaram maconha não apresentaram a 
consequência da porta de entrada, demonstrando, portanto, que esse padrão não é fixo entre jovens usuários.

Já Negrete e García-Aurrecoechea (2008), no México, utilizaram o DUSI-R para identificar fatores psicossociais de risco de consumo de substâncias ilícitas em estudantes $(\mathrm{N}=516)$ e para oferecer elementos para o desenho de programas de prevenção. Para tanto, a versão utilizada foi a adaptada e validada para o México por Negrete et al. (2006). Os fatores de previsão do consumo de substâncias ilícitas apresentados foram: um baixo controle de comportamento, com tendências a atuar impulsivamente e com agressividade; ter colegas com comportamento de abuso; e estar exposto com frequência a situações familiares de conflito e de violência e consumo de substâncias ilícitas e álcool no local.

Por fim, Jinez et al. (2009) realizaram uma pesquisa em escolas em Guadalajara (México), com 695 adolescentes, sendo 52,8\% do sexo feminino e 47,2\% do sexo masculino, em um estudo transversal. A versão do DUSI-R utilizada foi a adaptada do português para o espanhol, de forma autoaplicada, uma vez que utiliza as 10 áreas completas do DUSI-R, enquanto a versão espanhola não é tão completa. Foi, portanto, a primeira vez que uma versão completa do DUSI-R foi aplicada com estudantes mexicanos, tendo sido feita a necessária adaptação cultural.

Os resultados foram que $20,3 \%$ dos estudantes usavam drogas, dos quais $38 \%$ referem que o uso é somente por curiosidade. Ainda, os fatores de risco identificados foram: adolescentes do sexo masculino, idade menor que 13 anos, que cursavam o segundo e terceiro grau, viviam com familiares, tinham relacionamento ruim, usavam drogas movidos pela curiosidade e mostravam enfrentar situações desagradáveis, com 
predomínio e uso experimental de álcool e tabaco; o uso de substâncias ilícitas foi encontrado em menor porcentagem.

\section{Análise das aplicações em intervenções}

O segundo grupo de maior ocorrência das aplicações foi na área de intervenções, na qual foram encontradas 4 aplicações, sendo 1 intervenção terapêutica, 1 intervenção farmacológica e 2 intervenções no serviço, que passam a ser analisadas em detalhe.

\section{Aplicações quanto às intervenções terapêuticas}

Foi identificada uma aplicação do DUSI-R para a avaliação de intervenções breves, no estudo realizado por De Micheli et al. (2004), que avaliou a efetividade da intervenção breve e de uma orientação preventiva do uso de álcool e outras drogas, dirigidas a adolescentes. A amostra foi de 99 adolescentes que buscaram um serviço ambulatorial especializado, os quais foram divididos em dois grupos: um grupo de controle de usuários e um grupo de controle de não usuários, ambos no último mês. Um grupo recebeu intervenção breve e o outro, orientação preventiva, no caso de não serem usuários; além disso, todos foram avaliados por um período de 6 meses.

O DUSI-R foi utilizado para triagem do uso de álcool e/ou drogas entre os adolescentes, bem como para a área do uso de substâncias. Para avaliação da intensidade de problemas relacionados ao uso de substâncias, utilizou-se a densidade absoluta de problemas, ou seja, a porcentagem de respostas afirmativas na área. No 
grupo de controle de não usuários no último mês, no seguimento realizado ao final de seis meses, observou-se um aumento significativo na prevalência de consumo de maconha, álcool e tabaco, bem como na intensidade de problemas e comportamentos de risco. Ainda, no grupo de não usuários no mês, embora também tenha sido observado aumento na prevalência de consumo de substâncias lícitas (álcool e tabaco), este foi significativamente menor em frequência e intensidade do que o observado no grupo controle de não usuários no último mês. Além disso, neste grupo, não ocorreu aumento no uso de maconha.

Já no grupo de adolescentes usuários no último mês que receberam Intervenção Breve, observou-se redução significativa na proporção de usuários em relação à maioria das substâncias avaliadas, bem como na intensidade dos problemas e comportamentos de risco.

\section{Aplicação quanto às intervenções farmacológicas}

Solhkhah et al. (2005) utilizaram o DUSI-R, em conjunto com outros instrumentos, para medir intervenções farmacológicas em adolescentes $(\mathrm{N}=14)$ com uso de substâncias e comorbidade psiquiátrica, como transtorno de déficit de atenção e transtorno de humor. Os outros instrumentos utilizados foram ADHD Symptom Checklist e HAM-D, e foram obtidas as escalas para Clinical Global Impression (CGI) para abuso de substâncias, Transtorno do Déficit de Atenção com Hiperatividade (TDAH), ansiedade e depressão. Além disso, as medições foram feitas no início e após 3 e 6 meses. 
A bupropiona SR foi iniciada com $100 \mathrm{mg}$, uma vez ao dia, aumentando a dose até $400 \mathrm{mg} / \mathrm{dia}$. Treze das 14 pessoas envolvidas no estudo concluíram os 6 meses de tratamento e os resultados após 6 meses apresentaram reduções significativas nos índices do DUSI-R, sugerindo que a medicação foi bem tolerada e que pode ser eficaz para o tratamento do abuso de substâncias em adolescentes que apresentam comorbidade psiquiátrica e TDAH. Uma observação a ser feita sobre esse estudo é quanto à pequena representatividade da amostra $(\mathrm{N}=14)$.

\section{Aplicação quanto às intervenções no serviço}

Foram encontrados dois estudos sobre aplicações quanto à intervenção no serviço: Figlie et al. (2004) e Christie et al. (2010).

Figlie et al. (2004) fizeram, no Brasil, a aplicação do DUSI-R em conjunto com outros instrumentos, como dados sociodemográficos, procedimento de Desenho de Família com Estórias (DF-E), critérios de investigação sobre situações de estresse psicossocial vividas pela criança (CID-10), Self-Reporting Questionnaire (SRQ-20) e CAGE (Cut-down-Annoyed-Guilty-Eye-opener) familiar. O propósito do estudo foi investigar o perfil de crianças, adolescentes e familiares em um serviço de prevenção seletiva para filhos de dependentes químicos e construir alternativas de intervenção e tratamento para essa população. Foi concluído que há a necessidade de um serviço especializado de prevenção seletiva, dirigido a crianças, adolescentes e familiares afetados pela dependência química, uma vez que filhos de dependentes químicos representam um grupo de risco para o desenvolvimento de problemas biopsicossociais. 
Já Christie et al. (2010) aplicaram, na Nova Zelândia, o DUSI-R para avaliar se os jovens atendidos em um serviço de dependência química diferiam dos jovens participantes de serviços de saúde mental. Os resultados mostraram que os adolescentes participantes de serviços de dependência química reportaram um número significativamente maior de problemas com abuso de substância, baixo desempenho escolar e problemas de relacionamentos com colegas do que aqueles participantes de programas de saúde mental.

\section{Análise quanto à previsão de uso}

Do ponto de vista da previsão quanto ao de substâncias, foi encontrado apenas um estudo, realizado por Tarter e Kirisci (2001), que conduziram um estudo longitudinal com 354 adolescentes do sexo masculino, com idades entre 12 e 14 anos, após consentimento dos pais, o qual foi repetido aos 16 anos e depois aos 19 anos. O DUSI-R foi utilizado porque havia demonstrado boas propriedades psicométricas para quantificar a gravidade de saúde, os problemas comportamentais e os problemas psicossociais, concomitantemente ao uso de substâncias, porém a sua utilidade para identificar os jovens que podem desenvolver um transtorno de abuso ou dependência não havia sido ainda investigada.

O estudo apresentou um índice geral de severidade de problemas de $24 \%$ nas idades de 12 a 14 anos e, aos 16 e 19 anos, uma previsão de problema com o uso de substâncias, de acordo com o Diagnostic and Statistical Manual of Mental Disorders Third Edition - Revised (DSM-III-R), de 73 e 84\% de exatidão, respectivamente. A 
sensibilidade foi de $75 \%$ e a especificidade de $72 \%$. Além disso, o fato de os pais terem histórico de uso de substâncias não aumentou a previsão desse índice.

\section{Análise das aplicações em conjunto com outros instrumentos}

Além dessas aplicações do DUSI-R, foram também encontrados outros 5 estudos (17\%) que se referiam a aplicações em conjunto com outros instrumentos, cuja análise detalhada é apresentada a seguir.

Tarter et al. (2002) desenvolveram um método de triagem para identificar adolescentes com alto risco de cometer atos violentos na fase de jovens adultos. Além disso, os autores também buscaram utilizar esse instrumento de triagem em conjunto com dados de uso de substâncias e psicopatologias quando crianças e, também, por parte dos pais, para determinar a exatidão da previsão de comportamentos violentos.

A amostra era composta de homens com histórico de uso de substâncias $(\mathrm{N}=$ 38) e homens sem distúrbios psiquiátricos na idade adulta $(\mathrm{N}=61)$. Os filhos biológicos foram estudados em duas situações: nas idades de 12 e 14 anos; além disso, a ocorrência de atos violentos foi novamente medida em uma avaliação de seguimento quando os jovens tinham 19 anos. Para tanto, foi utilizada uma "Escala de Tendência à Violência" (Violence Proneness Scale), que foi desenvolvida a partir de alguns itens do DUSI-R. Um resultado de 10 ou superior nessa escala, nas idades de 12 e 14, previu um comportamento violento na idade de 19 anos, sendo que a exatidão da previsão foi de $77 \%$, a sensibilidade, $81 \%$ e a especificidade, $76 \%$. Além disso, problemas de uso de substância ou psicopatológicos e a frequência do uso de substância na infância não contribuíram para a previsão do comportamento violento. 
A conclusão do estudo foi que a "Escala de Tendência à Violência", que mede o ajuste à escola e o ajuste de relacionamento com os pares, em conjunto com um histórico de problemas psiquiátricos na infância, pode constituir um procedimento de triagem eficiente para identificar jovens que apresentam um alto risco de cometer atos de violência.

Por sua vez, Navarro e Pontillo (2002), na Venezuela, relacionaram a autoestima do adolescente com o risco de consumo de álcool, com a finalidade de estabelecer prioridades para a prevenção primária. A amostra foi constituída de 301 adolescentes, com idade entre 12 e 18 anos, tendo sido utilizada a versão do DUSI-R validada para a Venezuela por Amesty (1996), em conjunto com o inventário de autoestima de Coopersmith (1989).

O resultado foi que a relação entre a autoestima e o fator de risco de álcool é inversamente proporcional ( $r=-0,26$, com um nível de confiança de 95\%). Observa-se, portanto, que o DUSI-R pode ser aplicado em conjunto com outros instrumentos específicos, como no caso de avaliação da autoestima.

Nos Estados Unidos, Siewert et al. (2004), da Universidade do Colorado, adaptaram o DUSI-R para ser usado com pesquisas com fatores genéticos de comportamento ou outras pesquisas epidemiológicas, com amostras em ambientes não clínicos. A primeira meta da investigação foi obter um fator de estrutura e um conjunto de subescalas que pudessem prever o uso experimental e regular de álcool e drogas em uma amostra em uma comunidade. Uma meta secundária foi definir subescalas, de maneira que facilitassem a interpretação e o entendimento da evolução do uso e abuso de substâncias, por parte dos usuários. 
Ainda, foi investigado o fator estrutura dos itens de quatro áreas do DUSI-R, através de uma análise dos componentes principais das respostas de 1.266 adolescentes do Colorado Adolescent Twin Study. O resultado foi um conjunto de seis subescalas, mostrando uma consistência interna adequada, que forneceu uma ferramenta de pesquisa de fácil interpretação para investigar o relacionamento etiológico entre problemas com o uso de substâncias e outros comportamentos de risco.

Por sua vez, Tarter et al. (2007) aplicaram o DUSI-R para avaliar a relação entre a hiperatividade e o uso de substâncias em jovens adultos, em uma amostra com 112 meninos, com idade entre 12 e 14 anos. Além desse instrumento, foi aplicada "Entrevista Clínica Estruturada" (Structured Clinical Interview) para o DSM-IV, na idade de 22 anos. Seis novas escalas derivadas foram desenvolvidas, tendo definido o fator hereditário, e organizadas em fatores internalizantes e externalizantes como percursos para o abuso de substâncias, em consequência da hiperatividade na infância.

A conclusão foi que a hiperatividade e a previsão do abuso de substâncias têm uma relação direta. A hiperatividade também previu o comportamento neurótico, que, por sua vez, previu a baixa autoestima, conduzindo ao isolamento e ao consumo de substâncias. Observa-se, desse estudo, que o DUSI-R também é útil para o diagnóstico e o desenvolvimento de programas de prevenção, uma vez que o TDAH é um dos transtornos mentais mais comuns na infância e na adolescência (Szobot, 2011). Nesse sentido, os estudos nacionais e internacionais situam a prevalência do TDAH entre 3 e $6 \%$, os quais foram realizados com crianças em idade escolar, na sua maioria (Rohde et al., 1999).

Finalmente, Kirisci et al. (2008) investigaram se o DUSI-R pode ser combinado com escalas que medem problemas psiquiátricos atuais e futuros. As 
escalas foram desenvolvidas para triagem de déficit de atenção, transtornos de conduta e antissocial, ansiedade, depressão, e transtorno de uso de substâncias.

Foi realizado um estudo longitudinal com uma amostra de 328 garotos, sendo que o DUSI-R foi administrado quando os meninos tinham 12-14 anos e depois foi repetido aos 16, 19 e 22 anos. Todas as escalas identificaram jovens que foram diagnosticados pelo DSM-IV. Os resultados mostraram que as escalas de validade da previsão variaram de bom a excelente, sendo que linhas de corte foram definidas para cada escala nos locais de aplicação, para identificar jovens que demandavam um diagnóstico de avaliação mais completo.

Ainda, as análises da curva de ROC demonstraram boa precisão das escalas do DUSI-R para detectar indivíduos com classificação de transtorno psiquiátrico, com acurácia geral variando de 72 a 97\%. Já as escalas de transtorno de conduta, transtorno de personalidade antissocial e abuso de substâncias na idade de 12-14 anos previram os resultados para as idades de 19 e 22 de, respectivamente, 80 e $94 \%$ de sensibilidade.

\section{Contextos de aplicação}

Do ponto de vista do contexto (ou local) de aplicação dos instrumentos, a maior parte foi utilizada em ambientes de pesquisa ou escola. A tabela a seguir apresenta uma síntese dessas aplicações. 
Tabela 10 - Aplicação do DUSI-R por contexto de aplicação.

\begin{tabular}{|l|c|c|c|}
\hline \multicolumn{1}{|c|}{ Pesquisa } & Ocorrências & \% & N (Amostra) \\
\hline Escola & 13 & 43 & 301 a 6.417 \\
\hline Pesquisa & 9 & 30 & 84 a 354 \\
\hline Serviços ambulatoriais & 3 & 10 & 45 a 131 \\
\hline $\begin{array}{l}\text { Outros serviços } \\
\text { - Clínica (1), } \mathrm{n}=14\end{array}$ & & & \\
- Hospital (1), $\mathrm{n}=104$ & 5 & 17 & 14 a 1.310 \\
- Comunidade (1), $\mathrm{n}=1.266$ & & & \\
Escola e Comunidade (1), $\mathrm{n}=1.310$ & & & \\
\hline$\quad$ Clínica e Comunidade (1), $\mathrm{n}=158$ & 30 & 100 & \\
\hline TOTAL & & & \\
\hline
\end{tabular}

As aplicações do DUSI-R na área da pesquisa, incluindo as validações dos instrumentos, foram 9, o que corresponde a 30\% das aplicações, com amostras variando de 84 a 354: De Micheli e Formigoni (2000, 2002), n =213; Tarter e Kirisci (2001), $\mathrm{n}=354$; Tarter et al. (2002), $\mathrm{n}=$ 99; Tarter et al. (2006), $\mathrm{n}=224$; Tarter et al. (2007), n = 112; Kirisci et al. (2008), n = 328; Kirisci et al. (2009), n = 328; e Fidalgo et al. (2010), $n=84$.

Fora do ambiente de pesquisa, o maior número de aplicações foi em escolas (13 aplicações, que correspondem a 43\%), com amostras variando de 301 a 6.417: Navarro e Pontillo (2002), $\mathrm{n}=301$; Sandi et al. (2002), $\mathrm{n}=304$; Vittetoe et al. (2002), $\mathrm{n}=451$ a 1.170; Dalla-Déa et al. (2003), $\mathrm{n}=655$; Gosebruch et al. (2003), $\mathrm{n}=5.549$; De Micheli et al. (2004), $n=6.417$; Fraile Duvicq et al. (2004), $n=301$; Rebolledo et al. (2004), n = 490; Rodríguez e Villar Luis (2004), $\mathrm{n}=325$; Negrete et al. (2006), $\mathrm{n}=1.983$; Negrete e García-Aurrecoechea (2008), n = 516; Jinez et al. (2009), n = 695; e Ndetei et al. (2009), $\mathrm{n}=1.328$.

A aplicação em ambientes de serviços ambulatoriais foi em número menor (apenas 3 ocorrências, ou seja, 10\%), com amostras entre 45 a 131: De Micheli et al. (2004), n = 108; Figlie et al. (2004), n = 45; e Christie et al. (2010), n = 131. 
Por fim, foram encontradas 5 aplicações (17\%) em diferentes ambientes de outros serviços, com amostras variando de 14 a 1.310, em serviços como: Clínica (Solhkhak et al., 2005; $\mathrm{n}=14$ ), Hospital (Mathews; Pillon, 2004; $\mathrm{n}=104$ ); Comunidade (Siewert et al., 2004; $\mathrm{n}=1.266$ ), aplicações conjuntas em escola e comunidade (Moss et al., 1998; $\mathrm{n}=1.310$ ) e em clínica e comunidade (Aytaclar et al., $2003 ; \mathrm{n}=158)$.

\section{Dados do autor do instrumento}

Ralph E. Tarter. PhD. Diretor do Centro de Informação e Educação para Prevenção do Abuso às Drogas (CEDRO), financiado pelo NIDA. Professor de Ciências Farmacêuticas da Escola de Farmácia da Universidade de Pittsburg. Seus interesses de pesquisa concentram-se nos antecedentes e nas consequências neurocomportamentais do abuso de substâncias e na investigação para identificar os fatores de risco subjacentes ao biocomportamento de risco para os transtornos por uso de substâncias, dentro de uma perspectiva de desenvolvimento. Ainda, utiliza informações obtidas em estudos etiológicos, abrangendo genética, métodos bioquímicos, psicopatológicos e epidemiológicos.

\section{Informações sobre os pesquisadores que validaram o DUSI-R para o Brasil}

Profa. Dra. Denise De Micheli Avallone: possui graduação em Psicologia pela Universidade Paulista (1997), doutorado em Psicobiologia (2000) e pós-doutorado em

Ciências (2004) pela Unifesp. É professora adjunta da Disciplina Medicina e 
Sociologia do Abuso de Drogas (DIMESAD), do Departamento de Psicobiologia da Unifesp, e coordenadora do curso de Especialização em Terapias cognitivas para o tratamento de dependentes de substâncias psicoativas, do mesmo departamento. Tem experiência na área de Psicobiologia, com ênfase em adolescência, atuando principalmente nos seguintes temas: uso de drogas psicoativas, adolescentes, prevenção, triagem, diagnóstico e intervenção breve. É assessora da Fundação de Amparo à Pesquisa do Estado de São Paulo (FAPESP) e dos periódicos: Revista Brasileira de Psiquiatria, Psicologia Integral e Quality of Life Research. Credenciada como coorientadora do Departamento de Psicobiologia da Unifesp.

Profa. Dra. Maria Lúcia Formigoni: graduada em Ciências Biológicas Modalidade Médica pela Escola Paulista de Medicina (Unifesp), em 1979, mestre em Farmacologia (1982) e doutora em Ciências (1984) - área de concentração Psicofarmacologia - pela Escola Paulista de Medicina (Unifesp), e livre-docente em Psicobiologia pela Unifesp (2001). Atualmente, é chefe e professora adjunta do Departamento de Psicobiologia da Unifesp e membro temporário do comitê de experts da OMS para a definição das políticas sobre álcool, além de consultora da Secretaria Nacional Antidrogas (SENAD) e membro do conselho fiscal da Associação Fundo de Incentivo à Psicofarmacologia. 


\subsubsection{Teen ASI}

\section{Introdução}

O Teen ASI é uma entrevista semiestruturada, relativamente breve, desenvolvida pela equipe do Dr. Yifrah Kaminer, da Universidade da Connecticut (Estados Unidos). O Teen ASI é uma versão modificada do questionário ASI, amplamente utilizado em todo o mundo, originalmente desenvolvido para adultos (McLellan et al., 1980). Essa versão para adolescentes foi desenvolvida ao se perceber que a versão para adultos não abrangia questões fundamentais da vida do adolescente, como seu relacionamento com os amigos e as atividades escolares (McLellan et al., 1992; Kaminer, 1994; Kaminer et al., 1991). No Brasil, a tradução e a validação em amostra de adolescentes brasileiros foram realizadas por Sartes, De Micheli e Formigoni (2009). Além do original na língua inglesa, amplamente utilizado nos Estados Unidos e Canadá, já há versões validadas para o Brasil e a Espanha, entre outros.

\section{Descrição e objetivos}

O Teen ASI é uma entrevista semiestruturada para avaliação periódica de adolescentes com abuso de substâncias. Seu objetivo é avaliar a gravidade do uso de drogas em adolescentes, bem como problemas em outros aspectos de suas vidas. Esse instrumento utiliza uma abordagem multidimensional de avaliação e possui sete áreas: 
uso de substâncias psicoativas; situação escolar; emprego/sustento; relações familiares; amigos/relações sociais; situação legal; e situação psiquiátrica.

As perguntas referem-se a problemas no último mês, nos últimos três meses e à história do adolescente em cada uma dessas áreas. Já as respostas podem ser dicotômicas (ex.: "sim" ou "não") ou quantitativas (ex.: número de vezes de ocorrência de um evento), mas existem também algumas questões que permitem respostas abertas (Sartes, 2005). Segue o que cada área do Teen ASI avalia:

Tabela 11 - Áreas de avaliação do Teen ASI e o que avaliam.

\begin{tabular}{|c|c|}
\hline Área do T-ASI & O que avalia \\
\hline Uso de substâncias & $\begin{array}{l}\text { Frequência do uso atual e passado de } 10 \text { substâncias, tratamentos já } \\
\text { realizados, períodos de abstinência, overdose, dinheiro gasto com drogas } \\
\text { etc. }\end{array}$ \\
\hline Situação escolar & Faltas, atrasos, punição, atividades extracurriculares, notas. \\
\hline Emprego/sustento & $\begin{array}{l}\text { Padrão de emprego, faltas, atrasos, demissão, desemprego, satisfação } \\
\text { com desempenho etc. }\end{array}$ \\
\hline Relações familiares & Situação de moradia, conflitos, apoio familiar, regras, agressão etc. \\
\hline $\begin{array}{l}\text { Relacionamento com } \\
\text { pares/sociabilidade }\end{array}$ & $\begin{array}{l}\mathrm{N}^{\circ} \text { de amigos usuários ou não, namoro, conflitos, satisfação com os } \\
\text { relacionamentos, tempo de lazer. }\end{array}$ \\
\hline Situação legal & Liberdade condicional, condenações, prisões etc. \\
\hline Situação psiquiátrica & Presença de problemas psiquiátricos/emocionais e tratamentos. \\
\hline
\end{tabular}

Fonte: Sartes e De Micheli (2008, p. 43).

- Utilidade clínica: para avaliação no início, durante e no final do tratamento;

- Número de áreas: 7;

- Número de questões: 153 ;

- Ambientes de aplicação: ambulatórios e clínicas especializadas no tratamento do uso de álcool e outras drogas em adolescentes. Avaliações favoráveis sobre a utilidade clínica do Teen ASI têm sido reportadas por 
vários ambientes clínicos de pesquisa, principalmente nos Estados Unidos (Kaminer et al., 1993);

- Aplicabilidade em pesquisa: o Teen ASI pode ser utilizado periodicamente para avaliar as mudanças de gravidade nas áreas da vida do adolescente, em resposta ao tratamento (Kaminer et al., 1993);

- População-alvo:

- Faixa etária da versão brasileira: adolescentes entre 12 e 19 anos;

- Faixa etária da versão americana: adolescentes com uso de substâncias e comorbidades psiquiátricas;

- Aplicação:

- Formato: entrevista;

- Administrador por: diversos profissionais;

- Treinamento para aplicação: sim;

- Tempo de aplicação: a tabela a seguir apresenta uma síntese do tempo de aplicação do Teen ASI, conforme o tipo de questionário aplicado, o número de questões e o formato de aplicação. Na versão brasileira, a média é de 26 a 65 minutos (Sartes et al., 2009).

Tabela 12 - Tempo de aplicação do Teen ASI.

\begin{tabular}{|l|c|c|}
\hline Questionário & Número de Questões & Tempo de aplicação médio \\
\hline Teen ASI completo & 153 & 40-60 minutos \\
\hline $\begin{array}{l}\text { Teen ASI para } \\
\text { diferenciar usuários }\end{array}$ & 60 & 15 minutos \\
\hline $\begin{array}{l}\text { Teen ASI para internet } \\
\text { ou telefone }\end{array}$ & $68-215$ & $20-25$ minutos \\
\hline Teen ASI 2 & $\begin{array}{c}\text { 18 domínios } \\
\text { (na versão 1, são 7 domínios) }\end{array}$ & Superior a 40-60 minutos \\
\hline
\end{tabular}


- Investimento: domínio público.

\section{Análise dos resultados}

Duas perguntas-chave são feitas ao final de cada área, como, por exemplo, na área escolar, que serão respondidas de acordo com a escala a seguir, apresentada ao entrevistado: $0=$ Nada, $1=$ Pouco, $2=$ Moderadamente, $3=$ Muito, $4=$ Demais. $A$ gravidade de problemas em cada área é determinada a partir da combinação da classificação do entrevistador com a do próprio respondente em relação à necessidade de tratamento.

Utiliza-se a seguinte escala ordinal, com 5 escores possíveis:

- $0=$ nenhum problema, sem indicação de tratamento;

- 1 = problemas leves, tratamento se necessário;

- 2 = problemas moderados, sendo sugerido tratamento;

- 3 = problemas consideráveis, sendo necessário tratamento;

- 4 = problemas graves, tratamento absolutamente necessário.

Após analisar as questões em cada área, o entrevistador escolhe dois escores dessa escala, usando a resposta do paciente para decidir entre eles. Se o paciente considera muito necessário o tratamento, o entrevistador escolherá o maior escore, mas, se o paciente não o considera necessário ou dá pouca importância a ele, o entrevistador escolherá o menor escore (Sartes; De Micheli, 2008). 
- Medidas de confiabilidade utilizadas: teste e reteste, confiabilidade interna;

- Medidas de validação que foram derivadas/desenvolvidas: conteúdo, construto e critério (Kaminer et al., 1991).

Propriedades psicométricas - valores da versão brasileira

Quanto à confiabilidade interna, a curva ROC foi de 0,88 , apresentando uma taxa satisfatória de classificação correta. Já a consistência interna, avaliada pelo coeficiente Alfa de Cronbach, foi considerada boa em relação ao uso de substâncias $(0,89)$, aspectos legais $(0,81)$ e situação psiquiátrica $(0,80)$. Severidade $r=0,73$ e composto $r=0,72$. CIDI usado como padrão-ouro (Sartes et al., 2009).

\section{Propriedades psicométricas - valores da versão americana}

Utilidade clínica do instrumento foi considerada boa e a confiabilidade interobservadores foi de $\mathrm{r}=0,78$ (Kaminer et al., 1991).

Comparação das propriedades psicométricas das validações para Estados Unidos, Espanha e Brasil

A tabela a seguir apresenta uma síntese das propriedades psicométricas do Teen ASI, validado para os Estados Unidos, Espanha e Brasil. 
Tabela 13 - Comparativo entre as propriedades psicométricas do Teen ASI.

\begin{tabular}{|c|c|c|}
\hline Versão & Fonte & Resultados \\
\hline Estados Unidos & Kaminer et al. (1991) & $\begin{array}{l}\text { - Confiabilidade interna: } 0,78 \\
\text { - Confiabilidade da escala de substâncias: } 0,85 \text {. }\end{array}$ \\
\hline Espanha & Díaz et al. (2008) & $\begin{array}{l}\text { Escala de uso de substâncias: } \mathrm{Rho}=0,90 \\
\text { - } \\
\text { Escala de problemas: } \mathrm{Rho}=0,69 .\end{array}$ \\
\hline Brasil & Sartes et al. (2009) & $\begin{array}{l}\text { - Severidade: } r=0,73 \\
\text { - } \quad \text { Composto: } r=0,72 \\
\text { Área sobre a curva de } \mathrm{ROC}=0,88\end{array}$ \\
\hline
\end{tabular}

\section{Desenvolvimento e disseminação}

A tabela a seguir apresenta uma síntese dos 12 artigos encontrados nesta pesquisa, quanto à sua disseminação geográfica e respectivo ano de publicação.

Tabela 14 - Número de estudos por ano e respectivos países - Teen ASI.

\begin{tabular}{|c|c|l|}
\hline Ano & Núm. Estudos & \multicolumn{1}{c|}{ País(es) } \\
\hline 1998 & 1 & Estados Unidos (Kaminer et al., 1998) \\
\hline 1999 & 1 & Estados Unidos (Kaminer; Burleson, 1999) \\
\hline 2000 & - & - \\
\hline 2001 & - & - \\
\hline 2002 & 1 & Estados Unidos (Kaminer et al., 2002) \\
\hline 2003 & - & - \\
\hline 2004 & 1 & Estados Unidos (Kaminer; Burleson, 2004) \\
\hline 2005 & 1 & Estados Unidos (Brodey et al., 2005) \\
\hline 2006 & - & - \\
\hline 2007 & - & - \\
\hline 2008 & 5 & $\begin{array}{l}\text { Espanha (Díaz et al., 2008), Estados Unidos (4) (Brodey et al., } \\
\text { 2008; Kaminer; Bukstein, 2008; Winters et al., 2008) }\end{array}$ \\
\hline 2009 & 1 & Brasil (Sartes et al., 2009) \\
\hline 2010 & 1 & Espanha (Castro-Fornieles et al., 2010) \\
\hline $\mathbf{1 9 9 8 - 2 0 1 0}$ & $\mathbf{1 2}$ & 4 Países + 1 Avaliação Internacional \\
\hline
\end{tabular}




\section{Validações do instrumento}

A tabela a seguir apresenta uma síntese das validações do Teen ASI encontradas na pesquisa.

Tabela 15 - Artigos de validação do Teen ASI.

\begin{tabular}{|l|l|}
\hline Autor(es) e Ano & Validação \\
\hline Brodey et al. (2005) & Validação das versões para internet e telefone \\
\hline Díaz et al. (2008) & Validação para a Espanha \\
\hline Brodey et al. (2008) & Validação do Teen ASI-2 \\
\hline Sartes et al. (2009) & Validação para o Brasil \\
\hline
\end{tabular}

\section{Outras versões}

Uma nova versão do Teen ASI, amplamente revisada, foi desenvolvida por Brodey et al. (2005), para aplicação por telefone e internet. Além disso, Brodey et al. (2008) desenvolveram o Teen ASI-2, expandindo as dimensões analisadas de 7 para 18.

\section{Aplicações do instrumento}

As aplicações do Teen ASI encontram-se sumarizadas na tabela a seguir.

Tabela 16 - Aplicações do Teen ASI.

\begin{tabular}{|c|c|c|l|}
\hline \multicolumn{1}{|c|}{ Aplicação(ões) } & Núm. & $\%$ & \multicolumn{1}{|c|}{ Outro(s) instrumento(s)? } \\
\hline $\begin{array}{l}\text { Intervenções } \\
\text { - Intervenções terapêuticas } \\
\text { Kaminer et al. (1998) } \\
\text { Kaminer e Burleson (1999) }\end{array}$ & $\mathbf{5}$ & $\mathbf{6 2 , 5}$ & $\begin{array}{l}\text { Group Sessions Rating Scale (GSRS) } \\
\text { DISC, CBCL, Youth Self Report } \\
\text { (YSR), Situational Confidence } \\
\text { Questionnaire (SCQ) } \\
\text { Positron Emission Tomography } \\
\text { (PET), Análise toxicológica de urina }\end{array}$ \\
\hline Kaminer et al. (2002) & &
\end{tabular}




\begin{tabular}{|c|c|c|c|}
\hline $\begin{array}{l}\text { - } \quad \text { Intervenções no serviço } \\
\text { Kaminer e Burleson (2004) } \\
\text { - } \quad \text { Intervenções clínicas } \\
\text { Winters et al. (2008) }\end{array}$ & & & $\begin{array}{l}\text { Teen Treatment Services Review (T- } \\
\text { TSR), DISC, Análise toxicológica de } \\
\text { urina }\end{array}$ \\
\hline $\begin{array}{l}\text { Fatores de risco \& prevalência } \\
\text { Burleson e Kaminer (2008) } \\
\text { Castro-Fornieles et al. (2010) }\end{array}$ & 2 & 25 & $\begin{array}{l}\text { Dimensions of Temperament Survey } \\
\text { Revised (DOTS-R) }\end{array}$ \\
\hline $\begin{array}{c}\text { Disseminação do instrumento } \\
\text { Kaminer; Bukstein (2008) }\end{array}$ & 1 & 12,5 & \\
\hline TOTAL & 8 & 100 & $100 \%$ \\
\hline
\end{tabular}

Das 12 publicações encontradas, 4 se referiam à validação do instrumento, sendo uma validação para a Espanha (Díaz et al., 2008) e outra para o Brasil (Sartes et al., 2009). As outras 2 validações eram ainda para o mercado americano, sendo uma adaptação e validação do Teen ASI para aplicação via telefone e internet (Brodey et al., 2005) e outra validação da versão 2 do Teen ASI, para os Estados Unidos (Brodey et al., 2008).

Foram também encontradas 8 publicações referentes à aplicação das versões validadas do Teen ASI, sendo que uma delas não era propriamente uma aplicação e sim um panorama da disseminação internacional do instrumento (Kaminer; Bukstein, 2008) e as outras 7 se tratavam de aplicações propriamente ditas (Kaminer et al., 1998; Kaminer; Burleson, 1999; Kaminer et al., 2002; Kaminer; Burleson, 2004; Winters et al., 2008; Burleson; Kaminer, 2008; Castro-Fornieles et al., 2010).

A grande maioria das aplicações encontradas foi em ambientes de pesquisa, na avaliação de intervenções (5 aplicações, correspondendo a 74\%), sendo 3 avaliações de intervenções terapêuticas (Kaminer et al., 1998; Kaminer; Burleson, 1999; Kaminer et al., 2002), uma avaliação de intervenção no serviço (Kaminer; Burleson, 2004) e uma avaliação de intervenções clínicas (Winters et al., 2008). 
Além dessas aplicações em intervenções, foram encontrados 2 artigos sobre fatores de risco e prevalência (Burleson; Kaminer, 2008; Castro-Fornieles et al., 2010) e um artigo referente à disseminação do instrumento (Kaminer; Bukstein, 2008), cada um correspondendo a um índice de $13 \%$ sobre o total dos 8 artigos de aplicação.

Do ponto de vista da aplicação em conjunto com outros instrumentos, 5 das 8 publicações $(62,5 \%)$ que trataram da aplicação do Teen ASI foram feitas em conjunto com outros instrumentos (Kaminer et al., 1998: GSRS; Kaminer; Burleson, 1999: DISC, CBCL, YSR, SCQ; Kaminer et al., 2002: avaliação toxicológica de urina; Kaminer; Burleson, 2004: T-TSR, DISC e avaliação toxicológica de urina). Os principais instrumentos aplicados em conjunto com o Teen ASI foram: 2 aplicações de DISC, em Kaminer e Burleson (1999, 2004); 2 aplicações de Análise de Urina (Kaminer et al., 2002; Kaminer; Burleson, 2004) e, a partir daí, uma aplicação para cada instrumento, tais como: GSRS, em Kaminer et al. (1998); CBCL, em Kaminer e Burleson (1999); YSR, em Kaminer e Burleson (1999); SCQ em Kaminer e Burleson (1999); e T-TSR, em Kaminer e Burleson (2004). Como se pode observar, vários artigos aplicaram mais do que um instrumento em conjunto com o Teen ASI, o que passa a ser analisado a seguir.

\section{Análise das aplicações em intervenções}

Castro-Fornieles et al. (2010) utilizaram o Teen ASI para avaliar a prevalência e os fatores relacionados ao uso de substâncias em adolescentes com transtornos alimentares, análise que é realizada por muito poucos estudos. A amostra era de 95 pacientes, entre 12 e 17 anos, que atendiam aos critérios do Diagnostic and Statistical 
Manual - Fourth Edition - Text Revision (DSM-IV-TR) para o diagnóstico de anorexia nervosa e transtornos alimentares (não especificados).

Os autores concluíram que problemas de abuso de substâncias são comuns entre pacientes com transtornos alimentares, apresentando uma taxa de 14,7\% para tabaco, 3,2\% para maconha, 1,1\% para álcool e 1,1\% para outras substâncias. O estudo destacou a importância da avaliação dos pacientes com transtornos alimentares, bem como a necessidade de abordagens terapêuticas específicas.

\section{Aplicação em conjunto com outros instrumentos}

A tabela a seguir apresenta uma síntese das aplicações em conjunto do Teen ASI e outros instrumentos.

Tabela 17 - Aplicações em conjunto do Teen ASI e outros instrumentos.

\begin{tabular}{|l|c|l|}
\hline \multicolumn{1}{|c|}{ Instrumento } & Núm. & \multicolumn{1}{c|}{ Publicação } \\
\hline DISC & 2 & Kaminer e Burleson (1999, 2004) \\
\hline Análise toxicológica de urina & 2 & $\begin{array}{l}\text { Kaminer et al. (2002) } \\
\text { Kaminer e Burleson (2004) }\end{array}$ \\
\hline GSRS & 1 & Kaminer et al. (1998) \\
\hline CBCL & 1 & Kaminer e Burleson (1999) \\
\hline YSR & 1 & Kaminer e Burleson (1999) \\
\hline SCQ & 1 & Kaminer e Burleson (1999) \\
\hline T-TSR & 1 & Kaminer e Burleson (2004) \\
\hline DOTS-R & 1 & Burleson e Kaminer (2008) \\
\hline
\end{tabular}

No estudo realizado por Kaminer et al. (1998), o Teen ASI foi um dos instrumentos utilizados para avaliar processos de tratamento em TCC e terapia em grupo para adolescentes usuários de substâncias. O Teen ASI foi aplicado de forma complementar ao GSRS, que é uma medida de processo de terapia de grupo que 
determina a aplicabilidade para avaliação de tratamento em grupo de adolescentes, visto que o Teen ASI possui uma escala de severidade do uso de substâncias e em outras áreas da vida que pode auxiliar no complemento de avaliação de abordagens terapêuticas.

O GSRS foi desenvolvido por Getter et al. (1992) e contém uma lista de 7 itens, que representam características importantes e distintas da TCC (4 itens) e da terapia em grupo (3 itens). Ainda, se mostrou eficaz na medição do processo de tratamento de adolescentes com abuso de substâncias.

Kaminer e Burleson (1999) utilizaram o Teen ASI, além de outros instrumentos, tais como DISC, CBCL, YSR, SCQ, T-TSR, para avaliar a eficácia da TCC em relação à terapia em grupo inter-relacional (Brown; Yalom, 1977). As avaliações foram conduzidas após 3 e 15 meses da conclusão do tratamento e os resultados encontrados foram: o tratamento impactou positivamente os ganhos póstratamento; a TCC com aplicação baseada em manual tem potencial para uma intervenção breve eficaz com adolescentes em contextos de pacientes não hospitalizados; tanto a TCC quanto a terapia inter-relacional foram associadas a resultados similares no longo prazo.

Outra aplicação em que o Teen ASI foi utilizado para medir a eficácia de terapias de tratamento foi no estudo de Kaminer et al. (2002). Esse estudo comparou a eficácia da TCC em relação à terapia psicoeducacional, em adolescentes usuários de substâncias. Além do Teen ASI, outra medida para avaliar os resultados foi a aplicação de testes toxicológicos por meio da urina.

Com relação aos resultados apresentados, o transtorno de conduta foi significativamente associado com a não conclusão do tratamento e a baixa taxa de 
acompanhamento do paciente. Já a TCC apresentou taxas inferiores significativas de testes toxicológicos de urina em relação à terapia psicoeducacional para jovens adultos do sexo masculino. A maioria das subescalas do Teen ASI indicou melhoria sensível a partir da baseline, nas avaliações do follow-up após 3 e 9 meses, ao longo das condições de tratamento. Ainda, a redução no uso de substâncias independe das condições de tratamento.

Outra aplicação do Teen ASI foi na avaliação da correlação entre serviços e tratamentos de adolescentes usuários de substâncias, feita por Kaminer e Burleson (2004). A análise explorou se a participação em serviços comunitários auxiliares fora do programa de tratamento tradicional contribui para a melhoria dos resultados do tratamento de usuários adolescentes.

A avaliação dos serviços de tratamento, em conjunto com a avaliação do tratamento em si, é de vital importância para a melhoria dos resultados de curto e médio prazo nos programas de tratamento de adolescentes com abuso de substâncias, devido ao fato de que as taxas de abandono do tratamento são elevadas, bem como o índice de recaída (Kaminer, 2001; Winters, 1999). Por sua vez, reportaram que $60 \%$ dos adolescentes tiveram uma recaída durante os primeiros três meses de conclusão do tratamento e Kaminer et al. (2002), bem como Dennis et al. (2004), reportaram taxas semelhantes.

Além do Teen ASI, foram aplicados também o T-TSR e a análise toxicológica da urina, no início do tratamento e no acompanhamento de 3 e 9 meses, com 88 participantes. O T-TSR é uma modificação do Treatment Services Review, desenhado para avaliar o tipo e o número de entradas e saídas dos serviços comunitários auxiliares fornecidos aos adolescentes usuários de substâncias. A conclusão foi que, quanto 
maior o número de serviços terapêuticos oferecidos durante o tratamento, melhores são os resultados em curto prazo e, quanto maior o número de serviços terapêuticos oferecidos após o tratamento, piores os resultados em curto prazo. Esse é um estudo inovador, dada a escassez de pesquisas que exploram o envolvimento dos jovens em serviços auxiliares durante e após o tratamento.

Conforme abordado anteriormente, o tratamento para o abuso de álcool e outras drogas tem sido focado na TCC, na entrevista motivacional e na farmacoterapia, sendo que outra abordagem comum nessa área é o modelo Minnessota ou grupos de apoio, tipo Alcoólicos Anônimos e Narcóticos Anônimos (Silva et al., 2006). Nesta revisão, foram encontrados estudos sobre a avaliação da TCC, terapia em grupo inter-relacional e terapia psicoeducacional. Por outro lado, não foram identificados estudos medindo a eficácia da medicação, da entrevista motivacional e do modelo Minnessota, que se constituem, portanto, oportunidades para a aplicação do instrumento.

\section{Contextos de aplicação}

Todos os doze artigos selecionados para a pesquisa se aplicavam a ambientes clínicos e de pesquisa, sendo quatro estudos de corte transversal (Díaz et al., 2008; Brodey et al., 2008; Sartes et al., 2009; Castro-Fornieles et al., 2010), quatro estudos de ensaios clínicos (Kaminer et al., 1998; Kaminer; Burleson, 1999, 2004), um estudo de corte longitudinal (Kaminer; Bukstein, 2008), sendo as outras revisões de instrumentos e validações (Winters; Kaminer, 2008) um estudo de conversão do instrumento para aplicação via internet e telefone (Brodey et al., 2005). 
Os resultados do estudo de Díaz et al. (2008) confirmaram a utilização do Teen ASI em ambientes clínicos e de pesquisa, na versão validada para a Espanha. Já no estudo de Sartes et al. (2009), 30\% do grupo de adolescentes usuários (de um total de 100 usuários, dentro de uma amostra geral de 208 adolescentes) estava em tratamento em clínicas especializadas, local onde foi feita a avaliação. Todos os demais adolescentes foram abordados individualmente pela pesquisadora em diferentes locais - incluindo a escola, a casa e locais públicos -, sendo agendada uma entrevista para aplicação do instrumento.

\section{Dados do autor do instrumento}

Dr. Yifrah Kaminer: M.D. Sackler School of Medicine, MBA. University of Hartford, Tel Aviv University, Israel. É professor de Psiquiatria e Pediatria na Universidade de Connecticut e codiretor de pesquisa da Divisão de Psiquiatria de Criança e Adolescente, da mesma universidade. É também pesquisador no Injury Prevention Center e tem interesse em neurocomportamento e perspectivas de desenvolvimento de comportamento de alto risco, incluindo: abuso de substâncias, comportamento suicida, compulsão por jogos, comportamento do adolescente na direção. Tem oferecido suporte em pesquisas para o NIDA, National Institute on Alcohol Abuse and Alcoholism (NIAAA), Center for Substance Abuse Treatment (CSAT) e Donaghue Foundation. 


\section{Informações da pesquisadora que validou o instrumento para o Brasil}

Profa. Dra. Laisa Marcorela A. Sartes: possui graduação em Psicologia pela Universidade Federal de Juiz de Fora (2002) e mestrado (2005) e doutorado (2010) em Ciências pelo Departamento de Psicobiologia da Unifesp. Fez estágio de pósdoutorado no mesmo departamento, na área de Álcool e Drogas. Atuou como psicóloga e pesquisadora no ambulatório da Unidade de Dependência de Drogas (UDED) desse departamento e como supervisora de tutores de várias edições de dois cursos a distância, promovidos pela SENAD e Unifesp e relacionados à dependência de substâncias. Atualmente, é professora adjunta do Departamento de Psicologia da Universidade Federal de Juiz de Fora. Seus principais temas de trabalho e pesquisa são: uso de substâncias psicotrópicas, estudos de avaliação clínica e validação de instrumentos, teoria de resposta ao item, tratamento para dependentes de substâncias, familiares e adolescentes, baseado na TCC e na Terapia Familiar.

\subsubsection{CBCL}

\section{Introdução}

O CBCL é um instrumento de avaliação psicológica, criado no final da década de 1970 por Achenbach (1991), nos Estados Unidos, e traduzido para 55 países.

Outros dois instrumentos foram desenvolvidos pelo mesmo autor para o rastreamento de problemas de saúde mental em crianças e adolescentes, a partir de informações do professor (Teacher Report Form - TRF) e do próprio adolescente 
(YSR) (Duarte; Bordin, 2000). O TRF e o YSR foram recentemente traduzidos para o português, retrotraduzidos e adaptados culturalmente, encontrando-se atualmente em fase de testagem. Também está disponível no Brasil o Questionário de Capacidades e Dificuldades (Fleitlich et al., 2000), que é a versão brasileira do Strenghts and Difficulties Questionnaire (SDQ) (Goodman, 1997).

O CBCL (4-18 anos) encontra-se em desenvolvimento há mais de 4 décadas. Inicialmente, o professor Thomas Achenbach (1991), com auxílio de pais e diversos profissionais que trabalham diretamente com crianças e adolescentes (psicólogos, pedagogos, médicos, professores etc.), elaborou uma lista de comportamentos/queixas frequentemente encontrados nessas faixas etárias. Após a elaboração, a lista foi aplicada em uma larga escala da população norte-americana, com o objetivo de observar a coocorrência dos problemas listados. Assim, foi possível fazer uma análise fatorial, o que levou à elaboração das escalas empiricamente baseadas, que atualmente são utilizadas para avaliar as crianças e adolescentes com o uso de diferentes inventários do Achenbach System of Empirically Based Assessment (ASEBA).

Logo, os dados obtidos têm por base as experiências de pessoas que lidam com os clientes em diversos contextos e o relato do cliente sobre sua própria experiência. Não obstante, foram analisados estatisticamente, de maneira que identificassem os padrões de ocorrência dos problemas. Tais padrões, derivados da análise estatística, foram usados para construir as escalas síndromes, que marcam os conjuntos de problemas que coocorrem (Achenbach; Rescorla, 2004).

A análise fatorial dos itens dos inventários CBCL e YSR levou à elaboração de oito escalas de problemas de comportamento: Ansiedade/Depressão, Isolamento/Depressão, Queixas Somáticas, Problemas Sociais, Problemas de 
Pensamento, Problemas de Atenção, Comportamento Delinquente e Comportamento Agressivo. Alguns itens não se encaixaram em nenhuma dessas escalas e são apresentados como Outros Problemas. Essas escalas são reunidas em três grupos: Problemas Internalizantes, que reúne as três primeiras escalas; Problemas Externalizantes, que reúne as duas últimas escalas; e Problemas Totais, que inclui todas as escalas analisadas e todos os itens reunidos em Outros Problemas (Achenbach; Rescorla, 2001).

Ainda, buscando integrar os diferentes paradigmas utilizados para o estudo e para a avaliação das psicopatologias e para facilitar a aplicação dos dados usados no Sistema de Avaliação Empiricamente Baseado ao sistema de diagnóstico formal, Achenbach e Rescorla (2001), com o auxílio de 22 psicólogos e psiquiatras de 16 diferentes culturas, elaboraram as escalas orientadas pelo DSM-IV (APA, 1994).

Nesse sentido, utilizou-se o procedimento de avaliar quais itens do CBCL e dos outros questionários do ASEBA eram muito consistentes em relação às categorias diagnósticas descritas no DSM-IV (Achenbach; Rescorla, 2007). Encontraram-se correspondências para os seguintes diagnósticos: transtornos afetivos, transtornos de ansiedade, transtornos somáticos, TDAH, transtorno opositor desafiante e transtorno de conduta (Achenbach; Rescorla, 2001).

Ressalte-se que, baseados em décadas de pesquisas e experiências práticas iniciadas na década de 1960 (Achenbach; Edelbrock, 1978), os inventários do ASEBA conseguem avaliar semelhanças e diferenças do funcionamento humano em diferentes faixas etárias, condições e interações (Rocha; Silvares, 2008). De fato, o ASEBA é um sistema integrado de avaliação por meio de múltiplos informantes, no qual encontramos uma ampla gama de inventários que auxiliam no processo de avaliação 
das competências e dos problemas de comportamento, de maneira rápida e com baixo custo (Achenbach; Rescorla, 2001).

Tanto Achenbach (1991) quanto Rocha e Silvares (2008) apresentam argumentos para essa característica. Segundo Achenbach (1991), os pais ou seus substitutos são, geralmente, as mais importantes fontes de informação sobre as competências e os problemas de comportamento de seus filhos, visto que, em função da convivência, estão mais bem informados para avaliar as variações de comportamento que ocorrem nas diversas situações. Já de acordo com Rocha e Silvares (2008), é consenso entre os psicólogos clínicos que o envolvimento dos pais no processo de avaliação e a visão deles sobre o comportamento dos filhos são, muitas vezes, cruciais para definir a intervenção a ser realizada. Além dos pais, outros agentes sociais que servem como fontes de dados, como os professores e os pares, também são importantes no processo de avaliação de crianças e adolescentes. No caso dos adolescentes, a maturidade social e a maturidade cognitiva atingidas permitem que eles próprios relatem seus sentimentos e comportamentos nas diversas situações, o que os torna potenciais informantes no processo de avaliação (Achenbach, 1991).

\section{Descrição e objetivos}

O CBCL foi elaborado para avaliar problemas de comportamento e competências sociais de crianças e adolescentes, conforme relato dos pais, responsáveis ou professores, e também pode ser usado para avaliar problemas de comportamento de uma criança ao longo do tratamento ou pós-tratamento. Form reports, autorrelatos e observação direta também estão disponíveis para o CBCL. 
Este é um instrumento de triagem e rastreamento, que não substitui o diagnóstico médico e que tem como principal objetivo identificar problemas de saúde mental em crianças e adolescentes. Uma das características mais úteis do questionário do CBCL e de seu sistema de pontuação é que eles permitem a comparação das avaliações por diferentes observadores, como mãe, pai, responsáveis, professor, criança e adolescente (Achenbach, 1991).

\section{Utilidade clínica}

O CBCL foi projetado para identificar problemas de saúde mental em crianças e adolescentes, conforme relato dos pais ou professores (Achenbach, 1991).

\section{Número de escalas}

O CBCL permite agrupar os resultados em dois âmbitos: 1) competência social; e 2) problemas de comportamento. A competência social é agrupada em três escalas: atividade, sociabilidade e escolaridade, sendo que a soma dos escores brutos das três escalas fornece o escore final de competência social. Os problemas de comportamento, por sua vez, são agrupados nas escalas de internalização e externalização. A escala de internalização se subdivide em retraimento, queixas somáticas e ansiedade/depressão; já a escala de externalização, em comportamento delinquente e comportamento agressivo. Há, ainda, as subescalas de problemas com o contato social, problemas com o pensamento e problemas de atenção (Bordin et al., 1995). 
- Número de questões: 118. O CBCL proporciona o cruzamento de respostas de múltiplos informantes, tornando possível verificar o quão concordantes são as respostas fornecidas (ASEBA, 2006);

- Ambientes de aplicação: ambulatório, clínicas de pediatria, saúde mental, escolas e em levantamentos epidemiológicos;

- Aplicabilidade em pesquisa;

- População-alvo:

- Faixa etária da versão brasileira: crianças e adolescentes de 4 a 18 anos;

- Faixa etária da versão americana: crianças e adolescentes de 6 a 18 anos;

- Aplicação:

- Formato: entrevista e autopreenchimento;

- Administrador por: pode ser respondido pelos próprios pais ou responsáveis pela criança ou adolescente. Também pode ser administrado por um entrevistador;

- Treinamento para aplicação: não específico. É necessária familiaridade com o instrumento;

- Tempo de aplicação: 15 minutos;

- Investimento: 50 conjuntos - US\$ 25.00.

\section{Análise dos resultados}

A soma dos escores brutos obtidos nas subescalas comportamentais leva ao distúrbio total de problemas de comportamento. Além disso, os resultados ponderados 
no CBCL permitem classificar as crianças em: clínicas, não clínicas e limítrofes. Para as escalas sociais: clínicas, escore abaixo de 30; limítrofes, entre 30 e 33; e não clínica, acima de 33. Para as escalas comportamentais: clínica, acima de 70; limítrofe, entre 67 e 70; e não clínica, inferior a 67. Para o escore total: clínica, acima de 63; limítrofe, entre 60 e 63; e não clínica, abaixo de 60 (Bordin et al., 1995).

\section{Aplicação}

O CBCL é aplicado em formato de questionário, contendo 118 perguntas, para avaliar a competência social e os problemas de comportamento de indivíduos de 4 a 18 anos, a partir de informações fornecidas pelos pais (Bordin et al., 1995), em formato de autopreenchimento. Também pode ser aplicado por um avaliador, sendo o treinamento não específico, porém necessitando de familiaridade com o instrumento.

- Medidas de confiabilidade utilizadas: teste e reteste, confiabilidade interna, interentrevista;

- Medidas de validação que foram derivadas/desenvolvidas: conteúdo e construto (Achenbach, 1991).

\section{Propriedades psicométricas da versão americana - confiabilidade}

A faixa de valor de teste e reteste é $0,95-1,00$; o intervalo de confiabilidade entre os avaliadores é de 0,93-0,96; e a gama de consistência interna é 0,78-0,97. Ainda, a validade de critério foi avaliada e considerada aceitável. 


\section{Propriedades psicométricas da versão brasileira}

A versão brasileira do CBCL (4-18 anos) é denominada "Inventário de Comportamento da Infância e Adolescência" e possui dados preliminares de validação. As medidas de confiabilidade utilizadas na versão americana foram preservadas na versão brasileira, existindo uma sensibilidade de $87 \%$ (Bordin et al., 1995).

\section{Debate quanto à validação brasileira do $\mathrm{CBCL}$}

Rocha e Silvares (2008) pontuam que, quanto à validação da versão brasileira do CBCL, há algumas críticas na literatura. Nesse sentido, Bordin et al. (1995) realizaram um estudo de validação preliminar do CBCL (Achenbach, 1991), utilizando a avaliação psiquiátrica como modelo de comparação entre os resultados obtidos por meio desse inventário. O procedimento adotado foi o de comparar a avaliação feita pela mãe, que usou o CBCL, com a avaliação feita por um psiquiatra, que não teve acesso ao inventário respondido pela mãe. A correlação encontrada pelas autoras foi alta, o que sugere que o uso do questionário é válido no Brasil.

No entanto, deve-se atentar para o pequeno número de participantes avaliados nesse estudo e para sua caracterização homogênea (Silvares et al., 2006). Além disso, o modelo de validação selecionado tem recebido críticas em função da baixa correlação encontrada entre a avaliação psiquiátrica e a avaliação feita com instrumentos padronizados (Rettew et al., 2009).

Em uma meta-análise, Rettew et al. (2009) encontraram uma baixa concordância entre o diagnóstico obtido por meio de entrevista diagnóstica 
padronizada e o diagnóstico clínico, com kappa de 0,15 para crianças e 0,26 para adultos. Como há diversas variáveis que podem alterar um diagnóstico psiquiátrico (como, por exemplo, quem faz a entrevista diagnóstica), entende-se que esse tipo de avaliação não pode ser o único critério para a validação de um instrumento diagnóstico (Rettew et al., 2009). A despeito de tais ressalvas, o trabalho realizado por Bordin et al. (1995) foi um primeiro passo no sentido de validar o uso do CBCL no Brasil (Rocha; Silvares, 2006).

Por sua vez, Silvares et al. (2006), considerando a necessidade de novos estudos com o CBCL, visando, então, a alcançar normas brasileiras, analisaram os inventários respondidos por pais de crianças encaminhadas para atendimento em cinco diferentes clínicas-escola de psicologia. Encontraram-se resultados semelhantes ao estudo de Bordin et al. (1995) quanto à distribuição dos perfis e queixas principais. Os dados, no entanto, ainda não foram conclusivos, devido ao pequeno número de participantes e à distribuição heterogênea dentro das clínicas-escola envolvidas.

\section{Outras versões}

O Inventário dos Comportamentos de Crianças e Adolescentes entre 6 e 18 anos é um material, também elaborado pelo psiquiatra norte-americano Thomas M. Achenbach, que visa a obter, de maneira padronizada, o relato dos pais sobre o comportamento de seus filhos. Para tanto, o instrumento é dividido em duas partes: a primeira é composta por sete itens, que avaliam as competências da criança, abrangendo a prática de esportes e de outras atividades lúdicas, a participação em grupos ou equipes, a realização de tarefas em casa, os relacionamentos sociais e o 
desempenho acadêmico; e a segunda parte é composta por uma lista com 113 problemas de comportamento, sendo que os pais devem atribuir valor 0 (zero) quando o problema não é verdadeiro para seu filho, 1 (um) quando é um pouco ou algumas vezes verdadeiro e 2 (dois) caso o problema seja muito ou frequentemente verdadeiro para aquela criança (Silvares et al., 2006).

Essa lista de problemas de comportamento (CBCL) foi a primeira a ser elaborada por Achenbach, que se baseou nos primeiros estudos que desenvolveu no fim da década de 1960 e início dos anos 1970 (Achenbach, 1991). Diversas revisões foram feitas nos itens do questionário, sendo a atual versão (Achenbach; Rescorla, 2001) a terceira da série.

Por sua vez, o Inventário de Autoavaliação para Jovens é uma variação do CBCL/6-18, que utiliza um formato padronizado e foi elaborado para obter informações sobre o adolescente, a partir de seu próprio ponto de vista. A metodologia empregada para a elaboração desse inventário foi a mesma descrita para o CBCL e muitos itens são semelhantes nos dois instrumentos, o que facilita a comparação dos dados obtidos das duas fontes de informação (no caso, pais e/ou responsáveis e o próprio adolescente) (Achenbach, 1991; Achenbach; Rescorla, 2001).

O Inventário de Autoavaliação para Adolescentes é um questionário norteamericano de autoavaliação de comportamento para adolescentes (de 11 a 18 anos). Segundo Rocha e Silvares (2008), uma revisão da literatura indicou a ausência de validação desse instrumento no Brasil e a coexistência de duas traduções, aqui denominadas Formas A e B. Para superar tal dificuldade, visando a facilitar trabalhos futuros de validação, 90 adolescentes $(\mathrm{M}=13,12$; $\mathrm{DP}=0,805)$ de três cidades brasileiras preencheram sucessivamente as duas traduções: metade deles na sequência 
A-B e a outra metade na sequência B-A. Nas duas situações, os participantes fizeram um intervalo correspondente a uma aula antes de preencherem a segunda forma. Como resultado, não se encontraram diferenças estatisticamente significativas nas respostas dadas às duas formas, tendo sido o índice de correlação entre A e B alto para a maioria das escalas analisadas, indicando equivalência de conteúdo entre elas. Conclui-se, portanto, que o desejável é ter apenas uma forma em uso no Brasil, em função de os resultados terem demonstrado que as duas traduções são capazes de mensurar de maneira próxima os comportamentos propostos (Rocha; Silvares, 2008).

\section{Tipos de aplicação}

Dos 12 artigos encontrados sobre a aplicação do CBCL na área de abuso de substâncias em álcool e drogas em adolescentes, apenas 3 (25\%) eram referentes à previsão do uso de substâncias (Ferdinand et al., 2001; Creemers et al., 2009; Kornohen et al., 2010); todos os demais artigos (8 ou 75\%) eram referentes à prevalência e fatores de risco (Christensen; Bilenberg, 2000; Wall et al., 2000; Ferdinand et al., 2001; Ehlers et al., 2001; Salvo et al., 2005; Bordin et al., 2006; Furtado et al., 2006; Paula et al., 2007; Schmid et al., 2008; Ornoy et al., 2010; sendo que 4 dos 12 artigos encontrados se referiam a publicações de pesquisadores brasileiros (Salvo et al., 2005; Furtado et al., 2006; Bordin et al., 2006; Paula et al., 2007). 


\section{Aplicação do CBCL na identificação de comportamentos de risco e abuso de substâncias}

Em pesquisa realizada na Dinamarca, por Cristensen e Bilenberg (2000), foi aplicado o CBCL numa amostra de 103 crianças dinamarquesas, para uma população de geral de 780. As crianças alcoolistas tinham 17 dos 118 itens do CBCL. Em comparação à população de referência, as filhas de alcoolistas tinham maior grau de escores nas áreas de problemas internalizantes e depressão que os filhos. As crianças de pais alcoolistas também têm um grande risco (95\%) de comportamento internalizante, com sintomas depressivos e comportamento social desviante.

Wall et al. (2000) se valeram do CBCL para avaliar os problemas de comportamento em 96 filhos de indígenas e adolescentes em missões, baseados na presença ou ausência de dependência de álcool por parte dos pais e considerando também o sexo dos filhos. As descobertas sugerem que filhos de pais alcoólicos de índios em missões apresentam maiores problemas do que os filhos de pais indígenas não alcoólicos, porém os resultados também sugerem que os filhos de indígenas de missões não são mais vulneráveis a problemas de comportamento do que filhos de pais alcoólicos de outras origens étnicas.

Por sua vez, Ferdinand et al. (2001), na Holanda, investigaram a associação entre psicopatologias na adolescência e o uso de tabaco, álcool e outras drogas na juventude $(\mathrm{N}=787)$, utilizando o CBCL. A avaliação foi feita no início e em 2 followups, após 2 e 4 anos. As descobertas do estudo indicaram que os problemas na área do pensamento na escala do CBCL eram os principais fatores de predição do uso de 
álcool, enquanto a incidência do tabaco foi predita por problemas na área do pensamento e, também, na escala de comportamento delinquente.

Em pesquisa realizada por Ehlers et al. (2001), relata-se que os nativos americanos têm algumas das maiores taxas de abuso e dependência de álcool; no entanto, fatores de risco para o problema permanecem relativamente desconhecidos. A amplitude do componente P3 do potencial relacionado a eventos tem sido sugerida como um índice da "vulnerabilidade ao alcoolismo", especialmente quando é provocada por tarefas visuais em indivíduos mais jovens. Tarefas visuais P3, no entanto, não foram previamente investigadas em jovens nativos americanos.

Cento e quatro jovens da missão indiana, entre as idades de 7 e 13 anos, participaram do estudo. ERPs foram coletados através de dois paradigmas visuais: uma discriminação facial e uma estimativa da tarefa de orientação em linha. Análises de covariância revelaram que os participantes com história familiar de primeiro grau de alcoolismo tiveram menor amplitude do componente P3 nas derivações frontais para a tarefa de discriminação facial; já amplitudes P3 baixas, em áreas posteriores, foram encontradas na tarefa de discriminação de linha em crianças que tiveram pontuação acima de $75 \%$ em comportamentos delinquentes na aplicação do CBCL. Esses resultados são consistentes com as investigações em populações não indígenas, que demonstram que o componente final positivo do potencial de eventos relacionados é sensível à história familiar de dependência de álcool, assim como à história pessoal dos comportamentos exteriorizados.

No estudo de corte transversal realizado por Salvo et al. (2005), o modelo de Estilo Parental de Gomide é composto por sete práticas educativas avaliadas através de um Inventário de Estilos Parentais: cinco relacionadas ao desenvolvimento de 
comportamentos antissociais (abuso físico, punição inconsistente, disciplina relaxada, monitoria negativa e negligência) e duas favoráveis ao desenvolvimento de comportamentos pró-sociais (monitoria positiva e comportamento moral). O objetivo desse trabalho foi levantar quais práticas educativas poderiam ser preditoras de comportamentos listados pelo CBCL.

Participaram do estudo trinta crianças, com idades entre onze e treze anos, da rede pública de ensino, e um de seus pais. Dessa forma, todas as práticas encontradas como preditoras das subescalas do CBCL deveram-se a relações significativas entre elas. Os resultados apontaram para coeficientes de determinação variando de 0,16 a 0,72, ou seja, as práticas educativas explicaram de 16 a $72 \%$ da variância total das escalas e subescalas do CBCL.

Enquanto os coeficientes de regressão explicam a variância total, os coeficientes de regressão padronizados indicam a proporção em que as mudanças nas unidades de desvio padrão da variável preditiva afetam as mudanças no desvio padrão da variável dependente. Em suma, os resultados sugerem que determinadas práticas educativas podem predizer, significativamente, o comportamento da criança.

Já no estudo piloto realizado por Bordin et al. (2006), o objetivo foi estimar a prevalência de punição física grave de crianças/adolescentes em comunidade de baixa renda e examinar problemas de saúde mental nas crianças/adolescentes como um potencial fator associado. Esse trabalho é um estudo piloto brasileiro de corte transversal do World Studies of Abuse in Family Environments, tendo sido avaliada uma amostra probabilística de conglomerados, incluindo todos os domicílios elegíveis (mulheres de 15 a 49 anos, filho/filha menor de 18 anos). Ainda, uma dupla mãe-filho foi aleatoriamente selecionada por domicílio $(\mathrm{N}=89$; perda amostral $=11 \%)$. 
O desfecho clínico (punição física grave de crianças/adolescentes por mãe/pai) foi definido como sacudir/chacoalhar (se menor ou igual a 2 anos), chutar, esganar, sufocar, queimar, espancar ou ameaçar com arma, e três grupos de potenciais fatores associados foram examinados: criança/adolescente (idade, sexo, problemas de saúde física/mental); mãe (escolaridade, desemprego, problemas de saúde física/mental, punição severa na infância, violência conjugal); e pai (desemprego, embriaguez). Ainda, violência conjugal grave foi definida como chute, soco, espancamento ou uso/ameaça de uso de arma.

Os seguintes questionários padronizados foram aplicados por entrevistadores treinados: World Studies of Abuse in Family Environments Core Questionnaire, CBCL e SRQ-20, cujo resultado apresentou prevalência do desfecho clínico de 10,1\%. É importante notar que o ponto de corte utilizado nesse estudo para determinar os intervalos clínico e limítrofe do CBCL foi estabelecido de acordo com dados normativos americanos, pois não há dados brasileiros normativos disponíveis. No entanto, esse potencial problema é minimizado pela sensibilidade adequada do instrumento, quando comparado com o padrão-ouro diagnóstico psiquiátrico baseado na CID-10 e os critérios do DSM-IV.

Concluiu-se que a punição física grave de crianças/adolescentes era frequente na comunidade estudada, sendo que as vítimas tinham probabilidade aumentada de se tornarem futuras agressoras, visto que, quando ocorre violência intrafamiliar, a saúde mental das crianças e adolescentes pode estar comprometida.

Furtado et al. (2006), no Brasil, examinaram as diferenças de gênero na influência do alcoolismo paterno no desenvolvimento socioemocional das crianças e investigaram se o histórico de alcoolismo por parte dos pais é associado com um 
número maior de sintomas externalizantes nos filhos homens $(\mathrm{N}=219)$. Os resultados sugerem que diferenças de gênero parecem existir e contribuir para a diferença de tipos durante o desenvolvimento da criança e do adolescente.

Em outro estudo transversal, realizado por Paula et al. (2007), os principais objetivos eram estimar a prevalência de problemas de saúde mental em crianças e adolescentes com e sem prejuízo funcional global em comunidade urbana de baixa renda; estimar a capacidade de assistência da rede pública de serviços do município; e relacionar a capacidade de assistência à necessidade de tratamento em saúde mental da infância/adolescência.

Para tanto, participaram 479 crianças/adolescentes (de 6 a 17 anos, com perda amostral de 18,8\%), nas quais foram avaliados os problemas de saúde mental em crianças e adolescentes em nível clínico pela escala total de problemas da CBCL e/ou YSR. Como resultado, foi encontrada prevalência de problemas de saúde mental em crianças e adolescentes: 24,6\% (20,7-28,5), desconsiderando prejuízo funcional global; e 7,3\% (5,0-9,6), com prejuízo funcional global (casos que necessitam de tratamento). Ressalte-se que a capacidade anual de assistência dos casos com prejuízo funcional global é de $14 \%$ da demanda encontrada, sendo necessários cerca de sete anos para que todos possam ser tratados.

Assim, as conclusões apontaram que problemas de saúde mental em crianças e adolescentes são frequentes na comunidade estudada e que a infraestrutura atual da rede pública de serviços do município não está preparada para atender em tempo hábil aos casos que necessitam de tratamento.

Por sua vez, Schmid et al. (2008), na Alemanha, avaliaram a prevalência de sintomas emocionais e comportamentais e de doenças mentais em uma população de 
residential care $(\mathrm{N}=689$, idade entre 4 e 18 anos; média 14,4; $\mathrm{DP}=2,9)$, usando o CBCL. As conclusões indicaram que crianças e adolescentes em programas sociais e residenciais são uma população de alto risco e negligenciada, e que há a necessidade de prestar serviços psiquiátricos diagnósticos adequados, bem como tratamento multimodal para esse grupo.

O estudo realizado por Creemers et al. (2009) menciona que o aumento do conhecimento sobre os mecanismos pelos quais alguns indivíduos estão em risco de início precoce do consumo de maconha pode contribuir para a melhoria dos esforços de prevenção. Para tanto, o estudo concentrou-se sobre o papel no início da adolescência, o prazer de alta intensidade, o comportamento indisciplinado e sua interação na previsão de início de consumo de maconha dois anos mais tarde.

Foi analisada a vida de indivíduos, uma amostra de $81 \%(\mathrm{~N}=1.804)$ dos participantes (51,9\% meninas), do Adolescent Tracking Survey, um estudo populacional prospectivo geral, no norte da Holanda. As medidas incluídas foram os relatos dos pais de alta intensidade, prazer e pai e autorrelato do comportamento indisciplinado, hiperatividade, déficit de atenção, problemas de oposição e problemas de conduta; foram aplicados os instrumentos CBCL: 6-18 anos e YSR com idades entre 10-12. O início do uso de maconha foi avaliado na faixa etária de 12 a 14 anos, por meio de autorrelatos. As análises foram realizadas em Mplus. Os resultados do estudo apontam que a satisfação de alta intensidade na adolescência e os comportamentos indisciplinados, principalmente problemas de conduta e, em alguns, de déficit de atenção e hiperatividade, preveem o início do consumo da maconha na adolescência. Embora não tenhamos encontrado alguma medição para um comportamento perturbador geral, problemas de conduta, hiperatividade e déficit de 
atenção, a contribuição da alta intensidade do prazer na previsão do início do uso de maconha foi encontrada como sendo essencialmente independente do comportamento indisciplinado. Os autores concluem que a contribuição única de prazer de alta intensidade e os pontos de comportamento indisciplinado estão em caminhos diferentes para o início do uso de maconha.

Segundo a pesquisa realizada por Ornoy et al. (2010), a exposição pré-natal à heroína pode ter consequências a longo prazo para o desenvolvimento durante a infância e adolescência. A presente pesquisa estudou o desenvolvimento cognitivo, social e o funcionamento emocional de adolescentes expostos a drogas no pré-natal, e investigou em que medida a adoção precoce de crianças expostas pré-natal a drogas aliviaria os possíveis efeitos da exposição.

Métodos: O estudo incluiu 191 adolescentes (12-16 anos de idade) e seus pais em Israel, que tinham ou não sido expostos às drogas durante o pré-natal, de diferentes estados socioeconômicos e status adotivo. Os pais foram submetidos ao CBCL para avaliar problemas de comportamento, ao Conners Rating Scale (CRS) para avaliação do déficit de atenção em suas crianças e ao Wender Utah Rating Scale (WURS), uma medida de autorrelato de problemas relacionados com o TDAH.

Os adolescentes expostos a pelo menos um fator de risco (exposição a drogas, baixa classe econômica) foram piores do que aqueles expostos a nenhum desses fatores de risco, nos subtestes do WISC-III, no CBCL e no CRS. Os efeitos de fatores de risco não se acumulam. Contrariamente à nossa hipótese, a adoção não atenuou os efeitos da exposição pré-natal a drogas: para exposição a drogas o funcionamento cognitivo foi associado ao pior desempenho entre os expostos a Alto SES versus não expostos a Alto SES não adotaram crianças. A conclusão do estudo aponta que as crianças 
expostas a drogas de abuso pré-natal, incluindo as adotadas para longe, e as crianças que crescem em contextos de NSE baixo podem estar em risco relativamente reduzido do funcionamento cognitivo (embora ainda dentro do intervalo normal) na adolescência. As crianças expostas às drogas, que são de origens de NSE baixo, ou que são adotadas, podem estar em risco de menor funcionamento cognitivo e social do que crianças que não sofreram tais riscos.

Implicações práticas: Há a necessidade de um acompanhamento precoce e de longo prazo dos programas de intervenção, com o incentivo de habilidades cognitivas e sociais para crianças pré-natal expostas a drogas, para aliviar os possíveis efeitos de longo prazo da exposição ao risco, pois apresenta as intercorrelações entre as dependentes variáveis. Os resultados indicam que os problemas de comportamento mensurados pelo CBCL e CRS estão altamente correlacionados nessa amostra $(r=0,63)$. A pontuação para as medidas das crianças e de pais de TDAH mostram uma correlação significativa, $r=0,26$.

Na pesquisa realizada por Korhonen et al. (2010) com o objetivo de analisar problemas de externalização de comportamento e consumo de cigarros como preditores do consumo de maconha subsequentes em adolescentes holandeses $(\mathrm{N}=1.606,854$ meninas e 752 meninos), as vidas individuais do Adolescent Tracking Survey, estudo longitudinal em andamento, foram examinadas no início do estudo (idade 10-12(T1) e em duas avaliações de acompanhamento (Método: idades 12-15(T2) e 15-18(T3). A análise centrou-se no DSM-IV para avaliar os comportamentos externalizantes (conduta, hiperatividade, déficit de atenção e de oposição); a partir da constatação de problemas em T1, foram avaliados pelo YSR e CBCL e autorrelataram nunca fumar em T2 e sobre o consumo de cannabis em T3. Os resultados mostraram que todas as associações de 
pais e problemas de comportamento exteriorizado avaliado com maconha foram mediadas pelo hábito de fumar mais cedo. Considerando os problemas de autorrelatados, nenhuma dessas associações com maconha foram mediadas pelo fumo, exceto a influência de problemas de conduta autorrelatada em meninas. Curiosamente, mesmo após o ajuste para problemas de externalização, começaram a fumar mais precocemente e de forma consistente, independentemente de previsto o uso de maconha. $\mathrm{O}$ odds ratio ajustado para o tabagismo variou em meninos 4,8-5,2 (sempre), 10-12 (diário) e 22-23 (precoce), enquanto que as meninas 4,9-5,0, 5,6-6,1, e 27-28, respectivamente ( $\mathrm{p}<0,001$ para todos). Em suma, os resultados desafiam a visão de que problemas de comportamento exteriorizado diretamente prevê o início da maconha. Essas associações foram inconsistentes entre informantes e os sexos e muitas vezes eram mediadas por fumar mais cedo. O início precoce do tabagismo é um poderoso preditor de início mais tarde de maconha, independentemente do anterior problema de comportamento exteriorizado. Embora os problemas de comportamento exteriorizado são importantes como ponto de partida para a trajetória de uso de substâncias, o fumo precoce deve ser identificado como um importante marcador de risco de uso de substâncias.

\section{Dados do autor do instrumento}

O psiquiatra Dr. Thomas Achenbach desenvolveu uma série de questionários que avalia o funcionamento, comportamento, problemas emocionais e competências de crianças e adolescentes. ASEBA: mail@ aseba.org e www.aseba.org. 


\section{Informações do pesquisador que validou o instrumento para o Brasil}

A Profa. Dra. Isabel Altenfelder Santos Bordin possui graduação em Medicina pela Universidade Federal de São Paulo (1979), mestrado em Psiquiatria pela Universidade Federal de São Paulo (1992), mestrado em Medical Sciences no Canadá McMaster University (1994) -, e doutorado em Psiquiatria pela Universidade Federal de São Paulo (1996). É psiquiatra da infância e adolescência e chefe do Setor de Psiquiatria Social da Universidade Federal de São Paulo (desde 1999). É pesquisadora e membro do International Clinical Epidemiology Network (INCLEN) desde 1994. Suas pesquisas concentram-se na área de saúde mental da infância e adolescência e envolvem os seguintes temas: epidemiologia clínica, prevalência, fatores de risco, desenvolvimento e validação de questionários, violência doméstica, comportamento antissocial e gravidez na adolescência.

A Tabela 18 apresenta uma síntese comparativa entre os três instrumentos pesquisados e avaliados. 
Tabela 18 - Resumo dos instrumentos pesquisados e avaliados - versões brasileiras.

\begin{tabular}{|c|c|c|c|c|c|c|c|}
\hline $\begin{array}{c}\text { Instrumento e } \\
\text { População }\end{array}$ & Objetivo & Utilidade & Local & Formato & $\begin{array}{l}\text { Tempo de } \\
\text { Aplicação }\end{array}$ & $\begin{array}{c}\text { Treinamento e } \\
\text { Investimento }\end{array}$ & $\begin{array}{c}\text { Medidas de } \\
\text { Desempenho }\end{array}$ \\
\hline $\begin{array}{l}\text { DUSI-R } \\
\text { Adolescentes } \\
\text { de } 12 \text { a } 19 \text { anos. }\end{array}$ & $\begin{array}{l}\text { Triagem para uso } \\
\text { de substâncias. } \\
\text { Gravidade dos } \\
\text { problemas e outras } \\
\text { áreas relacionadas. }\end{array}$ & $\begin{array}{l}\text { Triagem. } \\
\text { Seguimento de } \\
\text { avaliação após } \\
\text { intervenção preventiva } \\
\text { ou terapêutica. } \\
\text { Des. programas. }\end{array}$ & $\begin{array}{l}\text { Ambulatórios } \\
\text { gerais, clínicas de } \\
\text { tratamento para } \\
\text { abuso de } \\
\text { substâncias, escolas } \\
\text { e levantamento } \\
\text { epidemiológico. }\end{array}$ & $\begin{array}{l}\text { Questionário de } \\
\text { autopreenchimento } \\
\text { ou entrevista } \\
\text { (149 perg.). } \\
\text { Formato reduzido } \\
\text { (15 perg.). }\end{array}$ & $\begin{array}{l}\text { De } 5 \text { a } 40 \\
\text { minutos. }\end{array}$ & $\begin{array}{l}\text { Não específico. } \\
\text { Necessária a } \\
\text { familiaridade c/ } \\
\text { instrumento. } \\
\text { Domínio público. }\end{array}$ & $\begin{array}{l}\text { Sensibilidade } \\
80 \% \text {. } \\
\text { Especificidade } \\
90 \% .\end{array}$ \\
\hline $\begin{array}{l}\text { Teen ASI } \\
\text { Adolescentes } \\
\text { de } 12 \text { a } 19 \text { anos. }\end{array}$ & $\begin{array}{l}\text { Avaliar uso de } \\
\text { substâncias e outras } \\
\text { áreas da vida. }\end{array}$ & $\begin{array}{l}\text { Avaliação. } \\
\text { Auxilia no } \\
\text { planejamento do } \\
\text { tratamento. } \\
\text { Acompanhamento } \\
\text { do paciente. } \\
\text { Avaliação do } \\
\text { tratamento no fim da } \\
\text { intervenção. }\end{array}$ & $\begin{array}{l}\text { Ambulatórios e } \\
\text { clínicas de } \\
\text { tratamento para o } \\
\text { abuso de } \\
\text { substâncias. }\end{array}$ & $\begin{array}{l}\text { Entrevista } \\
\text { semiestruturada } \\
\text { (153 perg.). }\end{array}$ & $\begin{array}{l}\text { De } 26 \text { a } 65 \\
\text { minutos. }\end{array}$ & $\begin{array}{l}\text { Necessário } \\
\text { treinamento. } \\
\text { Domínio público. }\end{array}$ & $\begin{array}{l}\text { Curva de ROC } \\
0,88 \text {. }\end{array}$ \\
\hline $\begin{array}{l}\text { CBCL } \\
\text { Crianças e } \\
\text { adolescentes } \\
\text { de } 4 \text { a } 18 \text { anos. }\end{array}$ & $\begin{array}{l}\text { Avaliar e identificar } \\
\text { problemas de } \\
\text { comportamento e } \\
\text { competência social. } \\
\text { Respondidos pelos } \\
\text { pais ou } \\
\text { responsáveis. }\end{array}$ & $\begin{array}{l}\text { Triagem e } \\
\text { rastreamento. } \\
\text { Des. programas. }\end{array}$ & $\begin{array}{l}\text { Ambulatórios } \\
\text { gerais, ambulatórios } \\
\text { e clínicas em saúde } \\
\text { mental, escolas e } \\
\text { levantamento } \\
\text { epidemiológico. }\end{array}$ & $\begin{array}{l}\text { Entrevista } \\
\text { (118 perg.). }\end{array}$ & 15 minutos. & $\begin{array}{l}\text { Não específico. } \\
\text { Necessária a } \\
\text { familiaridade c/ } \\
\text { instrumento. } \\
\text { Valor: } 50 \\
\text { conjuntos por } \\
\$ 25,00 \text {. }\end{array}$ & $\begin{array}{l}\text { Sensibilidade } \\
87 \% \text {. }\end{array}$ \\
\hline
\end{tabular}




\section{DISCUSSÃO}

Foram encontrados 54 artigos referentes à aplicação dos três instrumentos com adolescentes usuários de álcool e outras drogas, sendo que o instrumento com maior número de artigos foi o DUSI-R, com 30 artigos dos 54 encontrados $(55,6 \%)$, seguido do Teen ASI com 12 artigos (22,2\%) e, por fim, do CBCL com 12 artigos (22,4\%). Como todos os instrumentos foram desenvolvidos na década de 90, pode-se afirmar que há uma maior utilização do DUSI-R.

As publicações de validação dos instrumentos apresentaram uma boa qualidade, sendo que não foram encontrados questionamentos na literatura quanto às metodologias de validação utilizadas, com exceção do CBCL (Rocha; Silvares, 2008). Por outro lado, Silvares et al. (2006) encontraram resultados semelhantes ao estudo de validação do CBCL de Bordin et al. (1995) quanto à distribuição dos perfis e queixas principais.

Marques (2004) ressalta que, para melhorar a capacidade de realizar um diagnóstico, é feita a aplicação de questionários ou escalas, sendo que a literatura científica a esse respeito comprova que o relato dos jovens sobre o uso de drogas é geralmente confiável, desde que estabelecido um clima de confiança. Para usá-los, fazse necessário não só traduzi-los, mas adaptá-los e modificá-los segundo as necessidades e especificidades do público-alvo.

O DUSI-R é utilizado para medições da situação atual, identifica áreas com necessidade de prevenção e faz a avaliação da magnitude da mudança antes de uma intervenção/tratamento. Esse instrumento é voltado para usuários de álcool e outras drogas que se tem conhecimento ou suspeita, e identifica jovens que necessitem de 
programas de prevenção (Tarter, 1990). O DUSI-R mede a gravidade de problemas em 10 áreas, fornecendo um perfil de intensidade de problemas relacionados 1) ao uso de substâncias; 2) ao comportamento; 3) à saúde; 4) aos transtornos psiquiátricos; 5) à sociabilidade; 6) ao sistema familiar; 7) à escola; 8) ao trabalho; 9) ao relacionamento com amigos; e 10) ao lazer/recreação (Tarter, 1990). Contém 149 perguntas ao longo das 10 escalas (Tarter, 1990).

Embora o DUSI-R seja um bom instrumento de identificação de comportamentos de risco para o abuso de álcool e outras drogas em adolescentes, dando subsídios para a elaboração de programas de prevenção e também para a realização de triagens em ambientes de tratamento, ele não é o instrumento mais adequado para traçar um plano de tratamento mais específico, sendo necessária a aplicação de outras escalas voltadas para o diagnóstico do uso de substâncias e transtornos psiquiátricos (Kirisci et al., 2008). Por outro lado, além de identificar os problemas de saúde, comportamentos e problemas sociais, o DUSI-R tem utilidade prática para determinar se um exame de diagnóstico psiquiátrico mais completo é recomendável, antes de implementar programas de prevenção ou tratamento (Kirisci et al., 2008). O DUSI-R pode ser útil também para auxiliar no diagnóstico e no desenvolvimento de programas de prevenção, tal como para o TDAH, a exemplo do estudo de Tarter et al. (2007) nos Estados Unidos, que aplicaram o DUSI-R, após a sua adaptação, para avaliar a relação entre a hiperatividade e o uso de substâncias em jovens.

O Teen ASI é uma entrevista semiestruturada para a avaliação periódica de adolescentes com abuso de substâncias. Seu objetivo é avaliar o perfil de gravidade do uso de substâncias em adolescentes, bem como problemas em outros aspectos de sua 
vida. Utiliza uma abordagem multidimensional de validação e é uma modificação do ASI, versão para adultos.

Uma das áreas que o Teen ASI não avalia é o comportamento sexual de risco em adolescentes e a exposição à contaminação por doenças sexualmente transmissíveis e HIV/AIDS. Essa avaliação pode ser complementada pela aplicação de questionários específicos.

Embora o Teen ASI não avalie diretamente a influência do temperamento do paciente na resposta ao tratamento, o estudo de Burleson e Kaminer (2008) utiliza três dimensões do instrumento - uso de álcool, uso de outras substâncias e função psicológica -, quando os pesquisadores aplicaram o instrumento DOTS-R, desenvolvido por Windle e Lerner (1986).

No estudo de validação da versão brasileira, Sartes et al.(2009) ressaltam que para a validação das outras áreas do Teen ASI são necessários mais estudos para esclarecer a influência de etnia e de gênero no desempenho da avaliação das demais áreas do Teen ASI.

O CBCL é um instrumento de triagem e rastreamento que não substitui o diagnóstico médico. O principal objetivo é identificar problemas de saúde mental em crianças e adolescentes, sendo que na versão brasileira é voltado para faixa etária de 418 anos. Paula et al. (2007) apontam que os questionários utilizados, incluindo o CBCL, para avaliar a saúde mental na amostra de 479 crianças e adolescentes, são os mais utilizados em estudos internacionais de base populacional, e são amplamente recomendados para comparações transculturais. No entanto, é importante salientar que esses instrumentos identificam os casos com sintomas elevados sem estabelecer um diagnóstico psiquiátrico. 
O CBCL foi elaborado para avaliar problemas de comportamento e competências sociais em crianças e adolescente, a partir do relato dos pais, responsáveis ou professores. O CBCL também pode ser usado para medir a mudança de comportamento de uma criança ao longo do tratamento ou pós-tratamento.

\subsection{DUSI-R - vantagens e limitações encontradas nos estudos}

Uma das vantagens do DUSI-R é a sua disseminação internacional, sendo que está disponível atualmente em 15 línguas. A utilização do instrumento em vários países pode ser um sinalizador da sua aceitação em diferentes países, e é útil do ponto de vista de comparações entre diferentes contextos.

No período analisado por este estudo (janeiro de 1998 a agosto de 2010), foram encontrados $30(55,4 \%)$ estudos sobre o DUSI-R para adolescentes, aplicados em 14 países e também na América Central. A grande maioria dos estudos foi feita no continente americano, sendo que apenas 2 estudos foram encontrados fora desse continente - no Quênia (África) e na Nova Zelândia (Oceania).

Os anos de maior número de publicações foram entre 2002 e 2004, que totalizaram um número de $16(53,3 \%)$ publicações, do total das 30 encontradas. O Brasil foi um dos primeiros países a validar o DUSI-R (De Micheli; Formigoni, 2000), embora essa validação tenha sido feita apenas cerca de uma década após a validação americana. Os países onde foi encontrado um maior número de publicações foram os Estados Unidos (8), Brasil (6) e México (5).

Outro ponto que merece atenção é relacionado às propriedades psicométricas. A validação americana reportou um Alfa de Cronbach para uso de substâncias de 0,87 
e 0,88 , respectivamente, para o sexo masculino e feminino (Tarter et al., 1994), o que demonstra uma boa consistência interna do instrumento.

Ainda a seu favor foi demonstrada uma boa validade concorrente e de constructo, apontando o instrumento como de alta confiabilidade (Tarter et al., 1994; Amesty, 1996; De Micheli; Formigoni, 2002; Aytaclar et al., 2003; Negrete et al., 2006).

De Micheli e Formigoni (2000) realizaram a tradução, adaptação e validação do DUSI para o Brasil, concluindo que esse instrumento pode ser útil na triagem do uso de substâncias entre adolescentes brasileiros. De Micheli e Formigoni (2002) observaram que, nas respostas afirmativas na área do uso de substâncias, o DUSI-R apresentou $80 \%$ de sensibilidade e $90 \%$ de especificidade com uma taxa de acerto de $83,6 \%$ para a totalidade da amostra. A área sob a curva de ROC foi de 0,93 , o que demonstrou um bom desempenho global na área do uso de substâncias.

A validação para a Turquia (Aytaclar et al., 2003) também apresentou bons resultados, sendo que para a linha de corte de gravidade de $35 \%$ na pontuação geral de densidade do problema classificou corretamente $83 \%$ dos indivíduos com sensibilidade de $80 \%$ e especificidade de $87 \%$. Uma das diferenças entre a versão americana e a versão para a Turquia é que 33 itens foram eliminados da versão original, porque não eram apropriados para a população de adolescentes turcos. $\mathrm{O}$ artigo analisado não cita quais foram esses itens excluídos. Além disso, os entrevistados foram perguntados sobre o seu envolvimento com a justiça criminal.

Para o contexto Mexicano, Negrete et al. (2006) adaptaram o DUSI-R para a aplicação com adolescentes mexicanos $(\mathrm{N}=1.983)$, com idade média de 15,7 anos (desvio padrão: 1.4). O projeto consistiu na adaptação ao espanhol usual no México e 
foi comparada com o original em inglês, e com outras versões em espanhol, a qual recebeu sugestões de especialistas da área, sendo depois submetida a um piloto com estudantes e posteriormente feitos os ajustes pertinentes. Foram omitidas as escalas de "desempenho no trabalho" e "estado de saúde". A escala de "disfuncionalidade familiar" foi reestruturada em sua maioria, devido à baixa confiabilidade da versão original ao ser aplicada a estudantes (Rodríguez et al., 1999). Portanto, a versão utilizada foi composta de 87 perguntas, que registraram parâmetros adequados de confiabilidade e validade (Negrete et al., 2008).

A consistência interna geral do DUSI-R para o México teve como Alfa de Cronbach um resultado de 0,9451 , enquanto as escalas correspondentes para a maioria dos fatores registraram escores de confiabilidade superiores a 0,8 (Negrete et al., 2006).

Se por um lado as validações para os diferentes países (Estados Unidos, Brasil, Turquia e México) apresentaram bons resultados, por outro é importante observar que as validações para a Turquia e México têm um escopo diferente das validações para Estados Unidos e Brasil, o que pode se constituir em um ponto negativo em relação à comparação de resultados entre os diferentes países.

Outra vantagem do DUSI-R é o seu formato, sendo de simples aplicação, do tipo de autopreenchimento; entrevista; ou autopreenchimento no computador. A aplicação é feita pelo entrevistador ou pela própria pessoa e não há necessariamente necessidade de treinamento (Tarter, 1990).

Além disso, outro ponto favorável é o baixo custo, pois o DUSI-R não tem um custo direto de aplicação (é de domínio público), apenas um custo indireto, representado pelo tempo dos profissionais. 
Alguns autores avaliaram aspectos de resposta dos instrumentos, quanto ao mentir no seu preenchimento e também quanto aos efeitos da identificação do sujeito versus o anonimato dos adolescentes. Os resultados encontrados por Dalla-Déa et al. (2004) indicam que, em princípio, não há a necessidade da aplicação da escala de mentira do referido instrumento.

Outra vantagem do DUSI-R é a sua utilidade para a formulação de políticas públicas de álcool e outras drogas, com uma abordagem mais ampla do que apenas a disponibilização de informação sobre os efeitos nocivos do uso de substâncias, iniciando em uma idade mais cedo e avaliando não só os alunos, como também os pais.

Segundo De Micheli et al. (2004), a aplicação do DUSI-R contribui para a formulação de programas de intervenção preventiva em escolas. Uma das recomendações no estudo é que o planejamento e a execução de programas de prevenção devem ser mais abrangentes, em vez de focados apenas na informação sobre drogas.

A recomendação de Jinez et al. (2009) é a realização de mais avaliações do uso de substâncias entre os adolescentes e a implementação de intervenções preventivas em escolas, devido ao contato e uso de drogas cada vez mais cedo nos jovens. Uma das observações do estudo é que é importante avaliar o uso de drogas por parte dos pais ou dos adultos responsáveis (o que não foi avaliado no caso, por não ser o objeto do estudo). $\mathrm{O}$ argumento para isso é que os adolescentes necessitam de apoio, orientação e direção para facilitar o seu desenvolvimento e a sua capacidade de enfrentar, resistir e se recuperar de situações de risco (López; Costa, 2008). Uma oportunidade aqui pode ser a de avaliar o uso de substâncias por parte dos professores e demais profissionais 
da escola, e a sua influência no comportamento dos jovens. Uma das implicações que podem ser feitas do estudo de Fraile Duvicq et al. (2004) é que, devido ao fato dos adolescentes estarem iniciando o consumo de drogas cada vez mais cedo (11 anos, no caso estudado) e estar aumentando a prevalência do uso, é de extrema importância a realização de pesquisas e avaliações junto a estudantes, começando na idade da préadolescência.

Figlie et al. (2004), quando conduziram a avaliação de um serviço de saúde, também apresentaram uma conclusão na área de políticas públicas, recomendando que havia a necessidade de um serviço especializado de prevenção seletiva dirigido a crianças, adolescentes e familiares afetados pela dependência química, uma vez que os filhos de dependentes químicos representam um grupo de risco para o desenvolvimento de problemas biopsicossociais.

De maneira geral, pode-se observar que o uso do DUSI-R foi adequado para identificar o grupo de adolescentes que consome drogas, ou seja, que apresenta prevalência do uso de substâncias, identificando inclusive o tipo de droga utilizado, bem como as pessoas ou grupos que apresentam fatores de risco maiores do que o grupo de não usuários, ou indivíduos. Observa-se, portanto, que a aplicação do DUSI$\mathrm{R}$ contribui para a formulação de programas de intervenção preventiva em escolas. Os estudos encontrados foram com avaliações com os adolescentes, mas não foram encontrados estudos com os pais, responsáveis ou professores.

O autor do instrumento (Tarter, 1990) defende que uma das vantagens do DUSI-R é a sua aplicação rápida. Porém, na revisão dos artigos, foi identificado que uma das desvantagens do DUSI-R é o seu tempo de aplicação. Na pesquisa realizada 
no México por Jinez et al. (2009), usando a versão brasileira do DUSI-R adaptada para o espanhol, o tempo de aplicação variou de 30 a 40 minutos, de maneira autoaplicável. Visando a uma aplicação mais breve do DUSI-R, foram desenvolvidas versões reduzidas do instrumento no Chile (Fraile Duvicq et al., 2004) a partir do trabalho iniciado na Costa Rica (Murrelle et al., 1977).

No Brasil, Sartes e De Micheli (2008) já haviam identificado que, em situações de triagem, os profissionais preferem utilizar somente a tabela inicial do DUSI-R, que identifica a frequência do uso de substâncias no último mês, além das 15 questões da área 1, referente ao uso de substâncias, que é uma versão reduzida do DUSI-R, ao invés do questionário completo com 149 questões.

A partir daí, Fidalgo et al. (2010) conduziram a validação de uma versão reduzida do DUSI-R, que é um questionário de autorresposta com 15 questões, que avaliam a escala de uso de substâncias. Esse estudo é uma continuidade da pesquisa realizada em uma população americana para determinar se a escala de abuso de substâncias do DUSI-R discrimina jovens brasileiros em tratamento $(\mathrm{N}=41)$ de uma amostra da população em geral $(\mathrm{N}=43)$.

Ambos os estudos de versões reduzidas do DUSI-R (Chile e Brasil) concluíram que as escalas reduzidas de abuso de substâncias são válidas para triagem de jovens. Uma diferença entre as duas versões é que a versão brasileira apresenta um número menor de questões (15), diante das 48 questões da versão chilena.

Na versão chilena (Fraile Duvicq et al., 2004), para medir a confiabilidade do instrumento em sua totalidade e de cada uma das escalas, foi aplicado o coeficiente Alfa de Cronbach, que resultou em uma escala global altamente confiável $(0,91)$, o que se traduziu em alta consistência e homogeneidade. 
Na versão brasileira a pontuação média na escala de 15 itens para o abuso de substâncias no grupo de tratamento foi de 6,7 , contra 1,9 no grupo de comparação $(\mathrm{t}=$ $6,78, \mathrm{p}<0,001)$. A melhor nota de corte de duas avaliações positivas apresentou sensibilidade de $85 \%$ e especificidade de $70 \%$. Uma possível limitação da validação para o Brasil é o tamanho relativamente pequeno da amostra $(\mathrm{N}=41)$, que pode ter diminuído a acurácia da análise da sensibilidade e especificidade (Fidalgo et al., 2010).

A principal vantagem do desenvolvimento das escalas reduzidas é o menor tempo de aplicação (cerca de 5 minutos), diante do tempo aplicação maior do questionário completo (de 20 a 40 minutos) (Fraile Duvicq, 2004; Fidalgo et al., 2010).

Do ponto de vista da aplicação, Tarter (1990) defende que o DUSI-R é um instrumento útil na triagem para identificar os casos com abuso de álcool e outras drogas, auxiliando na avaliação em 10 áreas da vida do indivíduo e contribuindo para o monitoramento do tratamento e na avaliação pós-intervenção. Tarter e Kirisci (2001) defendem a aplicação do DUSI-R em pesquisa, na quantificação da gravidade em 10 áreas, em estudos sobre heterogeneidade dos subtipos, em alinhamento da avaliação do paciente com o plano de tratamento, e em levantamentos epidemiológicos e avaliação das necessidades.

A revisão dos artigos confirmou que o DUSI-R demonstrou boa flexibilidade, sendo que a grande maioria dos artigos encontrados sobre a utilização do DUSI-R foi em estudos de prevalência e fatores de risco, onde foram encontrados 16 estudos (62\% dos 26 estudos de aplicação). As outras aplicações encontradas foram: avaliação de intervenções $(4,15 \%)$; previsão de uso de substâncias $(1,4 \%)$; e aplicação em conjunto com outros instrumentos $(5,19 \%)$. Observa-se, portanto, uma baixa utilização do DUSI-R na avaliação de intervenções. 
Do ponto de vista do contexto das aplicações, excluindo os quatro artigos sobre a validação do DUSI-R, ficaram 26 artigos, sendo que a maioria das aplicações foi na área da pesquisa $(9,34,6 \%)$, empatados com a aplicação em escolas $(9,34,6 \%)$. A aplicação em ambientes de serviços ambulatoriais foi em número menor $(3,11,5 \%)$, sendo que, por fim, foram encontradas cinco aplicações $(19,2 \%)$ em diferentes ambientes de outros serviços. Dos instrumentos estudados, o DUSI-R foi o que apresentou o maior número de aplicações em escolas (9). Em relação ao tamanho das amostras estudadas, o DUSI-R se caracterizou por amostras maiores, com algumas aplicações na faixa de milhares de unidades, como o trabalho de De Micheli et al. (2004), que avaliou 6.417 adolescentes.

\subsection{Teen ASI - vantagens e limitações encontradas nos estudos}

A pesquisa sobre a revisão das validações do Teen ASI ao redor do mundo realizada por Kaminer (2008) recomenda que o trabalho clínico de competência necessita ser precedido de uma avaliação efetiva, que inclui o desenvolvimento adequado com escalas padronizadas e testadas psicometricamente.

O país com maior número de publicações do Teen ASI foi os Estados Unidos, contendo nove publicações ao todo (75\%), sendo uma delas referente à avaliação da disseminação internacional do Teen ASI. O país com maior número de publicações fora dos Estados Unidos foi a Espanha, tendo duas publicações (17\%), seguido do Brasil, com uma publicação (8\%). O ano com maior número de publicações foi 2008 , com quatro avaliações nos Estados Unidos (sendo que uma delas internacional) e uma avaliação na Espanha. 
Quanto aos países de aplicação dos 12 artigos selecionados, apenas um se refere ao contexto brasileiro, que é o estudo de Sartes et al. (2009) que se refere à validação do Teen ASI para a língua portuguesa para o Brasil. Observa-se, portanto, que não há no Brasil estudos que utilizaram o Teen ASI para avaliação de abordagens terapêuticas ou mesmo de serviços. Também não há validações do Teen ASI para versões via telefone e internet, a exemplo da validação americana de Brodey et al. (2005).

A validação da versão americana apresentou uma confiabilidade interna com $r$ $=0,78$ ao longo das escalas, enquanto que, em relação ao uso de substâncias, a confiabilidade foi de $\mathrm{r}=0,85$ (Kaminer et al., 1991). A revisão da literatura demonstrou que o Teen ASI apresentou boas propriedades psicométricas, constituindose em um instrumento válido e confiável para aplicação.

A validação da versão espanhola demonstrou boas propriedades psicométricas com adolescentes de língua espanhola que apresentam transtornos psiquiátricos (Díaz et al., 2008). A escala do uso de substâncias teve uma correlação significativa (Rho = 0,90; $\mathrm{p} \leq$ 0,01), com uma medida de "padrão de uso de alguma substância", e com “problemas subjetivos com drogas" (rank 0-32) (Rho =0,69, p $\leq 0,01)$. Todas as escalas, com exceção da escala de situação psiquiátrica, apresentaram significantes correlações com as escalas externas do Teen ASI, e também apresentaram discriminação entre os pacientes com e sem problemas com o abuso de substâncias.

A versão brasileira do Teen ASI de Sartes et al. (2009) demonstrou boa validade e pode ser um instrumento útil para avaliar a gravidade do uso de substâncias e outros problemas associados em adolescentes. Foi encontrada uma boa correlação entre o CIDI, usado como "padrão-ouro", e a severidade $(r=0,73)$ e composto $(r=$ 
0,72). A área sobre a curva de ROC foi de 0,88 , mostrando uma taxa de classificação satisfatoriamente correta. A consistência interna, avaliada pelo coeficiente Alfa de Cronbach, foi considerada boa, em relação ao uso de substâncias $(0,89)$, aspectos legais $(0,81)$ e aspectos psiquiátricos $(0,80)$. A versão brasileira do Teen ASI apresentou boa consistência interna na área do uso de substâncias válida.

Outro ponto positivo do Teen ASI é o fato de não ter custo de aplicação, por ser de domínio público, demandando, porém, o tempo dos profissionais.

Uma das características do Teen ASI é que, por ser uma entrevista semiestruturada, requer que os entrevistadores tenham alguma formação em avaliação e na aplicação do instrumento, sendo necessário ter flexibilidade, se o adolescente inicialmente demonstrar resistência à fornecer as informações válidas ou se este não entender claramente as perguntas (Winters; Kaminer, 2008). Antes da aplicação do Teen ASI, é necessária a aplicação de um questionário que identifique o uso de substâncias, como, por exemplo, o DUSI-R (Winters; Kaminer, 2008). A análise dos resultados é simples.

Uma desvantagem do Teen ASI é o tempo de aplicação das 154 questões do instrumento, que em torno de 45 a 60 minutos.

Diante do problema do tempo de aplicação, no estudo de validação da versão brasileira Sartes et al. (2009) propõem uma versão menor de 60 questões, para diferenciar usuários de não usuários. Não foram encontrados, porém, estudos de validação dessa versão reduzida para o Brasil.

Para o contexto americano, Brodey et al. (2005) converteram o Teen ASI para um formato autoaplicável via internet ou usando uma entrevista por telefone gravada, contendo de 68 a 215 itens. A versão via internet levou em média 25 minutos para ser 
completada, enquanto que a versão automatizada por telefone levou em média 18,5 minutos para ser completada. Uma ressalva a ser feita é que os participantes da pesquisa receberam voucher pela sua participação, embora não fossem obrigados a completar todo o questionário.

Essas versões são compatíveis com a necessidade dos serviços que trabalham com um grande número de adolescentes. A comparação entre os índices obtidos na avaliação feita por clínicos e na avaliação autoaplicável apresenta resultados consistentes para internet (confiabilidade média $=.74$ e desvio padrão $=.14$ ) e telefone (confiabilidade média $=.72$ e desvio padrão $=.16$ ). Essas descobertas sugerem que a aplicação do Teen ASI de forma automatizada é valida e potencialmente mais barata do que as avaliações realizadas pelos profissionais de saúde mental.

Após a validação em 2005, não foram encontrados artigos na revisão da literatura sobre a utilização dessa versão por telefone do Teen ASI. Uma razão para isso pode ser o fato de que uma aplicação na faixa de 20 a 25 minutos também pode ser considerada como demorada.

Na versão 2 do Teen ASI desenvolvida por Brodey et al. (2008) para os Estados Unidos, embora a avaliação seja mais ampla (18 áreas, diante das 7 áreas originais do Teen ASI original), pode haver um aumento do tempo de aplicação, o que exigiria um maior número de sessões para aplicá-lo, aumentando os valores de investimento na avaliação inicial. Não foram encontradas publicações com a validação dessa versão para o Brasil.

Os resultados do Teen ASI-2 mostraram que todas as áreas apresentam uma consistência interna entre adequada e excelente (Alfa de Cronbach variando de 0,54 a 0,88). Novas áreas avaliando fatores psicológicos apresentaram uma forte correlação 
com avaliações do "padrão-ouro" nas respectivas áreas. Não foram encontradas na literatura aplicações do Teen ASI-2 no período desta pesquisa.

Quanto à aplicação do Teen ASI, uma das suas principais vantagens defendidas por seus autores é que, além da avaliação inicial, ele auxilia no planejamento do tratamento e no seu acompanhamento. O Teen ASI pode ser utilizado periodicamente para avaliar as mudanças de gravidade nas áreas da vida do adolescente em resposta ao tratamento (Kaminer et al., 1993). Segundo Kaminer e Burleson (2004), o Teen ASI é essencial para conduzir o monitoramento pós-tratamento com todos os adolescentes que realizaram tratamento para o uso de substâncias psicoativas, bem como para examinar a relação entre características da juventude, suas necessidades, utilização de serviços e resultados.

Dos oito artigos encontrados sobre aplicações do Teen ASI (os outros quatro artigos eram referentes à validação do instrumento), a grande maioria era referente à avaliação de intervenções $(5,62,5 \%)$. Também foram encontrados dois artigos sobre fatores de risco e prevalência $(25 \%)$ e um artigo (12,5\%) sobre a validação do instrumento. Observa-se, portanto, um diferencial do Teen ASI, na avaliação de intervenções e planos de tratamento, em relação aos demais instrumentos.

Um diferencial defendido pelos autores do Teen ASI é a sua aplicação em diferentes contextos. Após a validação para os Estados Unidos, avaliações favoráveis sobre a utilidade clínica do Teen ASI foram reportadas por vários ambientes clínicos de pesquisa, principalmente nos Estados Unidos (Kaminer et al., 1993). A revisão da literatura, porém, encontrou aplicações apenas em ambientes clínicos e de pesquisa, não encontrando aplicações em outros contextos, como em escolas, por exemplo. Em 
função desses ambientes, as amostras do Teen ASI foram as menores encontradas, com o N variando de 10 a 371.

\subsection{CBCL - vantagens e limitações encontradas nos estudos}

O CBCL é um instrumento de avaliação psicológica criado no final da década de 1970, por Achenbach, nos Estados Unidos, e traduzido para 55 países (Achenbach, 1991).

O ASEBA é o sistema de avaliação baseado empiricamente mais usado e pesquisado do mundo, com mais de seis mil publicações, cujas pesquisas foram feitas em 67 culturas (Achenbach; Rescorla, 2007).

No Brasil, seu uso em pesquisas é crescente, como, por exemplo, as aplicações de uso geral feitas por Salvo et al. (2005); Rocha e Silvares (2006); e Silvares et al. (2006). Porém, a ausência de normas brasileiras pode levar a resultados pouco acurados, já que não é levado em consideração o aspecto cultural (Rocha; Silvares, 2008), diferente entre os países.

A validação da versão americana apresentou boas propriedades psicométricas, sendo a faixa de valor de teste e reteste: 0,95-1,00; o intervalo de confiabilidade entre os avaliadores: 0,93-0,96; a gama de consistência interna: 0,78-0,97; e a validade de critério foi avaliada e considerada aceitável (Achenbach, 1991).

A versão brasileira do CBCL (4-18 anos) é denominada "Inventário de Comportamento da Infância e Adolescência” e possui dados preliminares de validação. As medidas de confiabilidade utilizadas na versão americana foram preservadas na versão brasileira. Sensibilidade: $87 \%$, identificando corretamente $75 \%$ dos casos leves, 
$95 \%$ dos moderados e $100 \%$ dos casos graves. O trabalho também descreve o processo de adaptação cultural do CBCL em nosso meio, visando à sua aplicabilidade em populações de nível socioeconômico baixo (Bordin et al., 1995).

Observa-se, portanto, das validações americana e brasileira, sem mencionar a validação para os outros países, que não há questionamentos quanto à validade das propriedades psicométricas do CBCL.

Uma das diferenças em relação à aplicação do CBCL é o fato de os informantes serem os pais, responsáveis e professores, permitindo a comparação entre as respostas (Achenback, 1991). Uma vez que esse instrumento proporciona o cruzamento de respostas de múltiplos informantes, torna-se possível verificar o quão concordantes são as respostas fornecidas (ASEBA, 2006). Entre os benefícios defendidos pelos autores em relação ao CBCL, estão: a existência de uma ampla gama de inventários que auxiliam no processo de avaliação das competências e dos problemas de comportamento de maneira rápida e com baixo custo (Achenbach; Rescorla, 2001).

As afirmações quanto à gama de inventários e ao baixo tempo de aplicação foram confirmadas pela literatura, sendo que em relação a esse último fator o tempo necessário para a aplicação do questionário está em torno de 15 minutos.

Uma desvantagem do CBCL em relação aos outros dois instrumentos é o fato de ter custo para aplicação (US\$ 25,00 para 50 conjuntos), o que torna também o seu acesso mais restrito.

Embora existam milhares de artigos com a aplicação do CBCL em geral, foram encontrados apenas 12 artigos relacionados ao uso de substâncias por adolescente, pelo fato de não ser um instrumento voltado especificamente para essa aplicação. 
Os autores do CBCL defendem que, além das aplicações nas áreas de pesquisa, clínica e estudos de base populacional, o instrumento também pode ser utilizado para medir a mudança de comportamento de uma criança ao longo do tratamento ou póstratamento.

Entretanto, dos 12 artigos encontrados da aplicação de CBCL na área de abuso de álcool e outras drogas em adolescentes, a grande maioria dos artigos (9, ou $75 \%)$ era referente à avaliação de prevalência e fatores de risco, sendo que apenas três (25\%) artigos eram referentes à previsão do uso de substâncias. Não foram encontradas aplicações sobre avaliações de intervenção ao longo do tratamento, conforme apontado pelos autores.

O CBCL foi o instrumento que apresentou a maior variedade de aplicações, em diferentes ambientes, tais como: pesquisas, clínicas, escolas e comunidades, entre outros. Quanto ao N, este variou de 30 a 2.900, mostrando uma ampla gama de utilização quanto ao tamanho da amostra.

\subsection{Considerações finais}

Baseados em suas experiências clínicas e de ensino, Winters e Kaminer (2008) avaliam que a quantidade e a qualidade do treinamento dedicado para triagem e avaliação do uso, abuso e dependência de substâncias entre os adolescentes, realizado em escolas médicas e programas de residência psiquiátricas, são frequentemente insuficientes. Pouco ou nenhum treinamento é dado a respeito de como conduzir a triagem e a avaliação do envolvimento com o uso de substâncias e os problemas relacionados, e sob quais ferramentas são disponíveis para ajudá-los nesse processo. 
De acordo com Winters e Kaminer (2008), infelizmente, os relatórios de performance dos médicos pediatras que costumeiramente atendem a adolescentes para check-ups periódicos e para avaliar as suas necessidades médicas não têm sido muito encorajadores. Segundo uma pesquisa da Associação Americana de Pediatria, menos de metade dos pediatras pesquisados relatou haver feito a triagem dos adolescentes para uso de tabaco, álcool e outras drogas, e menos de $25 \%$ deles reconheceram se sentir confortáveis conduzindo uma avaliação compreensiva, ou oferecendo ou fazendo recomendações para o tratamento (AAP, 1997; Halpern et al., 2000; Price et al., 2007). A razão para esse baixo desempenho foi sintetizada por Van Hook et al. (2007) da seguinte maneira: tempo insuficiente, falta de treinamento para avaliar triagens positivas, necessidade de triagem de outros problemas médicos, falta de recursos de tratamento, falta de familiaridade com instrumentos de triagem e interferência dos pais (que podem resistir a deixar o filho sozinho com o profissional de saúde para a avaliação).

Não foram encontrados na literatura brasileira estudos investigando a realização de triagem para uso de substâncias em adolescentes, por parte de médicos pediatras e outros profissionais de serviços de saúde.

Winters e Kaminer (2008) ressaltam sobre a necessidade de continuar a melhorar as avaliações e o processo de acompanhamento posterior ao tratamento. Também é importante melhorar a comunicação e a colaboração entre os centros de pesquisa e tratamento para o bem da juventude com transtornos por uso de substâncias. 


\section{CONCLUSÃO E RECOMENDAÇÕES}

Diante do estudo realizado, conclui-se que os instrumentos avaliam o abuso de álcool e outras drogas e identificam os fatores de risco da seguinte forma:

- O Teen ASI auxilia na avaliação do adolescente com o abuso de álcool e drogas e no planejamento do tratamento, sendo que o principal local de aplicação é clínicas de tratamento;

- O DUSI-R é voltado para identificar uma população de adolescentes que tenha suspeita de comportamento de risco para o uso de substâncias, sendo que os locais de aplicação são escolas e clínicas de tratamento. Tanto o Teen ASI quanto o DUSI-R são instrumentos que avaliam o uso de substâncias, transtornos psiquiátricos, sociabilidade, sistema familiar, escola, trabalho, relacionamento com amigos, lazer e recreação;

- O CBCL é voltado para avaliar a saúde mental do adolescente, sobre comportamentos internalizantes e externalizantes. O diferencial desse instrumento é que ele é respondido pelos pais, responsáveis ou professores, e não é um instrumento específico para avaliar o abuso de álcool e outras drogas, mas auxilia na identificação de comportamentos que podem se tornar risco e levar à experimentação e ao uso de substâncias. Pode ser aplicado em larga escala em escolas, comunidades, diversas clínicas de tratamento em saúde mental e serviços de saúde de pediatria. 
$\mathrm{Na}$ escolha de instrumentos de avaliação, é imprescindível considerar: a organização do tempo a ser investido; os recursos financeiros nos locais de tratamento para formação de profissionais; e a administração para medir os resultados e como esses resultados podem efetivamente contribuir na melhora do tratamento.

Além disso, é importante o trabalho interdisciplinar para uma avaliação mais eficaz e incentivar que os profissionais de saúde e estagiários recebam treinamento formal para a avaliação de uso de substâncias, em pelo menos um instrumento de avaliação abrangente, e participem ativamente do processo.

Do ponto de vista do local de aplicação, o Teen ASI é voltado para ambientes de tratamento, como clínicas e ambulatórios, pois traça o perfil de gravidade sobre o uso de substâncias e em várias áreas da vida do adolescente, no início, durante e póstratamento.

O DUSI-R pode ser aplicado em serviços de saúde mental e também em escolas para identificar comportamentos de risco para o abuso de álcool e drogas, esses dados servem para a elaboração de projetos de prevenção.

Portanto, para escolher o instrumento mais adequado, é necessário ter a clareza do objetivo e do ambiente a ser aplicado; dependendo do objetivo do estudo, pode haver a necessidade de compor com outros instrumentos.

Recomendamos novos estudos sobre a avaliação inicial para o abuso de álcool e outras drogas em adolescentes, com a aplicação dos instrumentos estudados nesta pesquisa e outros que contribuam para que os adolescentes com uso de substâncias psicoativas possam ser mais bem avaliados e tenham acesso a um serviço e tratamento de qualidade e adequado às suas necessidades biopsicossociais. 
Em relação ao Teen ASI, considerando o seu tempo longo de aplicação, recomendamos o desenvolvimento de estudos sobre a validação de uma versão reduzida para o Brasil, além da aplicação por outros meios não presenciais (como telefone e internet, por exemplo).

Estudos futuros devem considerar os instrumentos GAIN e ASSIST para adolescentes, que também são voltados para a identificação e avaliação do abuso de álcool e outras drogas em adolescentes. O GAIN se encontrava em processo de validação quando da realização do presente estudo. Grande parte dos estudos pesquisados não avaliou as medidas de desempenho dos instrumentos pesquisados, portanto recomendamos que em estudos futuros que venham a aplicar instrumentos sejam avaliadas as medidas de desempenho.

Outra recomendação é a realização de pesquisas que investiguem o índice de utilização de instrumentos por parte dos profissionais de saúde, para permitir melhores diagnósticos da situação, e, com isso, fornecer subsídios para a formulação de programas e a sistematização de avaliações iniciais do uso de substâncias.

Um melhor entendimento da situação poderá então permitir a elaboração de programas e políticas públicas por parte do Ministério da Saúde e de associações de profissionais de saúde. Um exemplo de aplicação dos instrumentos de triagem e avaliação seria a inclusão dos mesmos nos manuais dos CAPS AD, bem como nos programas das Secretarias de Saúde Estaduais e Municipais. 


\section{ANEXOS}

\section{Anexo 1 - DUSI-R (Drug Use Screening Inventory)}

Adptação e tradução feita para o Brasil por De Micheli \& Formigoni, 1999.

Todos os dados colhidos através deste questionário são confidenciais e fazem parte de um projeto de pesquisa cujo objetivo é conhecer o real uso de drogas de uma amostra de jovens brasileiros e sua relação com problemas de saúde, psicológicos e sociais.

SUA RESPOSTA É MUITO IMPORTANTE. RESPONDA HONESTAMENTE E TENHA A CERTEZA QUE SUAS RESPOSTAS SERÃO MANTIDAS EM SEGREDO. NENHUMA PESSOA TERÁ ACESSO ÀS SUAS RESPOSTAS SEM O SEU CONSENTIMENTO.

Parte I - Quantas vezes você usou cada uma das drogas listadas abaixo no ÚLTIMO MÊS? PREENCHA os círculos, conforme a droga e as vezes que usou:

\begin{tabular}{|c|c|c|c|c|c|c|c|}
\hline & $\begin{array}{l}\text { Não } \\
\text { usei }\end{array}$ & $\begin{array}{l}\text { Usei de } \\
1 \text { a } 2 \\
\text { vezes }\end{array}$ & \begin{tabular}{|c|} 
Usei \\
de \\
3 a 9 \\
vezes \\
\end{tabular} & $\begin{array}{l}\text { Usei de } \\
10 \text { a } 20 \\
\text { vezes }\end{array}$ & $\begin{array}{l}\text { Usei mais } \\
\text { de } 20 \\
\text { vezes }\end{array}$ & $\begin{array}{c}\text { TENHO } \\
\text { PROBLEMAS } \\
\text { PELO USO } \\
\text { DESTA DROGA } \\
\end{array}$ & $\begin{array}{c}\text { ESTA É } \\
\text { MINHA } \\
\text { DROGA } \\
\text { PREDILETA } \\
\end{array}$ \\
\hline Álcool & 0 & $\mathrm{O}$ & $\mathrm{O}$ & $\mathrm{O}$ & $\mathrm{O}$ & $\mathrm{O}$ & $\mathrm{O}$ \\
\hline $\begin{array}{l}\text { Anfetaminas/ estimulantes } \\
\text { (SEM PRESCRIÇÃO MÉDICA) }\end{array}$ & $\mathrm{O}$ & $\mathrm{O}$ & $\mathrm{O}$ & $\mathrm{O}$ & 0 & $\mathrm{O}$ & $\mathrm{O}$ \\
\hline Exxtase & $\mathrm{O}$ & $\mathrm{O}$ & $\mathrm{O}$ & O & $\mathrm{O}$ & $\mathrm{O}$ & $\mathrm{O}$ \\
\hline Cocaína /crack & $\mathrm{O}$ & $\mathrm{O}$ & $\mathrm{O}$ & 0 & $\mathrm{O}$ & $\mathrm{O}$ & $\mathrm{O}$ \\
\hline Maconha & $\mathrm{O}$ & $\mathrm{O}$ & $\mathrm{O}$ & $\mathrm{O}$ & $\mathrm{O}$ & $\mathrm{O}$ & $\mathrm{O}$ \\
\hline $\begin{array}{l}\text { Alucinógenos } \\
\text { (LSD, Mescalina, etc.) }\end{array}$ & $\mathrm{O}$ & $\mathrm{O}$ & $\mathrm{O}$ & $\mathrm{O}$ & $\mathrm{O}$ & $\mathrm{O}$ & $\mathrm{O}$ \\
\hline $\begin{array}{l}\text { Tranquiilizantes } \\
\text { (diazepam, barbitúricos, etc.) } \\
\text { (SEM PRESCRIÇÃO MÉDICA) }\end{array}$ & $\mathrm{O}$ & $\mathrm{O}$ & $\mathrm{O}$ & $\mathrm{O}$ & $\mathrm{O}$ & $\mathrm{O}$ & $\mathrm{O}$ \\
\hline $\begin{array}{l}\text { Analgésicos } \\
\text { (SEM PRESCRIÇÃO MÉDICA) }\end{array}$ & $\mathrm{O}$ & $\mathrm{O}$ & $\mathrm{O}$ & $\mathrm{O}$ & $\mathrm{O}$ & $\mathrm{O}$ & $\mathrm{O}$ \\
\hline $\begin{array}{l}\text { Opiáceos } \\
\text { (morfina, heroína, etc.) }\end{array}$ & $\mathrm{O}$ & $\mathrm{O}$ & $\mathrm{O}$ & $\mathrm{O}$ & $\mathrm{O}$ & $\mathrm{O}$ & $\mathrm{O}$ \\
\hline Fenilciclidina (pó-de-anjo) & $\mathrm{O}$ & $\mathrm{O}$ & $\mathrm{O}$ & $\mathrm{O}$ & $\mathrm{O}$ & $\mathrm{O}$ & $\mathrm{O}$ \\
\hline Anabolizantes & $\mathrm{O}$ & $\mathrm{O}$ & $\mathrm{O}$ & $\mathrm{O}$ & $\mathrm{O}$ & $\mathrm{O}$ & $\mathrm{O}$ \\
\hline $\begin{array}{l}\text { Inalantes, solventes (cola, lança } \\
\text { perfume, etc) }\end{array}$ & $\mathrm{O}$ & $\mathrm{O}$ & $\mathrm{O}$ & $\mathrm{O}$ & 0 & $\mathrm{O}$ & $\mathrm{O}$ \\
\hline Tabaco & $\mathrm{O}$ & $\mathrm{O}$ & $\mathrm{O}$ & $\mathrm{O}$ & $\mathrm{O}$ & $\mathrm{O}$ & $\mathrm{O}$ \\
\hline Outras & $\mathrm{O}$ & $\mathrm{O}$ & $\mathrm{O}$ & $\mathrm{O}$ & $\mathrm{O}$ & $\mathrm{O}$ & $\mathrm{O}$ \\
\hline
\end{tabular}


Parte II - Por favor, responda todas as questões seguintes. Se alguma questão não se aplicar exatamente, responda considerando o que ocorre com maior freqüência (Sim ou Não). Responda as questões considerando o que ocorreu com você NOS ÚLTIMOS 12 MESES. Caso alguma questão não se aplique à você, responda "Não". Preencha completamente o círculo ao lado da resposta escolhida, com cuidado para não ultrapassar as bordas.

\section{ÁREA I - Uso de substâncias}

1. Alguma vez você sentiu "fissura" ou um forte desejo por álcool ou outras drogas?

\section{SIM O NÃOO}

2. Alguma vez você precisou usar mais e mais álcool ou drogas para conseguir o efeito desejado?

\section{SIM O NÃO O}

3. Alguma vez você sentiu que não poderia controlar o uso de álcool ou drogas?

\section{SIM O NÃO O}

4. Alguma vez você sentiu que estava dependente ou muito envolvido pelo álcool ou pelas drogas?

\section{SIM O NÃO O}

5. Alguma vez você deixou de realizar alguma atividade por ter gasto muito dinheiro com drogas ou álcool?

\section{SIM O NÃO O}

6. Alguma vez você quebrou regras ou desobedeceu leis por estar "alto" sob o efeito de álcool ou drogas?

\section{SIM O NÃO O}

7. Você muda rapidamente de muito feliz para muito triste ou de muito triste para muito feliz, por causa das drogas?

\section{SIM O NÃOO}

8. Você sofreu algum acidente de carro depois de usar álcool ou drogas?

\section{SIM O NÃO O}

9. Alguma vez você se machucou acidentalmente ou machucou alguém depois de usar álcool ou drogas?

\section{SIM O NÃO O}

10. Alguma vez você teve uma discussão séria ou briga com um amigo ou membro da família por causa de do seu uso de álcool ou drogas?

\section{SIM O NÃO O}

11. Alguma vez você teve problemas de relacionamento com algum de seus amigos devido ao uso de álcool ou drogas? 
12. Alguma vez você teve sintomas de abstinência após o uso de álcool (por exemplo: tremores, náuseas, vômitos ou dor de cabeça)?

\section{SIM O NÃO O}

13. Alguma vez você teve problemas para lembrar o que fez enquanto estava sob efeito de drogas ou álcool?

\section{SIM O NÃO O}

14. Você gosta de " brincadeiras" que envolvem bebidas "quando vai a festas? (Por exemplo: "vira-vira"; apostas para ver quem bebe mais rápido ou em maior quantidade; etc.)

\section{SIM O NÃO O}

15. Você tem problemas para resistir ao uso de álcool ou drogas?

SIM O

\section{NÃO 0}

16. Alguma vez você já disse uma mentira?

SIM O

\section{NÃO O}

\section{ÁREA II - Comportamento}

1. Você briga muito?

SIM O

NÃO 0

2. Você se acha melhor que os outros?

\section{SIM O NÃO O}

3. Você provoca ou faz coisas prejudiciais aos animais?

SIM O

NÃO 0

4. Você grita muito?

SIM O NÃO O

5. Você é teimoso?

SIM O NÃO O

6. Você é desconfiado em relação a outras pessoas?

SIM O NÃO O

7. Você xinga ou fala muitos palavrões?

SIM O NÃO O

8. Você provoca muito as pessoas?

\section{SIM O NÃO O}

9. Você tem um temperamento difícil?

SIM O

NÃO O

10. Você é muito tímido? 
11. Você ameaça ferir as pessoas?

\section{SIM O NÃO O}

12. Você fala mais alto que os outros jovens?

SIM O

NÃO 0

13. Você se chateia (ou se aborrece) facilmente?

\section{SIM O NÃO O}

14. Você faz muitas coisas sem antes pensar nas conseqüências?

\section{SIM O NÃO O}

15. Você se arrisca ou faz coisas perigosas muitas vezes?

\section{SIM O NÃOO}

16. Se você puder você tira vantagem das pessoas?

\section{SIM O NÃO O}

17. Geralmente você se sente irritado ou bravo?

\section{SIM O NÃO O}

18. Você gasta a maior parte do seu tempo livre, sozinho?

\section{SIM O NÃO O}

19. Você costuma se isolar dos outros?

\section{SIM O NÃO O}

20. Você é muito sensível a críticas?

SIM O NÃO O

21. Sua maneira de comer é melhor no restaurante do que em casa?

SIM O

\section{NÃO 0}

\section{ÁREA III - Saúde}

1. Você se submeteu a algum exame físico ou esteve sob cuidados médicos nos últimos 12 meses?

\section{SIM O NÃO O}

2. Você teve algum acidente ou ferimento que ainda o incomode?

\section{SIM O NÃO O}

3. Você tem problemas com o seu sono (dorme demais ou muito pouco)?

\section{SIM O NÃO O}

4. Recentemente, você perdeu ou ganhou mais de $4 \mathrm{~kg}$ ?

\section{SIM O NÃO O}

5. Você tem menos energia do que acha que deveria ter? 
6. Você tem problemas de respiração ou de tosse?

\section{SIM O NÃO O}

7. Você tem alguma preocupação sobre sexo ou com seus órgãos sexuais?

\section{SIM O NÃO O}

8. Alguma vez você teve relações sexuais com alguém que se injetava com drogas?

\section{SIM O NÃO O}

9. Você teve dores abdominais ou náuseas no ano passado?

SIM O NÃO O

10. Alguma vez a parte branca de seus olhos ficou amarela?

\section{SIM O NÃOO}

11. Você às vezes sente vontade de xingar?

\section{SIM O NÃO O}

\section{ÁREA IV - Transtornos Psiquiátricos}

1. Alguma vez você danificou a propriedade de alguém intencionalmente?

\section{SIM O NÃO O}

2. Você roubou coisas em mais de uma ocasião?

\section{SIM O NÃOO}

3. Você se envolveu em mais brigas do que a maioria dos jovens?

SIM O NÃO O

4. Você costuma fazer movimentos irrequietos com as mãos?

\section{SIM O NÃO O}

5. Você é agitado e não consegue sentar quieto?

\section{SIM O NÃO O}

6. Você fica frustrado facilmente?

\section{SIM O NÃO O}

7. Você tem problemas em se concentrar?

\section{SIM O NÃO O}

8. Você se sente triste muitas vezes?

\section{SIM O NÃO O}

9. Você rói unhas?

\section{SIM O NÃO O}

10. Você tem problemas durante o sono (pesadelos, sonambulismo, etc)? 
11. Você é nervoso?

\section{SIM O NÃO O}

12. Você se sente facilmente amedrontado?

SIM O

NÃO O

13. Você se preocupa demais?

\section{SIM O NÃO O}

14. Você tem dificuldade em deixar de pensar em determinadas coisas?

\section{SIM O NÃO O}

15. As pessoas olham com estranheza para você?

\section{SIM O NÃO O}

16. Você escuta coisas que ninguém mais do seu lado escuta?

SIM O NÃOO

17. Você tem poderes especiais que ninguém mais tem?

SIM O NÃO O

18. Você sente medo de estar entre as pessoas?

\section{SIM O NÃO O}

19. Freqüentemente você sente vontade de chorar?

\section{SIM O NÃO O}

20. Você tem tanta energia que você não sabe o que fazer com você mesmo?

\section{SIM O NÃO O}

21. Alguma vez você se sentiu tentado a roubar alguma coisa?

SIM O

NÃO O

\section{ÁREA V - Sociabilidade}

1. Você acha que os jovens de sua idade não gostam de você?

\section{SIM O NÃO O}

2. Em geral, você se sente infeliz com o seu desempenho em atividades com seus amigos?

\section{SIM O NÃO O}

3. É difícil fazer amizades num grupo novo?

\section{SIM O NÃO O}

4. As pessoas tiram vantagens de você?

\section{SIM O NÃO O}

5. Você tem medo de lutar pelos seus direitos? 
6. É difícil para você pedir ajuda aos outros?

SIM O NÃO O

7. Você é facilmente influenciado por outros jovens?

SIM O NÃO O

8. Você prefere ter atividades com jovens bem mais velhos que você?

SIM O NÃO O

9. Você se preocupa em como suas ações vão afetar os outros?

SIM O NÃO O

10. Você tem dificuldades em defender suas opiniões?

SIM O NÃO O

11. Você tem dificuldade em dizer "não" para as pessoas?

SIM O NÃO O

12. Você se sente desconfortável (sem jeito) se alguém o elogia?

SIM O NÃO O

13. As pessoas o enxergam como uma pessoa não amigável?

SIM O NÃO O

14. Você evita olhar nos olhos quando está conversando com as pessoas?

SIM O NÃO O

15. O seu humor as vezes muda?

SIM O NÃO O

ÁREA VI - Sistema Familiar

1. Algum membro de sua família (mãe, pai, irmão ou irmã) usou maconha ou cocaína no último ano?

\section{SIM O NÃO O}

2. Algum membro de sua família usou álcool a ponto de causar problemas em casa, no trabalho ou com amigos?

\section{SIM O NÃO O}

3. Algum membro de sua família foi preso no último ano?

\section{SIM O NÃO O}

4. Você tem tido discussões freqüentes com seus pais ou responsáveis que envolvam gritos e berros?

\section{SIM O NÃO O}

5. Sua família dificilmente faz coisas juntas?

\section{SIM O NÃO O}

6. Seus pais ou responsáveis desconhecem o que você gosta e o que não gosta?

SIM O NÃO O 
7. Na sua casa faltam regras claras sobre o que você pode e não pode fazer?

SIM O NÃO O

8. Seus pais ou responsáveis desconhecem o que você realmente pensa ou sente sobre as coisas que são importantes para você?

\section{SIM O NÃO O}

9. Seus pais ou responsáveis brigam muito entre si?

\section{SIM O NÃO O}

10. Seus pais ou responsáveis freqüentemente desconhecem onde você está ou o que você está fazendo?

\section{SIM O NÃO O}

11. Seus pais ou responsáveis estão fora de casa a maior parte do tempo?

\section{SIM O NÃO O}

12. Você sente que seus pais ou responsáveis não se importam ou não cuidam de você?

\section{SIM O NÃO O}

13. Você se sente infeliz em relação ao local no qual você vive?

SIM O NÃO O

14. Você se sente em perigo em casa?

SIM O NÃO O

15. Você as vezes fica bravo?

SIM O NÃO O

\section{ÁREA VII - Escola}

1. Você gosta da escola?

SIM O NÃO O

2. Você tem problemas para se concentrar na escola ou quando está estudando?

\section{SIM O NÃO O}

3. Suas notas são abaixo da média?

\section{SIM O NÃOO}

4. Você "cabula" aulas mais do que dois dias por mês?

\section{SIM O NÃO O}

5. Você falta muito à escola?

\section{SIM O NÃO O}

6. Alguma vez você pensou seriamente em abandonar a escola?

SIM O NÃO O

7. Freqüentemente, você deixa de fazer os deveres escolares? 
8. Freqüentemente, você se sente sonolento nas aulas?

\section{SIM O NÃO O}

9. Freqüentemente, você chega atrasado para a aula?

\section{SIM O NÃO O}

10. Neste ano, seus amigos da escola são diferentes daqueles do ano passado?

\section{SIM O NÃO O}

11. Você se irrita facilmente ou se chateia quando está na escola?

SIM O

NÃO O

12. Você fica entediado na escola?

SIM O NÃO O

13. Suas notas na escola estão piores do que costumavam ser?

SIM O NÃO O

14. Você se sente em perigo na escola?

SIM O NÃO O

15. Você já repetiu de ano alguma vez?

\section{SIM O NÃO O}

16. Você se sente indesejado nos clubes escolares (centro acadêmico, atlética, etc.) ou nas atividades extra-curriculares?

\section{SIM O NÃO O}

17. Alguma vez você faltou ou chegou atrasado na escola em consequiência do uso de álcool ou drogas?

\section{SIM O NÃO O}

18. Alguma vez você teve problemas na escola por causa do álcool ou das drogas?

\section{SIM O NÃO O}

19. Alguma vez você o álcool ou as drogas interferiram nas suas lições de casa ou trabalhos escolares?

\section{SIM O NÃOO}

20. Alguma vez você foi suspenso?
SIM O
NÃO 0

21. Você as vezes adia coisas que você precisa fazer?

SIM O

NÃO O

\section{ÁREA VIII - Trabalho}

1. Alguma vez você teve um trabalho remunerado do qual foi despedido?

\section{SIM O NÃO O}

2. Alguma vez você parou de trabalhar simplesmente porque não se importava? 
3. Você precisa de ajuda dos outros para procurar emprego?

SIM O NÃO O

4. Freqüentemente, você falta ou chega atrasado no trabalho?

\section{SIM O NÃO O}

5. Você acha difícil concluir tarefas no seu trabalho?

\section{SIM O NÃO O}

6. Alguma vez, você ganhou dinheiro realizando atividades ilegais?

\section{SIM O NÃO O}

7. Alguma vez você consumiu álcool ou drogas durante o trabalho?

\section{SIM O NÃOO}

8. Alguma vez você foi demitido de um emprego por causa de drogas?

SIM O NÃO O

9. Você tem problemas de relacionamento com seus chefes?

\section{SIM O NÃO O}

10. Você trabalha principalmente porque isto permite ter dinheiro para comprar drogas?

SIM O

NÃO O

11. Você fica mais feliz quando você ganha do que quando você perde um jogo?

SIM O

NÃO 0

\section{ÁREA IX - Relacionamento com amigos}

1. Algum de seus amigos usa álcool ou drogas regularmente?

\section{SIM O NÃO O}

2. Algum de seus amigos vende ou dá drogas a outros jovens?

\section{SIM O NÃO O}

3. Algum de seus amigos "cola" nas provas?

\section{SIM O NÃO O}

4. Você acha que seus pais ou responsáveis não gostam de seus amigos?

\section{SIM O NÃO O}

5. Algum dos seus amigos teve problemas com a lei nos últimos 12 meses?

\section{SIM O NÃO O}

6. A maioria dos seus amigos é mais velho do que você?

\section{SIM O NÃO O}

7. Seus amigos costumam faltar muito na escola? 
8. Seus amigos ficam entediados nas festas quando não é servido álcool?

\section{SIM O NÃO O}

9. Seus amigos levaram drogas ou álcool nas festas nos últimos 12 meses?

\section{SIM O NÃO O}

10. Seus amigos roubaram alguma coisa de uma loja ou danificaram a propriedade escolar de propósito nos últimos 12 meses?

\section{SIM O NÃO O}

11. Você pertence a alguma "gang"?

\section{SIM O NÃO O}

12. Atualmente, você se sente incomodado por problemas que esteja tendo com seus amigos?

\section{SIM O NÃO O}

13. Você sente que não tem nenhum amigo para quem possa fazer confidências?

\section{SIM O NÃO O}

14. Se comparado com a maioria dos jovens, você tem poucos amigos?

\section{SIM O NÃOO}

15. Alguma vez você foi convencido a fazer alguma coisa que você não queria fazer?

\section{SIM O NÃO O}

\section{ÁREA X - Lazer/Recreação}

1. Comparado com a maioria dos jovens, você faz menos esportes?

\section{SIM O NÃO O}

2. Durante a semana, você normalmente sai à noite para se divertir, sem permissão?

\section{SIM O NÃO O}

3. Num dia comum, você assiste mais do que duas horas de televisão?

\section{SIM O NÃO O}

4. Na maioria das festas que você tem ido recentemente, os pais estão ausentes?

\section{SIM O NÃO O}

5. Você exercita-se menos do que a maioria dos jovens que você conhece?

\section{SIM O NÃO O}

6. Nas suas horas livres você simplesmente passa a maior parte do tempo com os amigos?

\section{SIM O NÃO O}

7. Você se sente entediado a maior parte do tempo?

\section{SIM O NÃO O}

8. Você realiza a maior parte das atividades de lazer sozinho? 
9. Você usa álcool ou drogas para se divertir?

SIM O

NÃO O

10. Comparado a maioria dos jovens você se envolve menos em "hobbies" ou outras atividades de lazer?

SIM O

NÃO O

11. Você está insatisfeito com a maneira como passa seu tempo livre?

SIM O

NÃO O

12. Você se cansa muito rapidamente quando faz algum esforço físico?

SIM O

NÃO 0

13. Você alguma vez comprou alguma coisa que você não precisava?

SIM O

NÃO 0

\section{Cálculos:}

O DUSI possibilita o cálculo de 3 índices-

(Lembre-se que respostas afirmativas equivalem a presença de problemas. Portanto quanto mais respostas positivas tivermos, mais problemas.)

- Densidade Absoluta de problemas (DA) - é um indicador da gravidade de problemas em cada uma das áreas isoladamente. É calculada da seguinte forma:

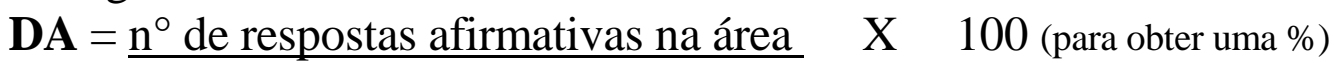
$\mathrm{n}^{\circ}$ de questões da área

Por exemplo:cálculo da DA_A1 (A1 é a área de Uso de Subst.)

(Supondo que nesta área eu tenha 9 questões respondidas afirmativamente), então:

$\mathbf{D A}=\underline{9} \times 100=60 \%$

15

- Densidade Relativa de problemas (NDR) - reflete a contribuição de cada uma das áreas para o total de problemas do indivíduo. Seu cálculo é:

$\mathbf{N D R}=\frac{\text { valor da DA da área }}{\sum \text { DA de todas as áreas }} \quad$ X 100 (para obter uma \%)

Neste caso não é possível dar um exemplo, pois o cálculo exige a somatória das densidades absolutas de todas as áreas (ou pelo menos daquelas que eu estou avaliando). 
- Densidade Global de problemas - é um indicador da gravidade geral de problemas. Seu cálculo é:

DG $=\underline{\text { soma das respostas afirmativas em todas as áreas }}$ X 100

149 (total de questões do instrumento)

Nesta versão revisada do DUSI, existe a ESCALA DE MENTIRA (EM). Esta escala refere-se a última questão de cada área do DUSI. Seu cálculo é:

EM = Soma das respostas NEGATIVAS da última questão de cada área.

OBS - Como são 10 áreas no total, uma pontuação de 5 ou mais (respostas negativas) é um alerta para possíveis resultados inválidos.

Lembre-se: estes 10 itens (EM) não entram para os cálculos das Densidades (absoluta, relativa e global).

\section{PONTOS DE CORTE}

Para que você saiba quem tem ou não problemas com o uso de álcool e/ou drogas, nós estabelecemos os seguintes pontos de corte para a área Uso de Substância (A1):

0 a $13 \%$ na DA (equivalente a até 2 respostas afirmativas) - sem uso ou uso sem problemas.

20\% na DA (equivalente a 3 ou mais respostas afirmativas) - uso considerável com presença de problemas.

53\% ou mais na DA (equivalente a 8 ou mais respostas afirmativas) uso pesado de álcool e/ou drogas. 

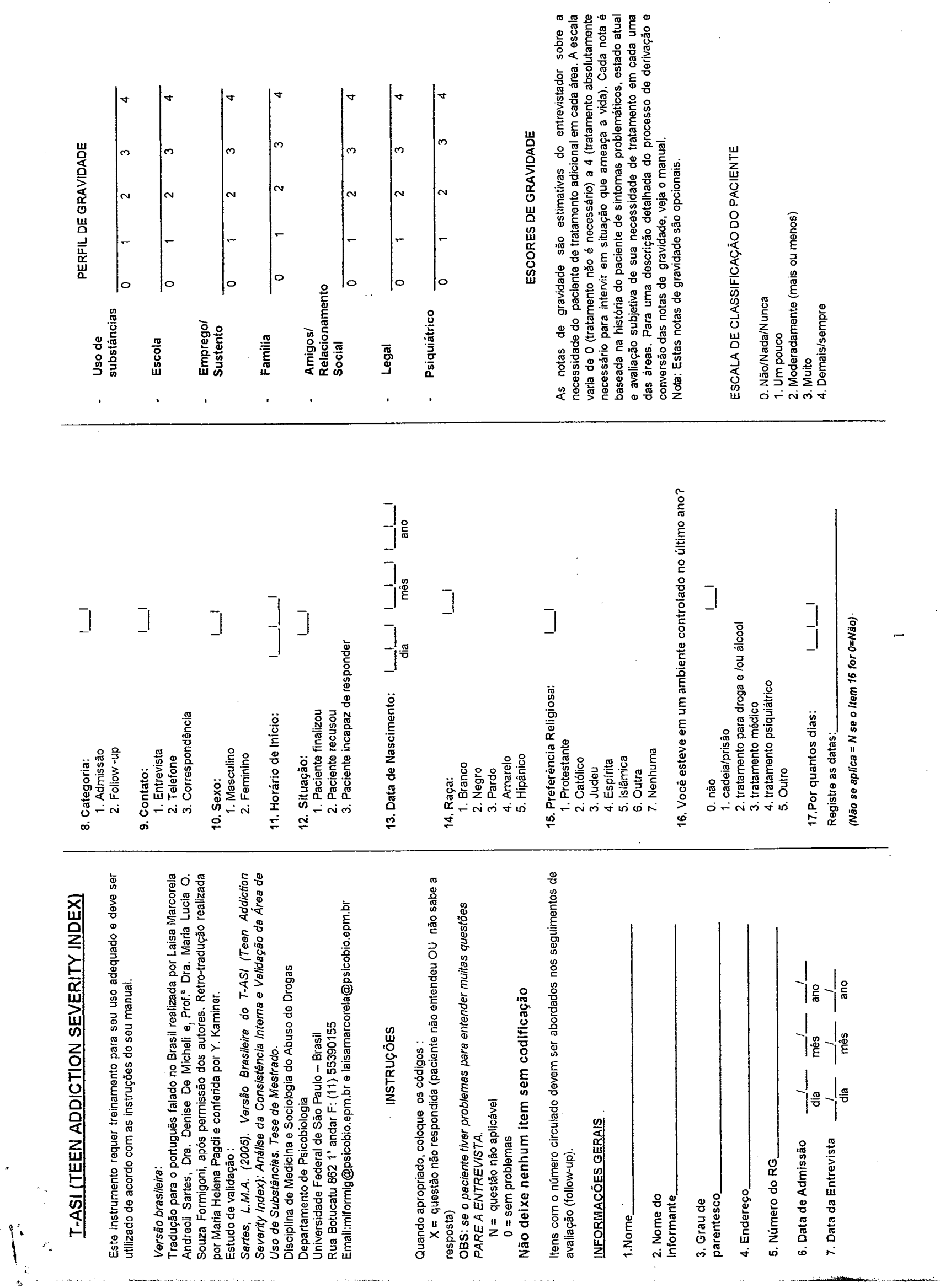

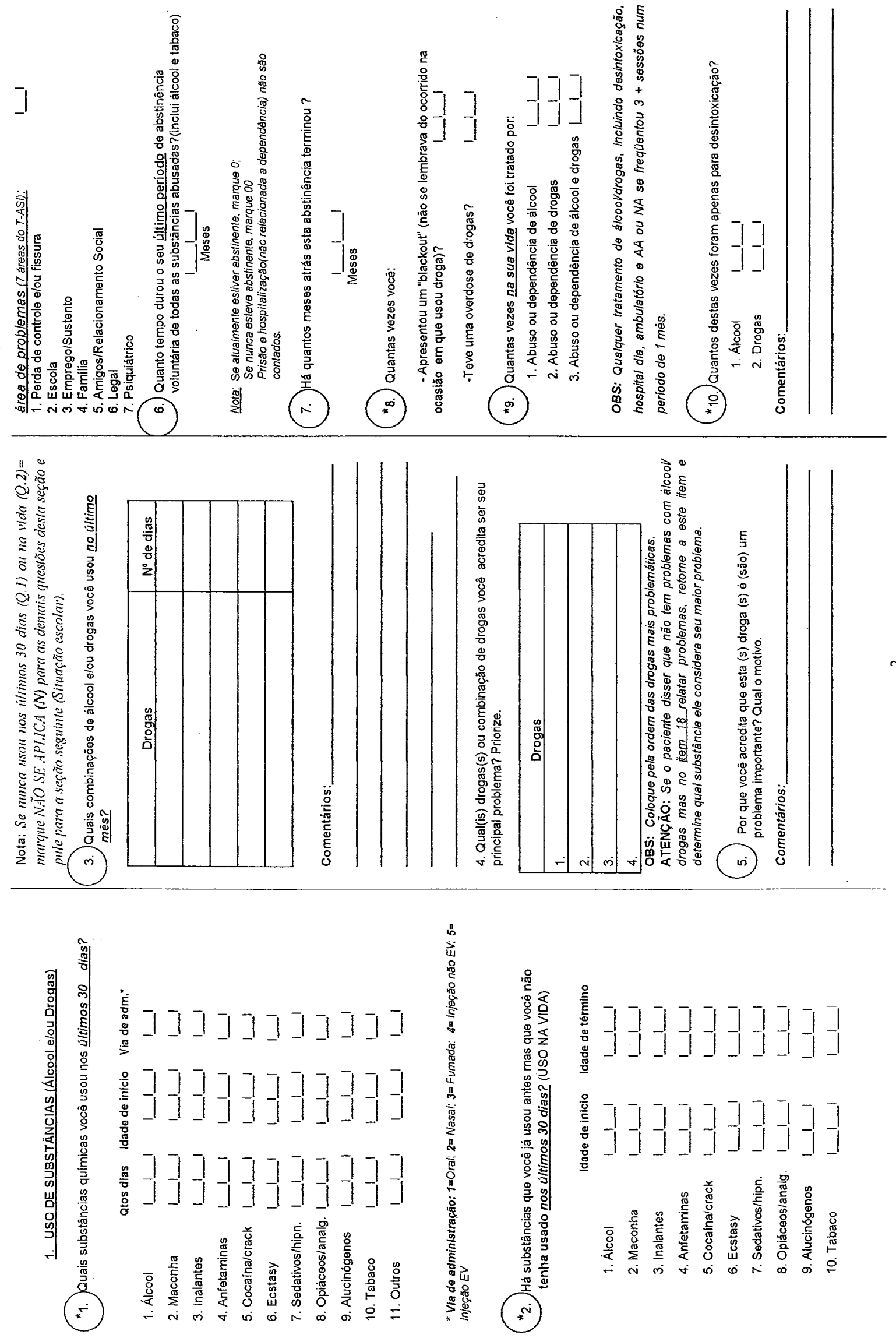

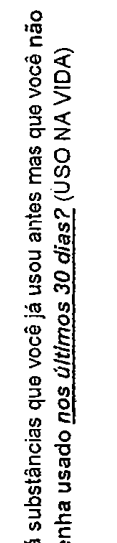
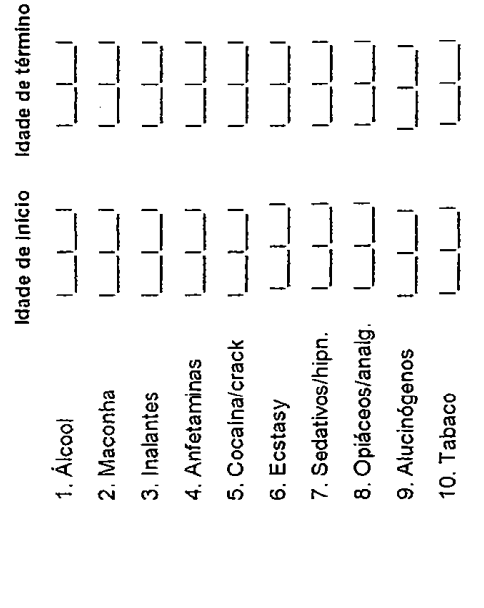

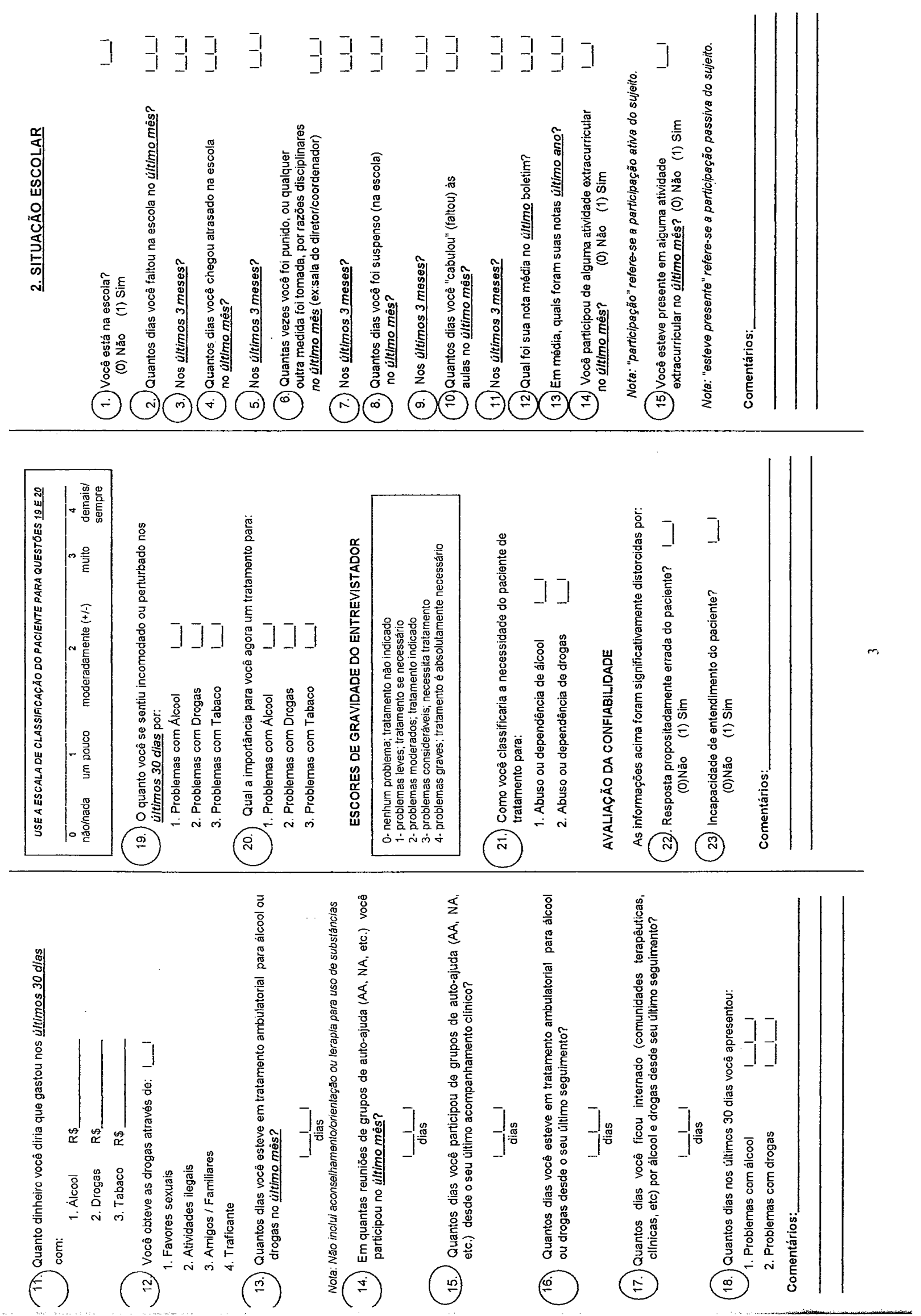

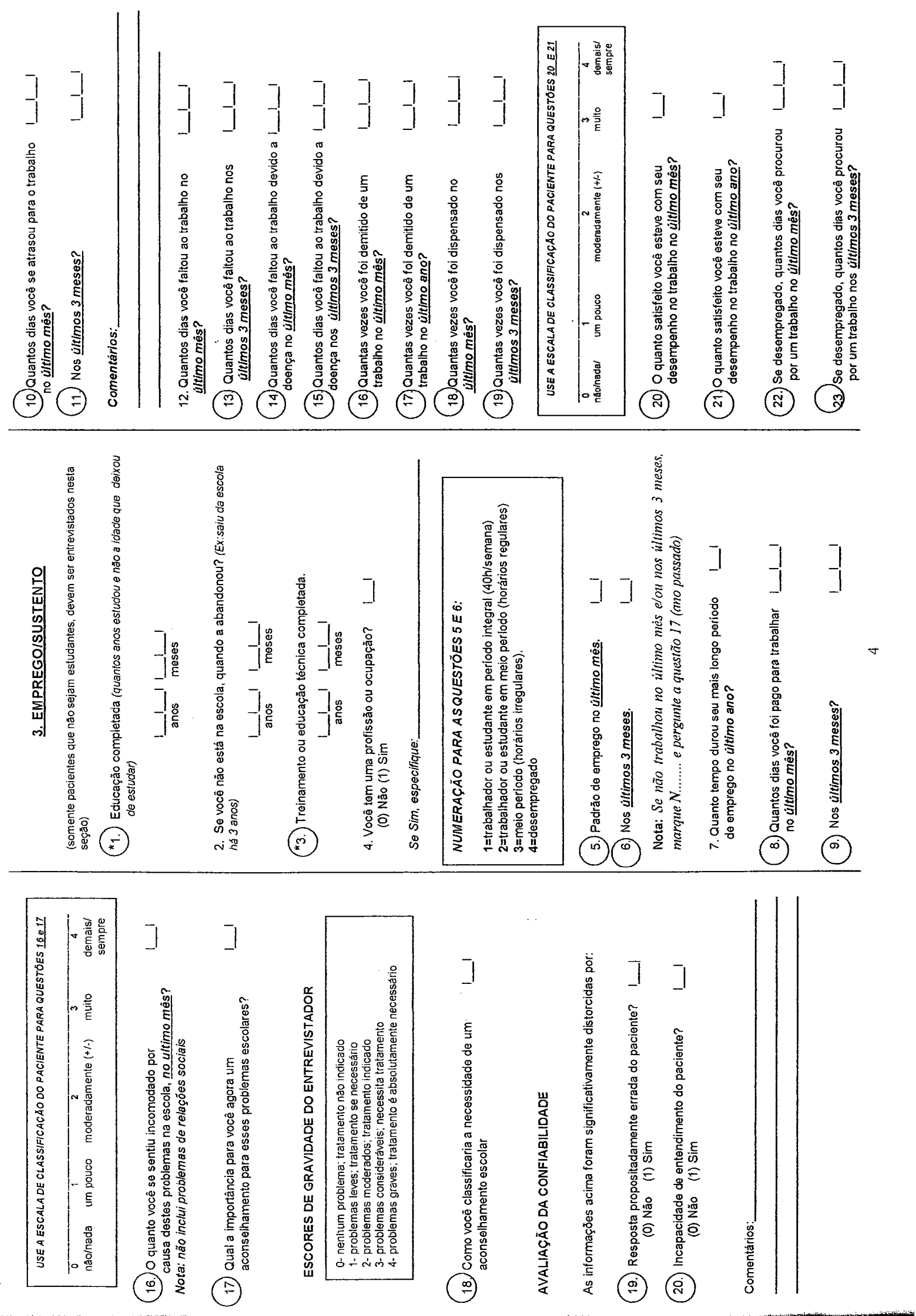

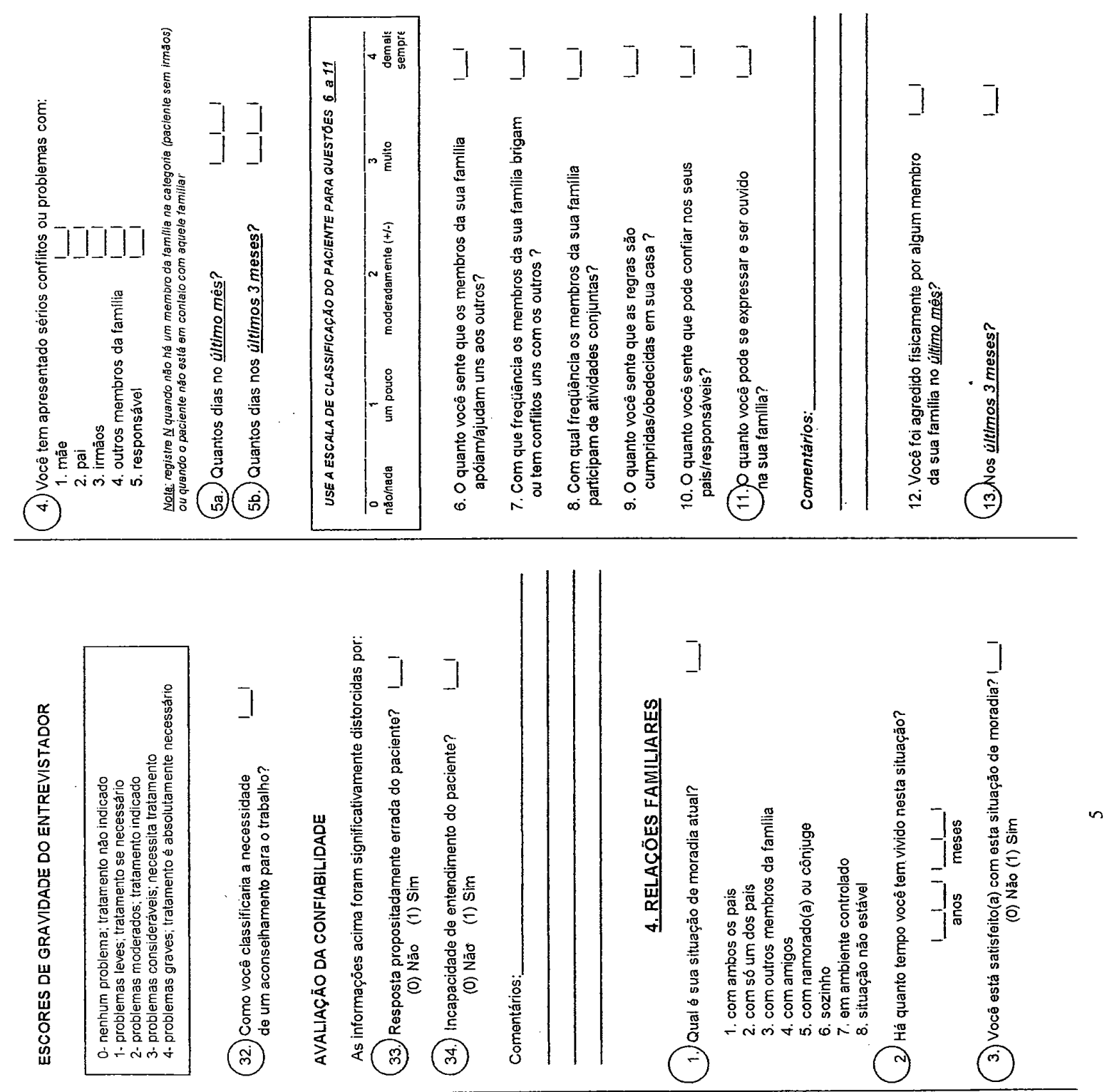

了] 3 3 J
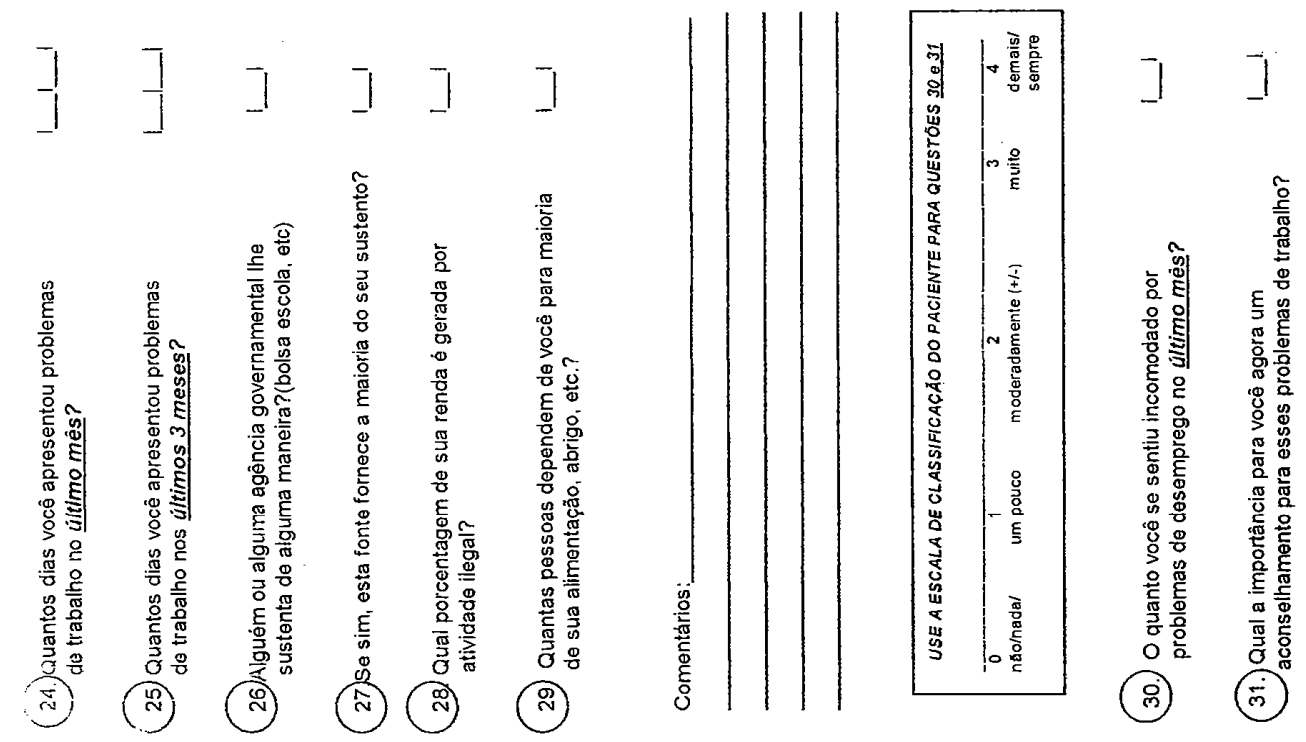

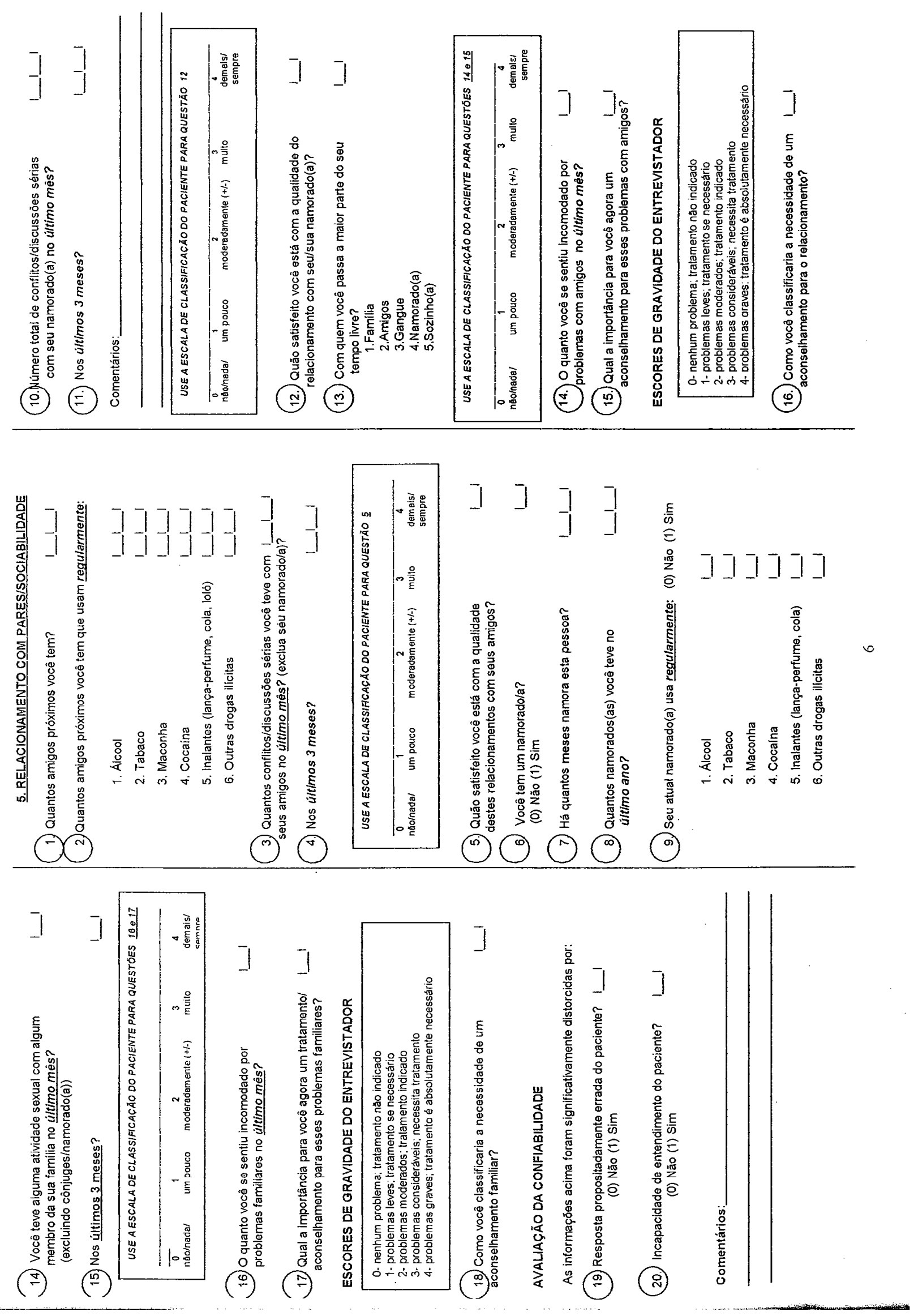

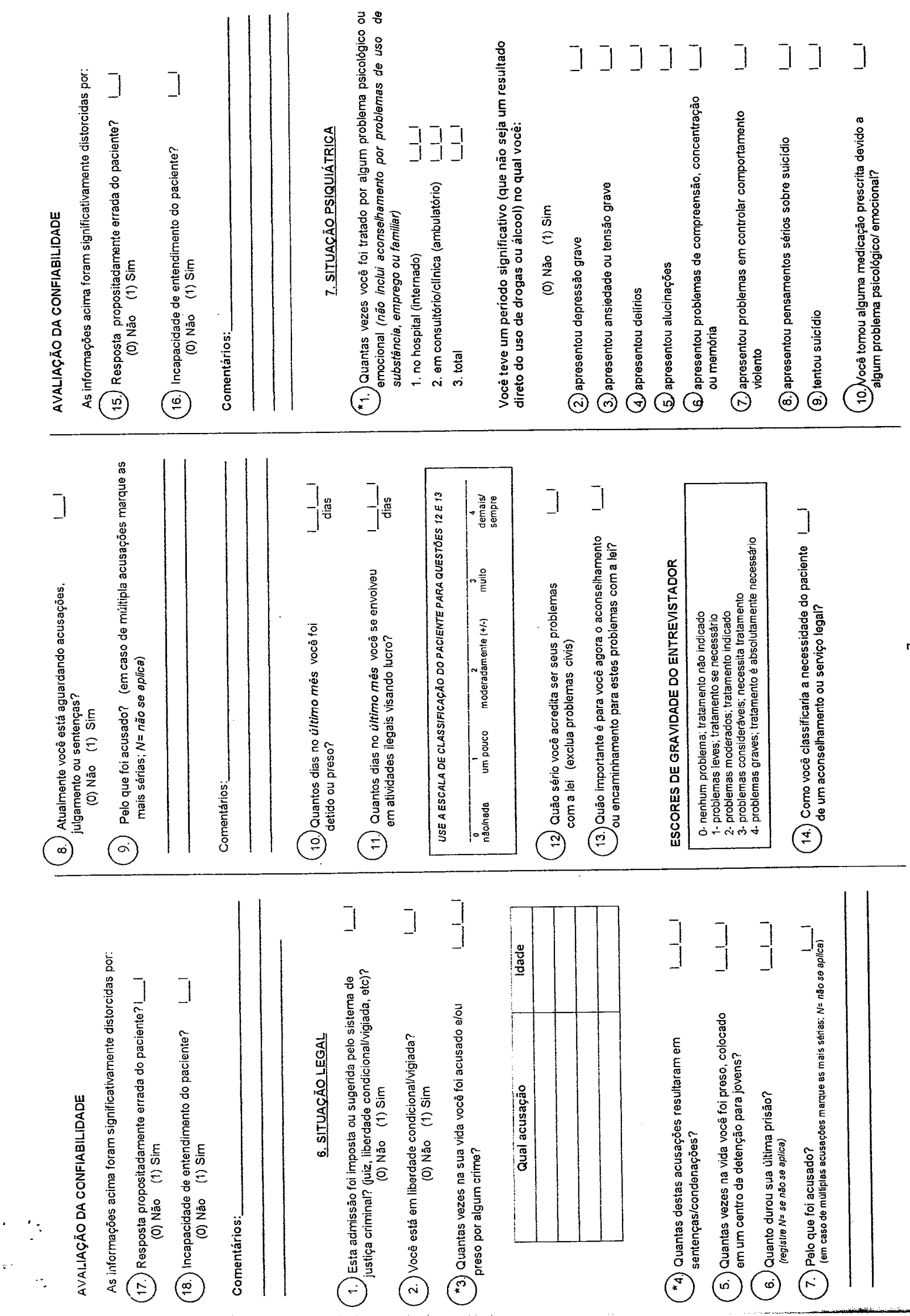

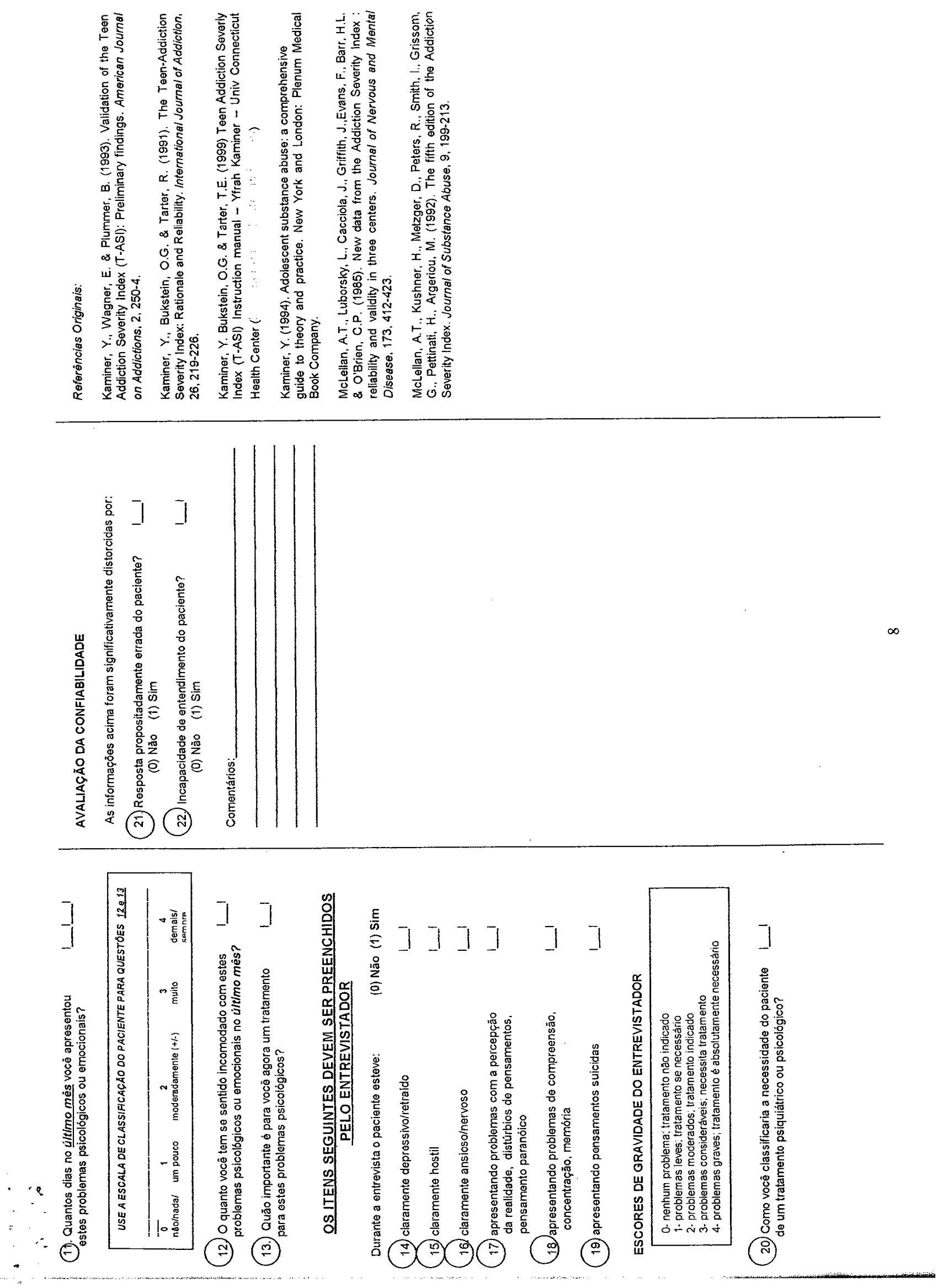


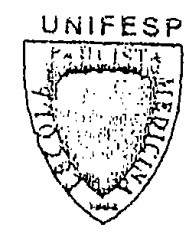

Centro de Atendimento e Apoio ao Adolescente

Disciplina de Especialidades Pediátricas

Departamento de Pediatria

MVENTÁRIO DE COMIPORTAMENTOS DA INFÂNCIA E ADOLESCENCIA

VERSAO BRASILEIRA DO "CHILD BEHAVIOR CIECKLIST" (CBCL)

Ficho nuricio

(Para faixa ctária de 4 a 18 anos)

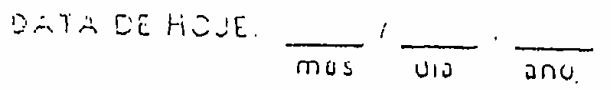

NUME EA CRIANCA OU ADOLESCENTE:

Sixo Masculino $\square$ ferninino

GRUPOETHEO OU RACA.

$150 i$

JiTA SENASCINENTO:

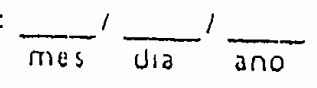

ESCOMAIDADE:

NÁ FREOUENTA ESCOLA $\square$
TRADALHO DOS PAIS: OCUPACAO KADITUA:. mosmo que njo eslejam iroojlimanuo no momento. Favor aspocilicar o lipe od ocudacjo por exemolo: mecanicu de juidinurers, jrolessor do scounus grau, duna ue casj. uinaleilo. lorneiso moeanico, vendedor du sapjlu: aruenio Jo exercilul

Tipo jotrabalkio do par.

Idaue:

H. Tipo de rouaho da mje:

Idade:

ESTA FICHA ESTA SENDO PREENCHIDA POR linlormanlel:

- Mise inornes:

$\because$ Psinomel:

Tulro: inomel:

Jrju oc parentesco ou lipo de relacionamento com a cibaça ou adolescentel:

Favor pioencher este quostionário de acordo com sou ponio do vista sobro o comporamenlo de zeu illho. mesmo que oulras pessoas najo concordam. Comentários adicionais sajo benvindos e pouern ser znol30os 20 lado.jo cada liom e no espaco existonte na pjoina J. 
1 Por lizvor cummere os esportes que seu lilho nuils gosta de praticar. Por idade, quania com outras crianças da mesma exemplo nalugĩo.

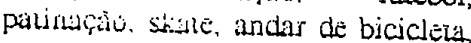
EIC

\section{$\square$ nemhun}

a)

b)

c) cada um?

$\begin{array}{lccc}\text { Nao } & \text { Menos } & \text { Denuro da } & \text { Mais que a } \\ \text { sei } & \begin{array}{c}\text { que a } \\ \text { média }\end{array} & \text { média } & \text { média } \\ \square & \square & \square & \square \\ \square & \square & \square & \square \\ \square & \square & \square & \square\end{array}$

Em comparaçăo com outras criancas da mesma idade, em que grau consegue se sair bem era cada um?

$\begin{array}{cccc}\text { Não } & \begin{array}{c}\text { Abaixo } \\ \text { sei }\end{array} & \begin{array}{c}\text { Denta da } \\ \text { média }\end{array} & \begin{array}{c}\text { Acima da } \\ \text { média }\end{array} \\ \square & \text { média } & & \\ \square & \square & \square & \square \\ \square & \square & \square & \square\end{array}$

l1 For livor enumere os Em comparação com outras crianças da mesma pussilerripus. auvidades e jogos idade, quano tempo aproximadamente pratica fivoritus du setu litho que nâo sejam cada um? esportes. Por exemplo: selos, bonccas, livros, rabulhos manuais, cantar. elc (uio inclua ouvir rádio, oid ver ielevisijo)

[ neptiman

a)

b)

c)

$-2$

11. Por ïvor enunere quaisquer oreurivicioss, clubes, equipes ou grupos a que seu filho(a) parença

[.] nenน่นแั

a)

b).

c)

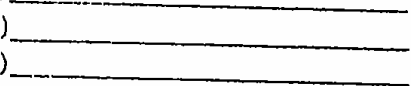

Ern comparacão com ourras criancas da mesma idade, em que grau é ativo(a) em cada un?

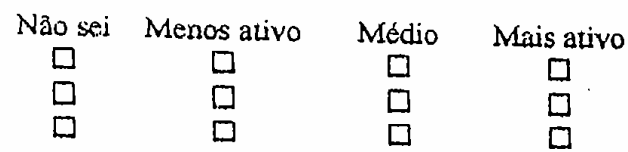

IV Por ravor enumere quaisquer Em comparação com outras crianças da mesma Empregüs on listefas de seu filho (a). idade,

Por cximplo: lavar a lousian, lomar em que grau consegue desempenhámlas bem? contin lisis criangiss, fazer a cama, elc. (imclui lanto trabalhos pagos como näo pugos)

口ncibun

a).

b)

\begin{tabular}{|c|c|c|c|c|c|c|}
\hline $\begin{array}{l}\text { Menos que } \\
\text { a média }\end{array}$ & $\begin{array}{l}\text { Denuro da } \\
\text { média }\end{array}$ & $\begin{array}{l}\text { Mais que } \\
\text { a média }\end{array}$ & Năo sei & $\begin{array}{l}\text { Abaixo } \\
\text { da }\end{array}$ & $\begin{array}{l}\text { Denuro da } \\
\text { média }\end{array}$ & $\begin{array}{l}\text { Acima dit } \\
\text { média }\end{array}$ \\
\hline $\begin{array}{l}\square \\
\square \\
\square\end{array}$ & $\begin{array}{l}\square \\
\square \\
\square\end{array}$ & $\begin{array}{l}\square \\
\square \\
\square\end{array}$ & $\begin{array}{l}\square \\
\square \\
\square\end{array}$ & $\begin{array}{c}\text { média } \\
\square \\
\square \\
\square\end{array}$ & $\begin{array}{l}\square \\
\square\end{array}$ & $\begin{array}{l}\square \\
\square \\
\square\end{array}$ \\
\hline
\end{tabular}

Em comparaça com outras crianças da mesma idade, em que grau consegue se sair bem em cada um?

ـ) $\quad \begin{array}{cccc}\text { Nâo sei } & \text { Abaixo da } & \text { Dentro da } & \text { Acima da } \\ \square & \text { média } & \text { média } & \text { média } \\ \square & \square & \square & \square \\ \square & \square & \square & \square \\ \square & \square & \square & \square\end{array}$

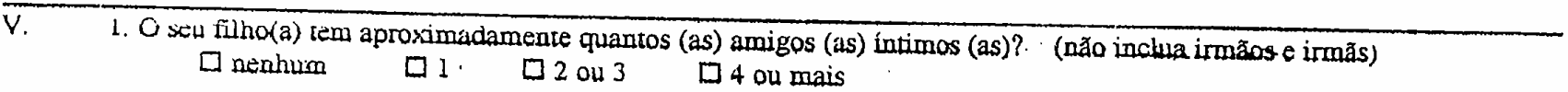

2. O. Situ Filho (a) tem arividade com os amigos (as) fora das horas de aula aproximadamente quantas vezes por semana? (não

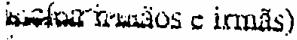
q Menos que 1
$\square \operatorname{lou} 2$
Q 3 ou mais 


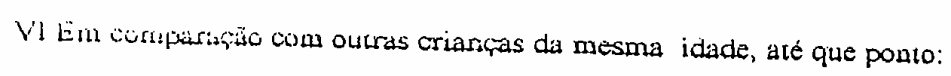

a) Cortis gue rilucionar-se dodequidaroente com os seus/suas iringos un irsiajs?

\begin{tabular}{ccccc} 
Pior & $\begin{array}{c}\text { Próximo (a) da } \\
\text { média }\end{array}$ & Melhor & & \\
$\square$ & $\square$ & $\square$ & $\square$ & não tem urmãos \\
$\square$ & $\square$ & $\square$ & & ou irmas \\
$\square$ & $\square$ & $\square$ & & \\
$\square$ & $\square$ & $\square$ & & \\
\hline
\end{tabular}

b) Corisegut se relacionar-se adequidemente com os outras craingist?

c) Conscisu= comportar-se ad dequidamente em relação aos pidis"

d) Conssuc divertir.se e urabilhar sozinho(a)

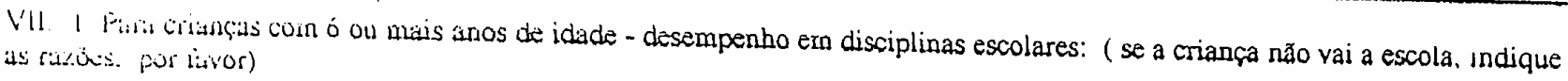
a) Ponugues
b) Malemánica
c) História ou Estudos Sociais
d) Ciências

Uutris nuilćrias - por e)

cicinplo: compulação,

linguis estrangcira.

Niso ivelua educaquio

Iisicin

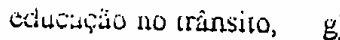
$\dot{c}$

$\begin{array}{cccc}\begin{array}{c}\text { Maus } \\ \text { resultados }\end{array} & \begin{array}{c}\text { Abaixo da } \\ \text { média }\end{array} & \begin{array}{c}\text { Dentro da } \\ \text { média }\end{array} & \text { Acima da média } \\ \square & \square & \square & \square \\ \square & \square & \square & \square \\ \square & \square & \square & \square \\ \square & \square & \square & \square \\ \square & \square & \square & \square \\ \square & \square & \square & \square \\ \square & \square & \square & \square\end{array}$

2. O seu lillo (a) freqüenta algum estabelecimento ou classe de ensino especial? $\square$ Năo $\square$ Sim - que tipo de escola ou
see?

3. O seu ilino (a) reperiu algum ano? $\square$ Não $\square$ Sim - qual e porque?

4. O seu ïllho (a) leve algum problema na escola, de aprendizagem ou outro? $\square$ Não $\square$ Sim - Descreva-o por favor, em
serrie? que seris:?

Quiritio coniegaram ésses problemas?

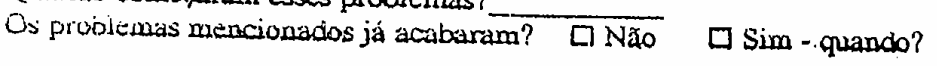

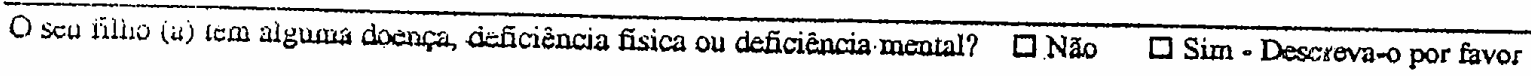

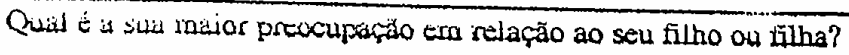

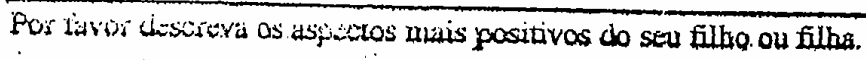


A lis ra ataxo écompos"la o liens quo doscrovem componamentos de criancas odoloscantas conjorme Tres possibilidados

O Tiem Falso ou comportamenio ousenle.

1 Bien parcialmente veroadeiro ou componamento as vezes piesente.

2 fíem basianic veroudeiro ou comporamenlo irtequentemente presenle.

Para casa Tein. taca um circulo a redor do numero 0, 1 ou 2. favor kaspondar tooos os trens, mesmo aqueles quo parocem najo Ter nenhuma rolacio com o

0 I 21 Eomporis-se do modo inianiil. como so livesso menos adada.

0122 Tem jurgia. Oescrova
01212 Outixz-so ó solidac

012 13. Parece eslar con!jux aiorvjau.

01214 . Chora muilo.

$01 \geq 15$. E crues com os arimas

o 12 16. E cruer, malliaia os pesiod:

01217. Fica no munoo a dua jervioc nos proprios pensamenic: loveraneios. ioumenios para nào lazer o que deveris lazer:

0 i 24 Tem asma ou bínquile. $\therefore \quad 0,18$. Machuca-so do proposito.
Tentou suicidar.se.

- $r 25$. Compono-se como sa losso do Sexo oposic

- i 2 6. Fal coco na calca ou loca do vaso sanicario lou lora do penicol.

- 12 r. Econvencioo. paba-se de si mesmo.

- 2 E distraldo, najo conseque prestar alencjo por muito lernpo.

1) 2 9. Njo consepue cirar ceros Densamentos da cadoca lobsessóesl. Dascruva:

0.12 19. Exige que prosiem alençào nela

012 20. Desiror as proprias coisas

0 : 2 21. Desiroi as coisas de sua Familia ou da outras crianças lou adolescentesl.

$0 \quad 12$ 22. E desovodiento em casa

012 23. E desodedionie na escola.

012 24. E dillcil para comer lnajo quer se ahmenlar direito.

01 1. 25. Näo sa da bem com outras criancas lou adolascentes.

01226 . Falla da arrependimerito, nia so sento culpado após ler se comporado mai. Descreva:

O 12 10. E apilado. näo para quieto.

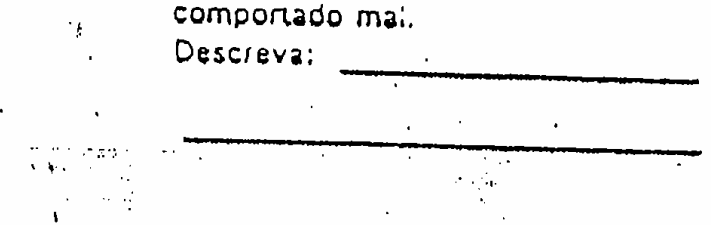

O 12 Tomabebida alcódicas

012 navo lomigue turminar ogle come cas 
01227 Fica com ciumes lacilmania

312 28. Come ou beog coisas qua náo sorvarn para ser comidas ou babioas. Doscrava:
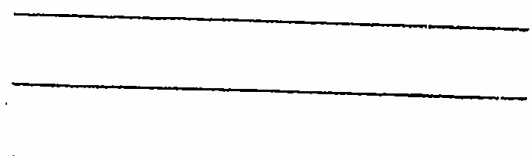

- 12 29. Ton múdo de cenos unimais. sibuaçós ou luoaras inajo inciur. ascoial.

Uescreva

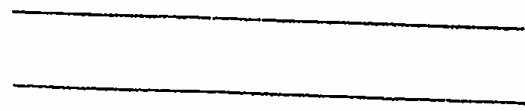

Q 3230 . Tenn medo oe ir a escola.

- 1231 . Tern mado de comater aloum aro desirulivo iconira si ou conira outrosl.

() 1232. :om mania- do porlaçjo.

Q 1233 . Ácha que ninoúem gosia dele.

o i 234 . Acha que os outros o perseguem.

- 1235. Sonio-se desvalorizado, intarior.

- 2 2 36. Miachuca-se com Ireqüencia, $10 \mathrm{~m}$ lendencia a solres acioentes.

0 1237 . Enrra em muitas bripas.

01238. E alvo de gozacòes frequentemente.

012 39. Anda em mas companhias.

- 12 40. Escuta sons ou vozes que não existem.

Descreva:

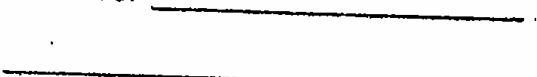

0. 1.

0. 12

012

$0: 12$
01
42. Prelera licar sozinno do que na compantia de outros.
- 12 43. Menie ou ongana os oulros
$032+4$ Roi unnas
01245. a nervoso, ienso.
01246. iem "rique neryoso.
Descreva

01247 Tem pesadelos

- 2 de. As oulras criancas lou adolascentes nào oosiam dele.

01249. Tem prisāo de ventre, intesunc Dieso.

- 12 50. E madroso ou ansioso demais

01251 Tom coniuras.

Q 1252. Sente-so excessivamento culpado

01253 . Corno exaperadamente.

01254 . Sento-se cansado demais.

012 55. Está pordo demais.

56. Na sua opinizo, apresenta quelxas llsicas por "norvoso" Isem causa medical:

012 a. Dores /diferentes das citadas abaixo,

- 12 b. Dores de cabeca.

o 12 c. Náuseas. enjoos.

o 12 d. Problemas com os olhos. Descreva:
e. Problernas de pele.
1. Doras de estomzoo ou de barrioa.
o. Vomitos.
h. Outras queixas.
Descrexa:

- 1.2.4. E impulsivo. poe sem perisar.

012 arginimita minto

012 Desrespenta regias

Hó poucass cousas que daib. mazer a ele. 
0 \{ $257 . A 13 c j$ lisicomanto as pessoas.

01258 . Fica cutucando o nariz. a pale ou outras parios oo corpo

Jescisva:

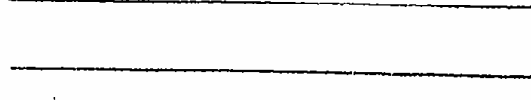

1) 1253 . inexe nas partes intimas am publico.

( 1250. Mexe demas nas partes intimas.

o $r$ =

- 12 c.z Edesastraoo. jesajerrado ftem má coordenaça motora).

5 1263 . Prefere brincar com criancas lou adolescentosi mas velnas.

- 12 oi. Prefero brincas com criancas lou auclescen(es) mais novas.

i. 1. 265 hacusa-se a falar.

o 7 ü Repete cenos atos várias vezes soguivas lcompulsóest.

Descreva:
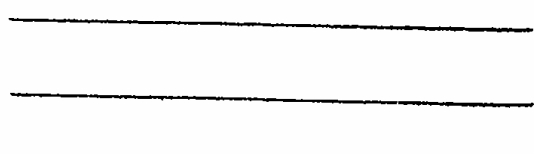

$0 \quad i z 57$. Fooe da casa.

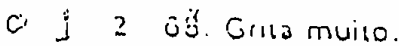

- 12 69. Eleservado. techado, nào conta suas coisas para ninquém.

O 1. 2 70. Vé coisas que nào existem. Descreva:
- 12 Ti. Fica som jeitro na frenio dos outios com jacllidade. proocuoado como qua as pessoas possam acriar oeio

(i) 1272 pófogonas rolsas

- 1 z 73 fom probiemas saxuais Desciava

01274 . Fica 50 mostrando ou fazendo palnzcaoas para chamar a ençào

01275 E Timios

o 2 2 76 . Dorme menos que a maioria oas clianças .ou aoolescentesi.

o 1277 Oorme rnars que a maroria das crianças lou adolescentes) durante o dia ou a noila.

Descreva

01278 . Lambuza-so ou brinca com as proprias lezes.

0 12 79. Tern problemas de Tala. Descrava:

0. 12 80. Fica com o olhar parado, "olnando o vazio".

o 1 2. 8 il. Houba em casa.

01282 . Rouba lora de casa.

0.728 . Junia coisas das quais näo nacessita. nem.wiliza.

Doscreva: 


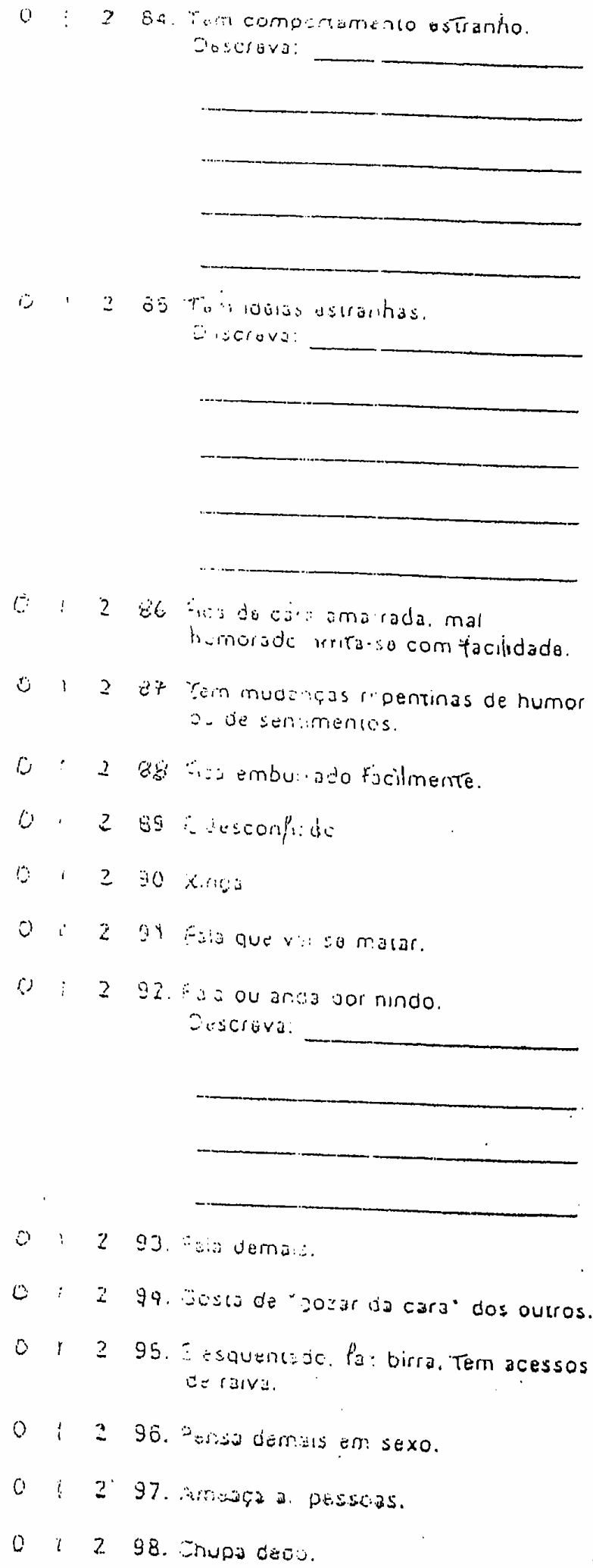

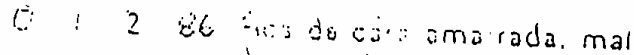
himorade urira-so com facilidado.

0 12 ef Tin mudecicas r.pentinas de humar o- je senmentos.

0. 2 ras injembu a o focilmente.

O. $239 \therefore-i e s c o n p: d$

$01230 x \sin$

0 i 2 ay ras que vi: so marar.

$0 \quad 292$ : 2 s ou arez jor nindo zescruva.

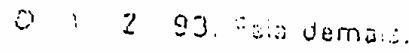

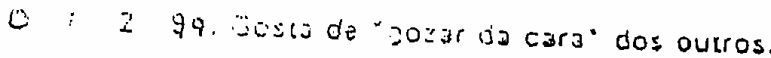

or 295. E esquencide. Pa: birra. Tem acessos de rava.

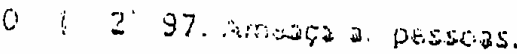

01298 . Inupa deo.

- 12 99. E praccupsoo oemais com oroum ou limpo:a. 012 100. Tem frobiamas a o o sono
Descrivis

012 10!. Cabula as aulas

012 102. E pourc ativo, mevimanta-se vacaros aman: ou falk - the onergia

012 103. Entel r. Triste ou japrimido

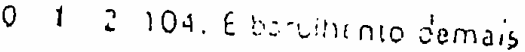

012 105. Fan uso ae drooss ou de bedidas diccoirc:

Descerva

012 106. Es.oga nu oestror cossas Dubicas lvinealsmo.

cescreva.

0 12 107. Fas xica na roupa durania o dia

0 1.2 108. Fa: xi.j. ca cama.

o 12 109. Fic s cho: smingando, lazando manh.

01.2110 . Gostaria oa ser do sexo oposio

0. 12 111. E rewalou. nío sa relaciona com os oures

D 12.112 . Emisito preocupado. Descrava: 


\section{REFERÊNCIAS}

Abraão I. Factores de Risco e factores para as toxicodependências: uma breve revisão. Revista Toxicodependência. 1999;5(2):48.

Achenbach System of Empirically Based Assessment (ASEBA). Manual for the assessment data manager program (ADM). Burlington, VT: ASEBA;2006.

Achenbach TM. Manual for the child behavior checklist/4-18 and 1991 profile. Burlington: University of Vermont Department of Psychiatry; 1991.

Achenbach TM, Bird HR, Canino G, Phares V, Gould MS, Rubio-Stipec M. Epidemiological comparisons of Puerto Rican and US mainland children: parents, teacher and self-report. J Am Acad Child Adolesc Psychiatry. 1990 Jan;29(1):84-93.

Achenbach TM, Edelbrock CS. The classification of child psychopathology: A review and analysis of empirical efforts. Psychol Bull. 1978;85:1275-301.

Achenbach TM, Rescorla LA. Manual for the ASEBA school-age forms \& profiles. Burlington, VT: University of Vermont, Research Center for Children, Youth, \& Families; 2001.

Achenbach TM, Rescorla LA. Mental health practitionersguide for the Achenbach System of Empirically Based Assessment (ASEBA). 4th ed. Burlington, VT:

University of Vermont, Research Center for Children, Youth, \& Families; 2004.

Achenbach TM, Rescorla LA. Multicultural supplement to the manual for the ASEBA school-age forms \& profiles. Burlington, VT: University of Vermont, Research Center for Children, Youth, \& Families; 2007.

American Academy of Pediatrics (AAP). Practices and attitudes toward adolescent drug screening. Periodic Survey of Fellows. 1997;(31).

American Psychiatric Association (APA). Diagnostic and statistical manual of mental disorders (DSM-IV). Washington, DC: APA; 1994.

Amesty E. Validación de una escala de factores de riesgo asociados al consumo de drogas - DUSI [dissertação]. Edo Zulia: Universidad del Zulia; 1996.

Armstrong BK, White E, Saracci R. Principles of exposure measurement in epidemiology. New York: Oxford University Press; 1994.

Aytaclar S, Erkiran M, Kirisci L, Tarter R. Substance abuse and associated psychosocial risk factors among Turkish male adolescents. Addict Behav. 2003;28(8):1419-29 [cited 2010 Juny 15]. Available from: www.sciencedirect.com. 
Banco Mundial. Relatório jovens em situação de risco de 2007. 2007 [citado set. 2008]. Disponível em: www.bancomundial.org.br.

Baus J, Kupek E, Pires M. Prevalência e fatores de risco relacionados ao uso de drogas entre escolares. Rev Saúde Pública. 2002;36:40-6.

Bordin IAS, Mari JJ, Caeiro MF. Validação da versão brasileira do Child Behavior Checklist (CBCL) (inventário de comportamentos da infância e adolescência): dados preliminares. Rev ABP-APAL. 1995;17(2):55-66.

Bordin IAS, Paula CS, Nascimento R, Duarte CS. Severe physical punishment and mental health problems in an economically disadvantaged population of children and adolescents. Rev Bras Psiquiatr. 2006; 28(4):290-6.

Brasil. Leis etc. Lei n. 8.069 de 13 de julho de 1990. Dispõe sobre o Estatuto da Criança e do Adolescente e dá outras providências. Diário Oficial da União, Brasília (DF). 199016 jul.

Brodey BB, Mcmullin D, Kaminer Y, Winters KC, Mosshart E, Rosen CS, Brodey IS. Psychometric characteristics of the Teen Addiction Severity Index-Two (TASI-2). Subst Abus. 2008;29(2):19-32.

Brodey BB, Rosen CS, Winters KC, Brodey IS, Sheetz BM, Steinfeld RR, Kaminer Y. Conversion and validation of the Teen-Addiction Severity Index (T-ASI) for internet and automated-telephone self-report administration. Psychol Addict Behav. 2005;19(1):54-61.

Brown S, Yalom ID. Interactional group therapy with alcoholics. J Stud Alcohol. 1977;38:426-56.

Burleson JA, Kaminer Y. Does temperament moderate treatment response in adolescent substance use disorders. Subst Abus. 2008;29(2):89-96.

Carlini EA, Galduróz JCF, Noto AR, Nappo SA. I levantamento domiciliar sobre o uso de drogas psicotrópicas no Brasil: estudo envolvendo as 107 maiores cidades do País - 2001. São Paulo: Centro Brasileiro de Informações sobre Drogas Psicotrópicas/Universidade Federal de São Paulo; 2002.

Carminatti VJP. Validação concorrente e confiabilidade da versão brasileira do ASSIST-WHO (Alcohol, Smoking and Substance Involvement Screening Test) para adolescentes [dissertação]. São Paulo: Universidade Federal de São Paulo; 2010.

Carmines EG, Zeller RA. Reliability and validity assessment. Beverly Hills: Sage; 1979. (Quantitative applications in the social sciences).

Carr MB, Vandiver TA. Risk and protective factors among youth offenders.

Adolescence. 2001;36(143):409-26. 
Cartana M, Santos SMA, Fenili RM, Spricigo JS. Prevenção do uso de substâncias psicoativas. Texto Contexto Enferm. 2004;13(2):286-9.

Carvalho V, Pinsky I, Silva RS, Carlini-Cotrim B. Drug and alcohol use and family characteristics: a study among Brazilian high-school students. Addict. 1995;90:6572 .

Castro-Fornieles J, Díaz R, Goti J, Calvo R, Gonzalez L, Serrano L, Gual A. Prevalence and factors related to substance use among adolescents with eating disorders. Eur Addict Res. 2010;16(2):61-8.

Catalano RF, Hawkins ID, Wells EA, Miller J, Brewer D. Evaluation of the effectiveness of adolescent drug abuse treatment, assessment of risk for relapse, and promising approaches for relapse prevention. Int J Addict. 1990-1991;25(9A10A):1085-140.

Christensen HB, Bilenberg N. Behavioural and emotional problems in children of alcoholic mothers and fathers. Eur Child Adolesc Psychiatry. 2000;9(3):219-26.

Christie G, Merry S, Robinson E. Do young people attending addiction services differ from those attending youth mental health services? Drug Alcohol Rev. 2010;29(4):406-12.

Claro HG. Tradução e a adaptação cultural do instrumento Global Appraisal of Individual Needs - Initial [dissertação]. São Paulo: Universidade de São Paulo; 2010.

Coopersmith S. Coopersmith self-esteem inventory. Palo Alto: Consulting Psychologists Press; 1989.

Creemers HE, Van Lier PA, Vollebergh WA, Ormel J, Verhulst FC, Huizink AC. Predicting onset of cannabis use in early adolescence: the interrelation between high-intensity pleasure and disruptive behavior. The TRAILS Study. J Stud Alcohol Drugs. 2009;70(6):850-8.

Cronbach LJ. Coefficient alpha and the internal structure of tests. Psychometrika. 1951;16(3):297-335.

Cronbach LJ, Meehl PE. Construct validity in psychological tests. Psychol Bull. 1955;52(4):281-302.

Dalla-Déa HRF, De Micheli D, Formigoni MLOS. Effects of identification and usefulness of the lie scale of the drug use screening inventory (DUSI-R) in the assessment of adolescent drug use. Drug Alcohol Depend. 2003;72(3):215-23.

De Micheli D, Fisberg M, Formigoni ML. Estudo da efetividade da intervenção breve para o uso de álcool e outras drogas em adolescentes atendidos num serviço de assistência primária à saúde. Rev Assoc Med Bras. 2004;50(3):305-13. 
De Micheli D, Formigoni ML. Screening of drug in a teenage Brazilian sample using the drug use screening inventory (DUSI). Addict Behav. 2000;25(5):683-91.

De Micheli D, Formigoni ML. Psychometric properties of the Brazilian version of the drug use screening inventory. Alcohol Clin Exp Res. 2002; 26(10):1523-8.

De Micheli D, Formigoni ML. Drug use by Brazilian students: associations with family, psychosocial, health, demographic and behavioral characteristics. Addiction. 2004; 99(5):570-8.

Dennis ML, Godley SH, Diamond G, Tims F, Babor T, Donaldson J, Liddle H, Titus JC, Kaminer Y, Webb C, Hamilton N. Main findings of the cannabis youth treatment randomized field experiment. J Subst Abuse Treat. 2004;27:197-213.

Díaz B, Arellánez J, Martínez J. Uso de drogas y factores psicosociales asociados entre estudiantes de educación media básica del estado de Nuevo León. In: Medina-Mora ME, coordenador. Observatorio mexicano en tabaco, alcohol y otras drogas, 2002. México: Consejo Nacional contra las Adicciones; 2002. p. 133-6.

Díaz R, Castro-Fornieles J, Serrano L, González L, Calvo R, Goti J, Kaminer Y, Gual A. Clinical and research utility of Spanish Teen-Addiction Severity Index (TASI). Addict Behav. 2008 [cited 2010 may 12];33(1):188-95. Available from: www.sciencedirect.com.

Duarte CS, Bordin IAS. Instrumentos de avaliação. Rev Bras Psiquiatr. 2000;22(2). Disponível em: http://dx.doi.org/10.1590/S1516-44462000000600015.

Dunn J, Laranjeira R. Transitions in the route of cocaine administration characteristics, direction and associated variables. Addiction. 1999;94(6):813-24.

Dupont RL. Prevention of adolescent chemical dependency. Pediatr Clin North America. 1987;34(2):495-505.

Ehlers CL, Wall LT, Garcia-Andrade C, Phillips E. Visual P3 findings in Mission Indian youth: relationship to family history of alcohol dependence and behavioral problems. Psychiatry Res. 2001;105(1-2):67-78.

Farrel AD, Danisch SJ, Howard CW. Risk factors for drug use in urban adolescents: identification and cross-validation. Am J Community Psychol. 1992;20(3):263-86.

Ferdinand RF, Blüm M, Verhulst FC. Psychopathology in adolescence predicts substance use in young adulthood. Addiction. 2001;96(6):861-70.

Fidalgo TM, Tarter R, Silveira ED, Kirisci L, Silveira DX. Validation of a short version of the revised drug use screening inventory in a Brazilian sample of adolescents. Am J Addict. 2010;19(4):364-7. 
Figlie N, Fontes A, Moraes E, Payá R. Filhos de dependentes químicos com fatores de risco bio-psicossociais: necessitam de um olhar especial? Rev Psiquiatr Clín (São Paulo). 2004;31(2):53-62.

Fleitlich BW, Cortazar PG, Goodman R. Questionário de Capacidades e Dificuldades (SDQ). Infanto. 2000;8:44-50.

Fletcher RH, Fletcher SW. Epidemiologia clínica: elementos essenciais. 4a ed. Porto Alegre: Artmed; 2004.

Fletcher RH, Fletcher SW, Wagner EHW. Clinical epidemiology: the essentials. 2nd ed. Baltimore: Williams \& Wilkins; 1988.

Formigoni MLOS, Castel S. Escalas utilizadas na avaliação de dependências: aspectos gerais. Rev Psiquiatr Clín. 1999;26(1 e 2):267-9.

Fraile Duvicq CG, Pereira NR, Carvalho AMP. Consumo de drogas lícitas e ilícitas en escolares y factores de protección y riesgo. Rev Lat Am Enfermagem. 2004 [citado 10 nov. 2011];12:345-51. Disponível em:

http://www.scielo.br/scielo.php?script=sci_arttext\&pid=S0104-

$11692004000700008 \& \operatorname{lng}=$ en $\& n r m=$ iso.

Furtado EF, Laucht M, Schmidt. Gender-related pathways for behavior problems in the offspring of alcoholic fathers. Braz J Med Biol Res. 2006;39(5):659-69.

Galduróz JCF, Noto AR, Fonseca AM, Carlini EA. V Levantamento nacional sobre o consumo de drogas psicotrópicas entre estudantes do ensino fundamental e médio da rede pública de ensino nas 27 capitais brasileiras - 2004. São Paulo: CEBRID/UNIFESP; 2004.

Getter H, Litt MD, Kadden RM, Cooney NL. Measuring treatment process in coping skills and interactional group therapies for alcoholism. Int J Group Psychother. 1992;42:419-30.

Goodman R. The strenghts and difficulties questionnaire: a research note. $J$ Child Psychol Psychiatr. 1997;38:581-6.

Gosebruch G, Sánchez M, Delva J, Wagner F, Anthony J. Family attention and tobacco smoking among adolescents in Central America, Panama, and the Dominican Republic. Subst Use Misuse. 2003;38(8):1037-62.

Halpern-Felsher BL, Ozer EM, Millstein SG, Wibbelsman CJ, Fuster CD, Elster $\mathrm{AB}$, Irwin CE Jr. Preventive services in a health maintenance organization: how well do pediatricians screen and educate adolescent patients? Arch Pediatr Adolesc Med. 2000;154(2):173-9. 
Hawkins JD, Catalano RF, Miller JY. Risk and protective factors for alcohol and other drug problems in adolescence and early adulthood: implications for substance abuse prevention. Psychol Bull. 1992;112(1):64-5.

Hulley SB, Cummings SR, Browner WS, Grady DG, Newman TB. Delineando a pesquisa clínica: uma abordagem epidemiológica. 2a ed. Porto Alegre: Artmed; 2003.

Jinez MLJ, Souza JRM, Pillon SC. Drug use and risk factors among secondary students. Rev Lat Am Enfermagem. 2009;17(2):246-52.

Johnston LD, O’Malley PM, Bachman JG. News and information services. Michigan: University of Michigan; 1996.

Jorge MR, Masur J. Questionários padronizados para avaliação do grau de severidade da síndrome de dependência do álcool. J Bras Psiquiatr. 1986;35(5):287-92.

Kaminer Y. Adolescent substance abuse: a comprehensive guide to theory and practice. New York: Plenum Medical; 1994.

Kaminer Y. Adolescent substance abuse treatment: where do we go from here? Psychiatr Serv. 2001;52:147-9.

Kaminer Y. The teen addiction severity index around the globe: the tower of babel revisited. Subst Abus. 2008;29(3):89-94.

Kaminer Y, Blitz C, Burleson J, Kadden R, Rounsaville BJ. Measuring treatment process in cognitive-behavioral and interactional group therapies for adolescent substance abusers. J Nerv Ment Dis. 1998;186(7):407-13.

Kaminer Y, Bukstein OG, Tarter RE. The teen addiction severity index: rationale and realiability. Int J Addict. 1991;26:219-26.

Kaminer Y, Bukstein OG. Adolescent substance abuse, psychiatric comorbidity and high-risk behaviors. New York: Taylor \& Francis; 2008.

Kaminer Y, Burleson JA. Psychotherapies for adolescent substance abusers: 15month follow-up of a pilot study. Am J Addict. 1999;8(2):114-9.

Kaminer Y, Burleson JA. Correlation between ancillary community services with adolescent substance use disorders treatment outcome. Subst Abus. 2004;25(2):1520.

Kaminer Y, Burleson JA, Goldberger R. Psychotherapies for adolescent substance abusers: short- and long-term outcomes. J Nerv Ment Dis. 2002;190:737-45. 
Kaminer Y, Wagner E, Plummer B, Seifer R. Validation of the Teen Addiction Severity Index (T-ASI): preliminary findings. Am J Addict. 1993;2:221-4.

Kelsey JL, Whittemore AS, Evans AS, Thompson WD. Methods in observational epidemiology. New York: Oxford University Press; 1996.

Kirisci L, Tarter R, Mezzich A, Reynolds M. Screening current and future diagnosis of psychiatric disorders using the revised drug use screening inventory. Am J Drug Alcohol Abuse. 2008;34(5):653-65.

Kirisci L, Hsu TC, Tarter R. Fitting a two-parameter logistic item response model to clarify the psychometric properties of the Drug Use Screening Inventory for adolescent alcohol and drug abusers. Alcohol Clin Exp Res. 1994;18:1335-41.

Kirisci L, Tarter R, Reynolds M. The violence proneness scale of the DUSI-R predicts adverse outcomes associated with substance abuse. Am J Addict. 2009;18(2):173-7.

Klerman GL. Diagnosis of psychiatric disorders in epidemiologic field studies. Arch Gen Psychiatry. 1985;42:723-4.

Korhonen T, Van Leeuwen AP, Reijneveld SA, Ormel J, Verhulst FC, Huizink AC. Externalizing behavior problems and cigarette smoking as predictors of cannabis use: the TRAILS Study. J Am Acad Child Adolesc Psychiatry. 2010 Jan;49(1):61-9.

López GKS, Costa JML. Conducta antisocial y consumo de alcohol en adolescentes escolares. Rev Lat Am Enfermagem. 2008;16(2):299-305.

Marques AC. A importância da avaliação inicial. In: Pinsky I, Bessa MA, organizadores. Adolescência e drogas. São Paulo: Contexto; 2004. p. 150-6.

Mathews IS, Pillon SC. Factores protectores y de riesgo asociados al uso de alcohol en adolescentes hijos de padre alcohólico, en el Perú. Rev Lat Am Enfermagem. 2004 [citado 10 nov. 2011];12(esp.):359-68. Disponível em: http://www.scielo.br/scielo.php?script=sci_arttext\&pid=S0104$11692004000700010 \& \operatorname{lng}=$ en\&nrm=iso.

McLellan AT, Alterman AI, Cacciola J, Metzger D, O'Brien CP. A new measure of substance abuse treatment: initial studies of the treatment services review. J Nerv Ment Dis. 1992;180:101-10.

McLellan AT, Luborsky L, Woody GE, O’Brien CP. An improved diagnostic evaluation instrument for substance abuse patients: the Addiction Severity Index. $J$ Nerv Ment Dis. 1980;168:26-33.

Menezes PR, Nascimento AF. Validade e confiabilidade das escalas de avaliação em psiquiatria. Rev Psiquiatr Clín (São Paulo). 1998;25(5-6):214-6. 
Menezes PR, Nascimento AF. Validade e confiabilidade das escalas de avaliação em psiquiatria. Rev Psiquiatr Clín (São Paulo). 1999;26(1-2).

Moss HB, Bonicatto S, Kirisci L, Girardelli AM, Murrele L. Substance abuse and associated psychosocial problems among Argentina adolescents: sex heterogeneity and familial transmission. Drug Alcohol Depend. 1998;52(3):221-30.

Murrelle L, Sandí L, Díaz A. Cuestionario sobre hábitos, actividades y relaciones de los jóvenes. Rev Cienc Soc. 1977;77:87-95.

Navarro M, Pontillo V. Autoestima del adolescente y riesgo de consumo de alcohol. Actual Enferm. 2002;5(1):7-12.

Ndetei DM, Khasakhala LI, Mutiso V, Ongecha-Owuor FA, Kokonya DA. Psychosocial and health aspects of drug use by students in public secondary schools in Nairobi, Kenya. Subst Abus. 2009;30(1):61-8.

Negrete BD, García-Aurrecoechea R. Factores psicosociales de riesgo de consumo de drogas ilícitas en una muestra de estudiantes mexicanos de educación media. Rev Panam Salud Publica. 2008;24(4)223-32.

Negrete BD, González D, García-Aurrecoechea R. Adaptación del drug use screening inventory para su aplicación con adolescentes mexicanos. Adicciones. 2006;18(2):197-210.

Noto AR. Levantamento sobre o consumo de drogas entre estudantes de escolas privadas paulistanas - 2010. São Paulo: FAPESP/UNIFESP; 2010 [citado set. 2010]. Disponível em: http://ultimosegundo.ig.com.br/brasil/alcool-33-dos-jovensde-escolas-privadas-de-sp-ja-tomaram-porre/n1237655782511.html.

Noto AR, Baptista MC, Faria S, Nappo AS, Galduróz JCF, Carlini EA. Drogas e saúde na imprensa brasileira: uma análise de artigos e jornais publicados em revistas. Cad Saúde Pública. 2003;19(1):69-79.

Observatório Europeu da Droga e da Toxicodependência (OEDR). Relatório anual 2003: a evolução do fenómeno da droga na União Européia e na Noruega. Luxemburgo: Serviço das Publicações Oficiais das Comunidades Européias; 2003.

Occhini M, Teixeira M. Atendimento a pacientes dependentes de drogas: atuação conjunta do psicólogo e do psiquiatra. Estud Psicol (Natal). 2006;11(2):229-36.

Organização Mundial da Saúde (OMS). Transtornos devido ao uso de substâncias. In: Organização Pan-Americana da Saúde, Organização Mundial da Saúde, organizadores. Saúde mental: nova concepção, nova esperança. Relatório sobre a saúde no mundo. Brasília: Gráfica Brasil; 2001. p. 58-61.

Ornoy A, Daka L, Goldzweig G, Gil Y, Mjen L, Levit S, Shufman E, BarHamburger R, Greenbaumg CW. Neurodevelopmental and psychological 
assessment of adolescents born to drug-addicted parents: effects of SES and adoption. Child Abuse Negl. 2010;34:354-68.

Paula CS, Duarte CS, Bordin IAS. Prevalence of mental health problems in children and adolescents from the outskirts of Sao Paulo City: treatment needs and service capacity evaluation. Rev Bras Psiquiatr. 2007;29(1):11-7.

Pinsky I, Bessa MA, organizadores. Adolescência e drogas. São Paulo: Contexto; 2004.

Portney LG, Watkins MP. Validity of measurements. In: Portney LG, Watkins MP. Foundations of clinical research: applications to practice. Norwalk: Appleton \& Lange; 1993. p. 69-85.

Price JH, Jordan TR, Dake JA. Pediatricians' use of the 5 A's and nicotine replacement therapy with adolescent smokers. J Community Health. 2007;32:85101.

Raposo C. A política de atenção integral à saúde do adolescente e jovem: uma perspectiva de garantia de direito à saúde. Revista em Pauta. 2009 [citado jun. 2011];6(23). Disponivel em: http://www.e-publicacoes.")*MG'*FO,3)BG\$5\$F*)7+1( )\# "( F*(+\&\%)F7+n8\%)FcdDFdclG!

Rebolledo EAO, Medina NMO, Pillon SC. Factores de riesgo asociados al uso de drogas em estudiantes adolescentes. Rev Lat Am Enfermagem. 2004;12 (esp.):36975 .

Reich T, Cloninger P, Van Eedevegh JP, Rice RS, Mullaney J. Secular trends in the familial transmission of alcoholism. Alcohol Clin Exp Res. 1988;12(4):458-64.

Rettew DC, Lynch AD, Achenbach TM, Dumenci L, Ivanova MY. Meta-analyses of agreement between diagnoses made from clinical evaluations and standardized diagnostic interviews. Int J Methods Psychiatr Res. 2009 Sep;18(3):169-84.

Rocha MM, Silvares EFM. Projeto triagem: avaliação de adolescentes na triagem das clínicas-escola com o uso do CBCL e do YSR [relatório de pesquisa]. São Paulo: Instituto de Psicologia, Universidade de São Paulo; 2006.

Rocha MM, Silvares EFM. Um estudo comparativo entre duas traduções brasileiras do Inventário de Auto-avaliação para Jovens (YSR). Psicol Teor Prat. 2008;10(1):14-24.

Rodríguez MG, Villar Luis MA. Estudio descriptivo del uso de drogas en adolescentes de educación media superior de la ciudad de Monterrey, Nueva León, México. Rev Lat Am Enfermagem. 2004;12(esp.):315-30. 
Rodríguez S, Arellánez J, Díaz B, González D. Ajuste psicosocial y consumo de drogas. Cidade do México: Centros de Integración Juvenil; 1999. (Informede investigación 97-27).

Rohde LA, Biederman J, Busnello EA, Zimmermann H, Schmitz M, Martins S. ADHD in a school sample of Brazilian adolescents: a study of prevalence, comorbid conditions and impairments. J Am Acad Child Adolesc Psychiatry. 1999;38(6):716-22.

Salvo CG, Silvares EFM, Toni PM. Práticas educativas como forma de predição de problemas de comportamento e competência social. Estud Psicol (Campinas). 2005;22(2):187-95.

Sanchez ZM, Nappo SA. A sequiência de drogas consumidas por usuários de crack e fatores interferentes. Rev Saúde Pública. 2002;36(4):420-30.

Sanchez ZM, Oliveira LG, Nappo SA. Razões para o não-uso de drogas ilícitas entre jovens em situação de risco. Rev Saúde Pública. 2005;39(4). Disponível em: http://dx.doi.org/10.1590/S0034-89102005000400013.

Sandi L, Díaz A, Ugalde F. Drug use and associated factors among rural adolescents in Costa Rica. Subst Use Misuse. 2002;37(5-7):599-611.

Sartes LMA. Versão brasileira do T-ASI (Teen Addiction Severity Index): análise de consistência interna e validação da área de uso de substâncias [dissertação]. São Paulo: Universidade Federal de São Paulo; 2005.

Sartes LMA, De Micheli D. A detecção do uso abusivo em adolescentes usando o DUSI e o T-ASI. In: Duarte PCAV, Formigoni MLOS, organizadores. Detecção do uso abusivo e diagnóstico da dependência de substâncias psicoativas. Módulo 3. (SUPERA). Brasília: Secretaria Nacional de Políticas sobre drogas; 2008.

Sartes LMA, De Micheli D, Formigoni MLOS. Psychometric and discriminative properties of the Teen Addiction Severity Index (Brazilian Portuguese version). Eur Child Adolesc Psychiatry. 2009;18:653-61.

Schmid M, Goldbeck L, Nuetzel J, Fegert JM. Prevalence of mental disorders among adolescents in German youth welfare institutions. Child Adolesc Psychiatry Ment Health. 2008;2(1):2.

Scivoletto S. Tratamento psiquiátrico ambulatorial de adolescentes usuários de drogas [tese]. São Paulo: Universidade de São Paulo; 1997.

Scivoletto S. Tratamento psiquiátrico de adolescentes usuários de drogas. In: Laranjeira R, Andrade AG, Focchi GRA, Leite MC. Dependência química: novos modelos de tratamento. São Paulo: Roca; 2001. p. 65-85. 
Scivoletto S, Morihisa R. Conceitos básicos em dependência química de álcool e outras drogas na adolescência. Jornal Brasileiro de Dependência Química. 2001;2(1):30-3.

Search Institute. Profiles of student life and behaviors. Minneapolis: Search Institute; 2003.

Semltz L, Gold MS. Adolescent drug abuse. Psychiatric Clinics of North America. 1986;9:455-73.

Siewert EA, Stallings MC, Hewitt JK. Factor structure and concurrent validity of the drug use screening inventory in a community adolescent sample. Addict Behav. 2004;29(3):627-38.

Silva VA, Mattos HF. Os jovens são mais vulneráveis às drogas? In: Pinsky I, Bessa MA, organizadores. Adolescência e drogas. São Paulo: Editora Contexto; 2004. p. $31-44$.

Silva VA, Santos MC, Bessa M. Infância, adolescência e uso de cocaína/crack. Associação Brasileira de Psiquiatria. 2006 [citado 24 out. 2006]. Disponível em: http://www.abpbrasil.org.br/departamentos/coordenadores/coordenador/noticias/?dep $=9 \&$ not $=145$.

Silvares EF, Meyer SB, Santos EOL, Gerencer TT. Um estudo em cinco clínicasescola brasileiras com a lista de verificação comportamental para crianças (CBCL). In: Silvares EFM, organizador. Atendimento psicológico em clínicas-escola. Campinas: Alínea; 2006. p. 59-72.

Solhkhah R, Wilens TE, Daly JBA, Prince JB, Van Patten SL, Biederman J. Bupropion SR for the treatment of substanceabusing outpatient adolescents with attentiondeficit /hyperactivity disorder and mood disorders. J Child Adolesc Psychopharmacol. 2005;15(5):777-86.

Spitzer RL, Endicott J, Robins E. Clinical criteria and DSM-III. Am J Psychiatry. 1975;132:1187-92.

Streiner DL. Thinking small: research designs appropriate for clinical practice. Can J Psychiatr. 1998;43(7):737-41.

Streiner DL, Norman GR. Health measurement scales: a practical guide to their development and use. New York: Oxford University Press; 1989.

Szobot CM, Eizirik M, Cunha RD, Langleben D, Rohde LA. Neuroimagem no transtorno de déficit de atenção/hiperatividade. Rev Bras Psiquiatr. 2011 [cited 2011 Nov 10];23(suppl. 1):32-5. Available from:

http://www.scielo.br/scielo.php?script=sci_arttext\&pid=S1516-

44462001000500010\&lng=en\&nrm=iso. 
Tarter RE. Evaluation and treatment of adolescent substance abuse: a decision tree method. Am J Drug Alcohol Abuse. 1990;16(1-2):1-46.

Tarter RE, Kirisci L. Validity of drug use screening inventory for predicting DSMIII-R substance use disorder. J Child Adolesc Subst Abuse. 2001;10(4):45-53.

Tarter RE, Kirisci L, Feske U, Vanyukov M. Modeling the pathways linking childhood hyperactivity and substance use disorder in young adulthood. Psychol Addict Behav. 2007;21(2):266-71.

Tarter RE, Kirisci L, Vanyukov M, Cornelius J, Pajer K, Shoal GD, Giancola PR. Predicting adolescent violence: impact of family history, substance use, psychiatric history, and social adjustment. Am J Psychiatry. 2002;159(9):1541-7.

Tarter RE, Mezzich A, Kirisci L. Reliability of drug use screening inventory in adolescents alcoholics. J Child Adolesc Subst Abuse. 1994;3:25-36.

Tarter RE, Vanyukov M, Kirisci L, Reynolds M, Clark DB. Predictors of marijuana use in adolescents before and after licit drug use: examination of the gateway hypothesis. Am J Psychiatry. 2006;163(12):2134-40.

United Nations Office on Drugs and Crime (UNODC). World drug report. 2010 [cited 2010 Sept]. Available from: http://www.unodc.org/.

Van Hook S, Harris SK, Brooks T, Carey P, Kossack R, Kulig J, Knight JR. The "Six T's": barriers to screening teens for substance abuse in primary care. $J$ Adolesc Health. 2007;40:456-61.

Verhulst FC, Achenbach TM, Ferdinand RF, Kasius MC. Epidemiological comparisons of American and Dutch adolescents' self-report. J Am Acad Child Adolesc Psychiatr. 1993;32(6):1135-44.

Vittetoe K, López M, Delva J, Wagner F, Anthony J. Behavioral problems and tobacco use among adolescents in Central America and the Dominican Republic. Rev Panam Salud Publica. 2002;11(2):76-82.

Wall TL, Garcia-Andrade C, Wong V, Lau P, Ehlers CL. Parental history of alcoholism and problem behaviors in Native-American children and adolescents. Alcohol Clin Exp Res. 2000;24(1):30-4.

Windle M, Lerner RM. Reassessing the dimensions of temperamental individuality across the life span: the Revised Dimensions of Temperament Survey (DOTS-R). $J$ Adolesc Res. 1986;1:213-30.

Winters KC. Treating adolescents with substance use disorders: an overview of practice issues and treatment outcome. Subst Abus. 1999; 20(4):203-25. 
Winters KC, Kaminer Y. Screening and assessing adolescent substance use disorders in clinical populations. J Am Acad Child Adolesc Psychiatry. 2008;47(7):740-4.

Winters KC, Stinchfield R, Bukstein OG. Assessing adolescent substance use and abuse. In: Kaminer Y, Bukstein OG, editors. Adolescent substance abuse, psychiatric comorbidity and high-risk behaviors. New York: Taylor \& Francis; 2008. p. 53-85.

World Health Organization (WHO). Child and adolescent health and development. 2003 [cited 2008 Sept 5]. Available from: www.who.int/child-adolescenthealth/PREVENTION/adolescent.htm. 


\section{BIBLIOGRAFIA CONSULTADA}

Brasil. Ministério da Saúde. Saúde do adolescente e do jovem. [citado 11 maio 2011]. Disponível em: www.portaldasaude.gov.br/saudedoadolescenteedojovem.

Calderón Santamaría AE. Factores de riesgo asociados al uso de drogas en adolescentes [dissertação]. Maracaibo: Universidad Rafael Urdaneta; 2010.

Cohen J. A coefficient of agreement for nominal scales. Educ Psychol Meat. 1960;20:37-46.

Giancola P, Martin C, Tarter R, Moss H, Pelham W. Executive cognitive functioning and aggressive behavior in preadolescent boys at high risk for substance abuse. $J$ Stud Alcohol. 1996;57(4):352-9.

Kaminer Y, Burleson JA, Goldberger R. Cognitive behavioral coping skills and psychoeducation therapies for adolescent substance abuse. J Nerv Ment Dis. 2002;190(11):737-45.

Kessler FHP. Desenvolvimento e validação da sexta versão da Addiction Severity Índex (ASI 6) para o Brasil e outras análises em uma amostra multicêntrica de usuários de drogas que buscam tratamento no país [tese]. Porto Alegre: Faculdade de Medicina, Universidade Federal do Rio Grande do Sul; 2011.

Kosten TR, Rounsaville BJ, Kleber HD. Concurrent validity of the Addiction Severity Index. J Nerv Ment Dis. 1983;171:606-10.

McLellan AT, Luborsky L, Cacciola J, Griffith J, Evans F, Barr HL, O'Brien CP. New data from the Addiction Severity Index: reliability and validity in three centers. J Nerv Ment Dis. 1985;173:412-23.

National Institute of Health. National Institute on Drug Abuse. Developing successful drug abuse prevention programs. NIDA Notes. 1999;14(6):15.

Resch F, Parzer P, Brunner R, Bella study group. Self-mutilation and suicidal behavior in children and adolescents: prevalence and psychosocial correlates: results of the BELLA study. Eur Child Adolesc Psychiatry. 2008;17(Suppl 1):17:92-8.

Tarter R, Vanyaukov M, Giancola P, Dawes M, Blackson T, Mezzich A, Clark DB. Etiology of early age onset substance use disorder: A maturational perspective. Dev Psychopathol. 1999:11:657-83. 